Portland State University

PDXScholar

Spring 6-1-2017

\title{
Wicked Water Problems: Can Network Governance Deliver? Integrated Water Management Case Studies from New Zealand and Oregon, USA
}

Jacqueline Dingfelder

Portland State University

Follow this and additional works at: https://pdxscholar.library.pdx.edu/open_access_etds

Part of the Public Policy Commons, and the Water Resource Management Commons Let us know how access to this document benefits you.

\section{Recommended Citation}

Dingfelder, Jacqueline, "Wicked Water Problems: Can Network Governance Deliver? Integrated Water Management Case Studies from New Zealand and Oregon, USA" (2017). Dissertations and Theses. Paper 3623.

https://doi.org/10.15760/etd.5515

This Dissertation is brought to you for free and open access. It has been accepted for inclusion in Dissertations and Theses by an authorized administrator of PDXScholar. Please contact us if we can make this document more accessible: pdxscholar@pdx.edu. 
Wicked Water Problems: Can Network Governance Deliver?

Integrated Water Management Case Studies from New Zealand and Oregon, USA

\author{
by \\ Jacqueline Dingfelder \\ A dissertation submitted in partial fulfillment of the \\ requirements for the degree of
}

\author{
Doctor of Philosophy \\ in \\ Public Affairs and Policy \\ Dissertation Committee: \\ Craig Shinn, Chair \\ Jennifer Allen \\ Peter Paquet \\ Veronica Dujon
}

Portland State University

2017 
(C) 2017 Jacqueline Dingfelder 


\begin{abstract}
Integrated water management is a wicked public policy problem with no clear path to resolution. This dissertation is an in-depth qualitative comparative analysis of two collaborative governance processes created to tackle complex water problems in New Zealand and Oregon, U.S.A. Both cases convened a wide range of state and non-state actors in efforts to find common ground, build consensus for change, and develop innovative water policy solutions.

The goal of this comparative case study analysis is to gain a better understanding of collaborative network governance frameworks as applied to integrated water management and primary factors for success. The proposition posits that collaborative networks involving public, private, and non-profit actors are better equipped than government-driven efforts to develop desired outcomes. To test this proposition, the research questions probe the role of state and non-state policy actors, conditions for collaboration, strength of actor ties, development of trust and social capital, barriers to success, and the role of climate change as a policy driver in these two case studies.

The comparative case study analysis yields fascinating insights that add to the network governance literature. In the New Zealand case, a collaborative-led process called the Land and Water Forum (LAWF) showed that this ongoing network offers benefits to creating consensus on complex water issues. LAWF succeeded in moving policy conversations forward where previous government-led efforts had failed. Within the LAWF collaborative network, non-state actors formed strong ties; however, relationships with state actors exhibited weaker ties.
\end{abstract}


With Oregon's integrated water policy, a collaborative network approach created a more conducive environment for meaningful dialogue among vested interests, and built some levels of interdependency and trust, thus generating a wider array of policy options than through previous legislative and bureaucratic efforts. However, long-standing political, legal, and institutional challenges continue to constrain effective integrated water management and the delivery of integrated outcomes in Oregon. The Oregon case did not exhibit strong leadership within the collaborative to broker challenging policy issues. Also, it faced implementation challenges as one state agency was given responsibility for stewarding integrated water management but lacked authority for implementation or coordination with other state agencies. Overcoming fragmented natural resource governance arrangements remains a daunting challenge.

This research revealed three key findings: 1 . in both cases, collaborative network governance worked well for framing and designing new integrated water policies, but encountered implementation challenges; 2 . managing the complexities around the intersection of top-down, vertical command and control governance with horizontal collaborative approaches remains an ongoing challenge to New Public Governance; and 3. the two cases represent examples of the use of formal and informal processes for policy development. The benefits of collaborative governance for policy development are substantial, and the limitations appear to be obstacles to overcome and not fatal flaws. The main challenge lies in transitioning from policy and planning to applying changes on the ground affecting the way we manage water today and in the future. 


\section{ACKNOWLEDGEMENTS}

I would like to thank the Ian Axford board and the Fulbright New Zealand staff for making the New Zealand portion of my academic journey possible. The Ian Axford fellowship afforded me the opportunity to study and research New Zealand's freshwater policy reform process first hand over a seven-month period in 2016. I would like to express my gratitude to the Ministry for the Environment staff whose assistance in navigating New Zealand's freshwater policy process, finding key documents, and addressing my never-ending inquiries was invaluable. Thank you to my New Zealand academic advisor, Dr. Elizabeth Eppel, from Victoria University's School of Government for providing peer review, feedback, and academic guidance throughout my New Zealand research experience.

My heartfelt gratitude to all the New Zealanders and Oregonians I interviewed for this research project. I appreciate how generous individuals were with their time, and their willingness to share their insights and perspectives on integrated water resource planning and management. I would also like to thank Heike Schiele, a kindred spirit who generously served as one of my academic peer reviewers for my New Zealand case study. Her Ph.D.dissertation provided insights about integration of Māori perspectives in freshwater planning, and her enthusiasm for sharing her research served as an inspiration for my Ph.D.dissertation research and writing process.

A very special thank you to my Oregon friends and colleagues Andree Tremoulet, $\mathrm{Ph} . \mathrm{D}$. and Lisa Seales, Ph.D.for providing academic peer review, input and guidance throughout my dissertation research and writing. And I am grateful for the years of 
guidance and counsel from my academic advisor, Dr. Craig Shinn and the members of my dissertation committee: Dr. Jennifer Allen, Dr. Peter Paquet, and Dr. Veronica Dujon.

Last but not least, I could not have completed my dissertation without the unwavering support of my life-long partner, Tom Gainer, who has been a steady presence throughout this academic journey. Tom provided steadfast companionship and support, home-cooked meals, and editing services throughout this wonderful learning experience. 


\section{TABLE OF CONTENTS}

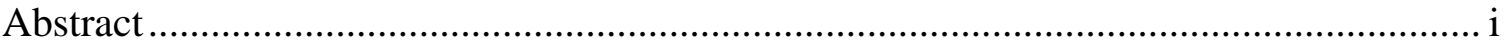

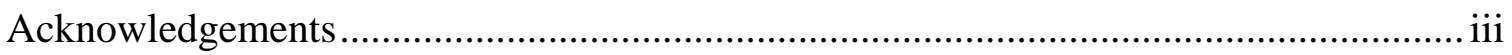

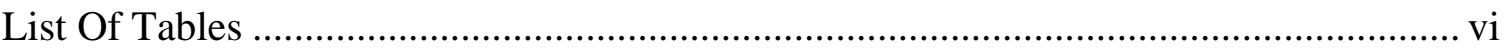

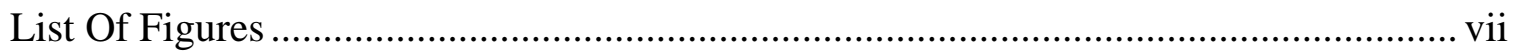

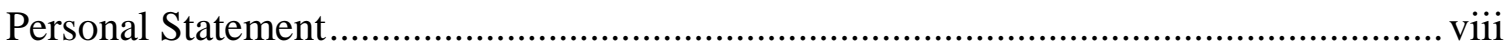

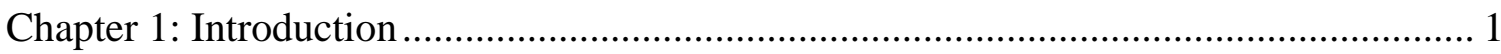

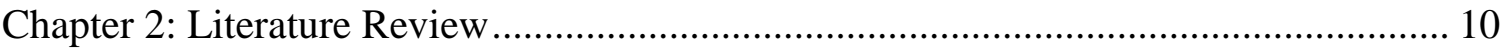

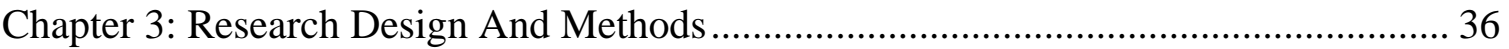

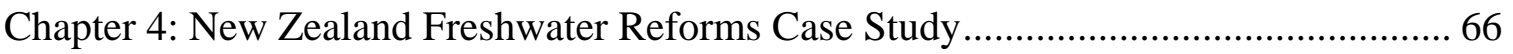

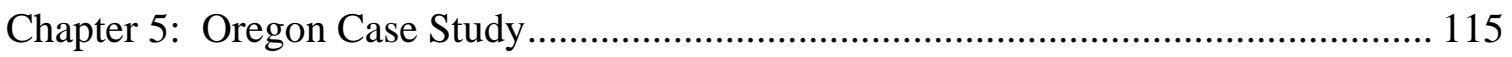

Chapter 6. Comparative Analysis Of Cases........................................................ 180

Chapter 7. Conclusions And Implications For Further Policy Research ....................... 218

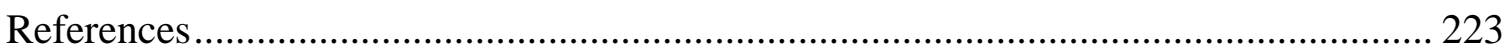

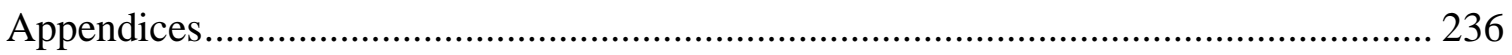

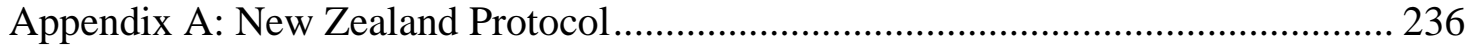

Appendix B: Oregon Interview Protocol .......................................................... 238

Appendix C: Dissertation Codebook ..................................................................... 240

Appendix D: New Zealand Land And Water Forum Membership............................ 243

Appendix E: Oregon Integrated Water Resources Strategy .................................. 246 


\section{LIST OF TABLES}

Table 2.1 Characteristics of New Public Governance......................................35

Table 3.1 Research Data Sources for Case Study Analyses..................................46

Table 3.2 Methods Used for Addressing Quality and Validity..............................59

Table 4.1 Strengths and Weaknesses of New Zealand's Land and Water Forum..........107

Table 5.1 Guiding Principle of Oregon's Integrated Water Resources Strategy...........145

Table 5.2 Policy Advisory Group's Vision for the Strategy...........................145

Table 5.3 Strengths and Weaknesses of Oregon's IWRS Process...........................173

Table 6.1 Comparative Analysis on Research Guide Question Responses....................182 


\section{LIST OF FIGURES}

Figure 3.1 Inductive/Deductive Reasoning Process......................................... 54

Figure 4.1 New Zealand Location Map.........................................................67

Figure 4.2 New Zealand Legislative and Regulatory Instruments...............................75

Figure 5.1 Map of Oregon, USA.........................................................116

Figure 5.2 Oregon's Water Institutional Framework .....................................128

Figure 6.1 Comparative Water Policy Drivers in N. Z. and Oregon............................193

Figure 6.2 Collaborative Network for New Zealand Freshwater Policy Framework......215

Figure 6.3 Collaborative Network for Oregon Integrated Water Resources Strategy.....216 


\section{PERSONAL STATEMENT}

I have been captivated with rivers and their landscapes since I was a young girl. In college, I pursued biology because of my love of science, but soon gravitated toward studying physical geography with an emphasis on hydrology and geomorphology processes. Once I entered the professional world, I realized that I needed a more practical application of my field to be employable and went on to pursue a Master's Degree in environmental planning with a focus on water resources management. Through that course of study, I was introduced to the concept of integrated watershed management, a process which promotes the coordinated management of water (water quality and quantity, surface and groundwater) and land. This holistic water management perspective was considered an innovative and radical approach in the 1980s. Fortunately, when I moved to Oregon in the early 1990s, political leaders had recognized the importance of taking a holistic approach to watershed management, and I found gainful employment as a watershed coordinator and planner. Since that time, I have been fortunate to be actively engaged in Oregon water governance, watershed management, and policy development through my professional experience and 12-year tenure in the Oregon legislature.

Although water management has been my primary personal and career focus, more recently I began following the work of the International Panel on Climate Change and became acutely aware of the profound impacts of climate change on water resources, especially in the Western United States. During my 24-year tenure in the West, I have witnessed diminishing snowpacks, higher than average temperatures, increasing wildfires, and greater frequency and intensity of droughts. The potential impacts of 
climate change appear inexorable. This sparked my interest in learning how our existing water governance regimes are equipped to respond to increasing issues around scarcity and climate variability.

My interest in this Ph.D.study comes from my own experiences in developing and implementing water management plans and policies at the local, regional, and subnational levels. By working on water policy in Oregon, I learned first-hand about the challenges of initiating changes to an outdated water management regime. Through that process, I began exploring integrated water governance models globally and learned about New Zealand's integrated approach to freshwater management, including the reform process currently underway. In 2016, I conducted my research in New Zealand as an Ian Axford Policy Fellow under the New Zealand Fulbright Program. As part that program, I observed and interacted with government officials, interested parties, Māori (indigenous peoples of New Zealand), citizens, academics, scientists, and others engaged in integrated water management and collaborative governance. Through my research and findings around network and collaborative governance, I aim to provide insights for both policy makers and practitioners seeking tools for meaningful integrated water governance and management. 


\section{CHAPTER 1: INTRODUCTION}

\section{"Many of the wars this century were about oil, but those of the next}

century will be over water."

--World Bank Vice President, Dr Ismail Serageldin, 1995

One of today's most compelling environmental issues concerns management of the world's freshwater resources. Competing demands for limited water supplies, including population growth, land use changes, agricultural intensification, and climate change, have placed additional pressures on existing water resources. The Intergovernmental Panel on Climate Change (IPCC) and others warn that climate change will have extensive impacts on water resources, and that new governance and management tools are needed to ensure optimal water management. The 2008 IPPC report, Climate Change and Water, identified that current water management practices may not be robust enough to cope with the impacts of climate change on water supply reliability, flood risk, health, agriculture, energy, and aquatic ecosystems (IPCC, 2008). Water resource management is often delivered through a top-down governance model that is ill-equipped to respond nimbly to changing conditions. Water governance typically focuses on managing either water quantity or water quality, often through separate delivery mechanisms by disparate agencies, thus creating a fragmented approach that fails to manage water in an integrated manner. This outdated governance structure has fallen short in optimizing existing supplies by failing to protect or improve water 
quality and avoid over-allocation, ${ }^{1}$ often resulting in political conflicts, inefficient use, and inequitable distribution and impacts. In addition, past water governance models have relied on a vertical, top-down technical management approach that engages a sphere of limited voices via the "iron triangle" model (Heclo, 1978), leaving out key viewpoints, especially those of non-state actors. The term iron triangle refers to the alignment of interests and actions among three key actors in public policy making: regulated industry or other special interests, legislative oversight committees, and the regulatory agency, which often results in regulatory policies that tend to protect or promote the regulated industry (Heclo, 1978). I posit that collaborative, networked governance models are more appropriate for managing water in an integrated manner. Thus, I propose that there is a need to transition from a top-down, hierarchical, command and control approach to a horizontal, collaborative policy development framework.

In public policy terms, water resource management, where scarcity and competing demands for limited resources increasingly dominate, presents a "wicked" public problem. Wicked problems are problems of such scale, persistency, and complexity as to defy solution by a single scale of governance (e.g., national or local government level) or mode (hierarchies, markets, or collaboration) (Russell, Frame, and Lennox, 2011). Due to its complexity, interconnectedness, and fragmented systems, water governance can be characterised characterized as a wicked policy problem.

\footnotetext{
${ }^{1}$ Over-allocation of water rights refers to a situation where the rights granted to use water exceed the supply during a certain period in time.
} 
U.N. Secretary-General Ban Ki-moon stated that, "water is a classic common property resource. No one really owns the problem. Therefore, no one really owns the solution" (U.N. General Assembly Address, February 6, 2008). He went on to say "international cooperation is crucial to overcoming the problem, calling for governments, business and civil society to form new and innovative partnerships" (U.N. General Assembly Address, February 6, 2008). In Oregon, we, too, face a wicked public policy problem when it comes to managing our water resources in an integrated and sustainable manner. As a state, we are struggling to overcome historic fragmentation of our water governance and management systems that have evolved over time. Water governance is delivered across agencies, districts, and utilities through a patchwork of uncoordinated and overlapping laws, policies, and rules. This fragmentation has resulted in government failures to manage water effectively and efficiently. To adapt U.N. Secretary-General Ban Ki-moon's expression, no one entity in Oregon really owns the problem, as responsibility is divided among multiple actors. Therefore, no one really owns the solution.

To illustrate the complex and interdisciplinary nature of water, listed below is a sample of the principal expectations placed upon Oregon's current water management framework:

protecting human health by ensuring potable and safe drinking water improving water quality by minimizing both point and non-point source pollution and enforcing water quality standards balancing multiple demands for limited water supplies (e.g., irrigation, municipal, industrial, recreation, ecosystems, 
fisheries, tribal, and hydropower) including resolving over-allocation of water rights

protecting and restoring wetlands, estuaries, and coastal areas

managing groundwater and replenishing oversubscribed aquifers

managing stormwater

ensuring adequate data to make informed decisions

balancing economic and ecological needs

meeting future water demands for both in-stream and out-of-stream uses

$>$ minimizing the impacts of land use practices (i.e., urban development, forestry, agriculture) on waterways

regulating dams and ensuring flow for fish and hydropower

managing water through a fragmented governance system with divided authority (i.e., myriad of federal and state natural resource agencies, state and local boards and commissions, regional and local water/wastewater utilities, irrigation and flood control districts, etc.)

$>$ managing water at various spatial scales (i.e., national, state, regional, local) managing water in an interdisciplinary manner.

Balancing these competing demands in an effective and resilient manner given increasing pressures from population growth, climate variability, and scarcity presents a daunting challenge. In addition, disputes have escalated in recent years between stakeholders that want to consume water (e.g., farmers, municipalities) and stakeholders that want to conserve water in-stream (e.g., environmentalists, recreationalists). Trade- 
offs between economic (e.g., consumptive out-of-stream uses for irrigation, industry, drinking water) and environmental uses (e.g., in-stream uses for fish, wildlife, water quality, and recreation) are inescapable. Furthermore, legislative or legal efforts to resolve water problems often end in a zero-sum game scenario, creating winners and losers. Hence, the problem of managing water resources in a sustainable, effective and transparent manner highlights the challenges facing policy makers and water resource managers.

Oregon is not unique in having an antiquated, patchwork water governance system. Managing water resources in a holistic, integrated manner is more the exception than the norm. Under most water frameworks, water resources are subject to a top-down, command and control ${ }^{2}$ approach administered through bureaucratic government silos. This often leads to a fragmented and uncoordinated governance arrangement, illequipped to respond to increasing pressures from population growth, land use intensification, over-allocation, and climate variability. Existing water governance arrangements fall short in protecting water quality and optimizing existing supplies, resulting in political conflicts, inefficient uses, and inequitable distribution.

To promote more effective management of limited water resources, policy makers have recently recognized the strong need for an integrated approach to address challenges created by the silo effects of existing management regimes. This approach, known as Integrated Water Resources Management (IWRM), stresses the importance of integrated

\footnotetext{
2 Command and control policy refers to environmental policy that relies on regulation as opposed to financially-based or other incentives.
} 
and participatory management practices, instead of command and control, and considers multiple viewpoints on how water should be managed (Medema, McIntosh, and Jeffrey, 2008). IWRM considers the interconnectedness of water resources (quality and quantity, surface water and groundwater), the interactions between land and water, and the interrelationships with cultural, environmental, social and economic uses of water. (IWRM concepts are presented in more detail in Chapter 2, Literature Review.)

\section{Research Rationale}

This research contributes to governance theory by examing how government institutions are adapting water management regimes to deal with wicked policy issues. Through this study, I review two collaborative water governance models at national and subnational levels in order to assess how successful these institutional arrangements ${ }^{3}$ are in delivering an integrated approach to water management. I compare water governance in New Zealand and the State of Oregon, USA. Both systems are premised on an IWRM approach but with different legal and governance frameworks. The aim of this research was to gain a better understanding of how water governance is adapting to address issues such as scarcity due to climate change.

Before embarking on the comparative case study analysis, it is important to underscore the different institutional and cultural factors underlying these two case studies, and recognize that these differences affect integrated water management

\footnotetext{
${ }^{3}$ Throughout this report I refer to the term institutions using the following meaning: "institutions consist of cognitive, normative, and regulative structures and activities that provide stability and meaning to behaviour. Institutions are transported by various carriers -- culture, structures and routines -- and they operate at multiple levels of jurisdiction" (Scott, 1995, p.33).
} 
governance. These different institutional factors will not be a matter of this investigation; however, I will return to these differences in the concluding chapters. It is also important to note that this study investigates water management at two different levels of government: at the national level in New Zealand and at the sub-national level in Oregon.The New Zealand case study focuses on collaborative network structure at the central government level whereas the Oregon case study is focused on a state collaboration network at the sub-national level.

New Zealand operates under a constitutional monarchy with a parliamentary system of government. The central government provides overarching policy guidance, whereas regional councils, organized around catchments, develop and implement regionally-based freshwater policies and plans. In contrast, the United States operates under a federalist system, a concept derived from the U.S. Constitution, and represents a power sharing arrangement between federal and state governments. The federal government has certain powers; however, powers not specifically assigned to the federal government are delegated to the states. Each U.S. state works within a national context, but each state supports a distinctive water governance system based on its own culture, history, and political institutions. Oregon is a populist state, and this focus helped define the state's political history and culture around direct democracy and citizen involvement in policy boards and commissions associated with natural resource agencies. Historically, Oregon's state agencies involved in natural resource and environmental management evolved along traditional resource allocation, management and regulatory lines creating fragmented institutional arrangements. This disjointed water governance structure is still 
in place today and creates challenges for delivering integrated water management in Oregon.

\section{Theoretical Basis for Research}

The primary theoretical basis for this research is to build upon the work of the New Public Governance (NPG) movement, which focuses on network and collaborative theories. NPG emphasizes trust- and legitimacy-building characteristics of public governance, which include: (1) being value-centered, with a focus on promoting the larger common good; (2) emphasizing the creation of government processes that facilitate long-lasting and implementable agreements among wide-ranging stakeholders; and (3) creating a public good through co-production that involves public, private, and non-profit sectors (Morgan and Cook, 2014, pp. 5-6). Using the NPG as a starting frame, I research the role of these NPG principals in governance as it relates to water management, and examine whether new factors emerge as parameters for success.

In this research project, I explore the role of network and collaborative theory in integrated water governance and management. This research studies whether a mixed form of administrative authority (horizontal and vertical relationships) offered through networks are better suited than historic top-down governance approaches to water resource management. In addition, I investigate how collaborative network processes have influenced the framing and development of integrated water policies.

Through this research and findings, I aim to provide insights for both policy makers and practitioners seeking tools for meaningful water planning and governance. Researching innovative and collaborative governance approaches will help inform decision-makers as they tackle issues such as scarcity due to climate change. My research 
goals are to gain a better understanding of network governance frameworks as applied to integrated water management, including the key defining elements, necessary conditions for collaboration, and primary factors for success.

\section{Dissertation Overview}

My dissertation contains seven chapters. Chapter 1 details a personal statement and introduction to my research subject, collaborative network governance and integrated water management. Chapter 2 provides a critical review of existing literature related to policy domains most relevant to my research: integrated water management and governance, network governance, collaborative water governance, and new public governance. Chapter 3 outlines the research design and methods including the research questions and proposition at risk, research philosophies, data collection, data analysis and validation methods, and potential research limitations. Chapter 4 presents a comprehensive case study analysis of New Zealand's freshwater reforms, including a review of background information and chronological history, governance institutions and policy frameworks, interview results and data analysis, and key themes in comparison to network governance theoretical constructs. Chapter 5 provides parallel information for the Oregon case study analyzing development of an Integrated Water Resources Strategy. In Chapter 6, an analysis and discussion of the research study findings, including an in-depth comparative examination between the two case studies is presented. This chapter also addresses to what extent the research findings answer the research questions, and how these findings relate back to the literature. Chapter 7 outlines the final conclusions, study limitations, and implications for future research. 


\section{CHAPTER 2: LITERATURE REVIEW}

This chapter provides a critical review of existing literature related to the primary area of study and focuses on the following policy domains: integrated water management and water governance, network governance, collaborative governance, and new public governance. Rather than providing a broad review of water law and policy, I focus on governance of water systems. A practical review of water law and policy for each case study is provided in Chapters 4 and 5. The literature review first defines terms relevant to the subject matter, then identifies important theoretical frameworks associated with each policy domain, and finally, covers literature that specifically relates to each domain.

\subsection{Integrated Water Resources Management and Water Governance}

Traditional governance structures have changed in response to increasingly complex challenges, the dynamic nature of intergovernmental relations, trends toward deregulation, and political pressures for a limited and less intrusive government. Water resources management, where scarcity and competing demands for limited resources increasingly dominate, presents a wicked public problem that has outgrown the siloed, vertical approach grounded in hierarchical authority. Governing water resources through vertical, top-down methods has resulted in a fragmented approach that is ill equipped to respond to increasing pressures due to competing demands, over appropriation, population growth, land use impacts, and climate change.

To promote more effective management of limited water resources, policy makers both in the U.S. and internationally have recognized the need for a new public management construct addressing challenges created by boundary problems (i.e., 
working across jurisdictional and organizational boundaries) and silo effects. This approach, known as Integrated Water Resources Management (IWRM), emphasizes collaboration and cooperation instead of command and control, and recognizes the interconnectedness of water resources, resource managers, stakeholders, and resource decisions in promoting comprehensive planning and management (USACE, 2010).

First, it is important to distinguish between the terms "water management" and "water governance," as these terms are used throughout the research. The term "water management" refers to "operational activities including the operation, monitoring, strategic planning, and implementation of measures," whereas the term "water governance" comprises "the rules under which a management system operates and the different actors and networks that help develop and implement water policies" (PahlWostl, 2009, p. 1).

Water governance refers to the process through which government and nongovernment actors and citizens interact to produce rules, practices, and behaviors through which water is managed and outcomes are achieved. More specifically, water governance can be described as:

$>$ deciding who gets what water, when, and how

a range of political, social, economic and administrative systems that are in place to develop and manage water

determining the delivery of water services at different levels of society

a decision-making process rather than operational approaches (Russell et al., 2011). 
The Global Water Partnership defines water governance as "the range of political social, economic and administrative systems that are in place to regulate development and management of water resources and provisions of water services at different levels of society" (Rogers \& Hall, 2003, p. 88). Water governance is a set of collective actions aimed towards a common goal and coordinated among diverse stakeholder groups (Lubell \& Fulton, 2008). Wiek and Larson (2012) suggest that water governance is "explicitly distinguished, on the one hand side, from government activities, and on the other hand side, from management activities (e.g., by water utilities), both of which indicate activities of specific actor groups and goals" (p. 3156).

IWRM represents a management framework that was developed to deal with water complexity and improve natural resource management outcomes (Medema, McIntosh, \& Jeffrey, 2008). IWRM's origins can be traced back to the first UNESCO International Conference on Water in 1977 and the early works of Carl Walters (Walters and Hilborn, 1978). Coined as a tool for an "integrationist agenda" (Medema et al., 2008), IWRM promotes the integrated and coordinated management of water and land as a way of balancing resource protection while meeting social and ecological needs and promoting economic development (Odendaal, 2002).

Following from that early UNESCO work, the Dublin principles were formulated through an international consultative process culminating in the 1992 International Conference on Water and the Environment in Dublin. The principles to promote changes in those concepts and practices that are considered fundamental to improved water resources management (Global Water Partnership, 2000). The four Dublin principles are: 
1) fresh water is a finite and vulnerable resource, essential to sustain life, development and the environment;

2) water development and management should be based on a participatory approach, involving users, planners and policymakers at all levels;

3) women play a central part in the provision, management and safeguarding of water; and

4) water has an economic value in all its competing uses and should be recognized as an economic good (Global Water Partnership, 2000, pp. 13-14).

These Dublin principles contributed to the Agenda 21 recommendations (included in Agenda 21 Chapter 18 on freshwater resources) adopted at the United Nations Conference on Environment and Development (UNCED) in Rio de Janeiro, 1992. Since then, these principles (referred to as the Dublin-Rio principles) have found universal support amongst the international community as the guiding principles underpinning IWRM (Global Water Partnership, 2000, p 14).

IWRM was endorsed by the Global Water Partnership (GWP) as: "a process which promotes the coordinated development and management of water, land and related resources, in order to maximize the resultant economic and social welfare in an equitable manner without compromising the sustainability of vital ecosystems" (GWP, technical advisory committee report 2000, p. 22). IWRM emphasizes the following principles:

that water is a public good or common pool resource (as articulated by Garret Hardin in "The Tragedy of the Commons," which describes the problem of collectively managing shared resources (Hardin, 1968) 
the need to create a government process that facilitates agreement among wideranging stakeholders

the designation of water as public good involving public, private, and non-profit sectors.

The key goal of IWRM is to promote integration and coordination as a means of achieving more holistic water management and improving the sustainable use of water resources. Similar to the concept of sustainability, IWRM involves a continuous process of balancing objectives and making trade-offs in an informed manner rather than an end state to be achieved (Medema et al., 2008). The IWRM approach is promoted as a more efficient, equitable, and sustainable tool for managing water resources and for coping with conflicting demands. For policy-making and planning, taking an IWRM approach requires that:

water development and management takes into account the various uses of water and the range of people's water needs;

planning be integrated across spatial and temporal scales and disciplines;

$>$ stakeholders (those responsible for and affected by management intervention) are given a voice in water planning and management;

policies and priorities consider water resource implications, including the twoway relationship between macroeconomic policies and water development and management;

$>$ water planning and strategies are incorporated into broader social, economic, and environmental goals (Global Water Partnership, 2004). 
IWRM also recognizes the value of local knowledge and collaborative learning in influencing decision making (Durette \& Barcham, 2009). Scientific knowledge plays a large role in IWRM; however, local community and indigenous knowledge can help fill the gaps in scientific knowledge used in freshwater management (Durette \& Barcham, 2009). Successful implementation relies on three components:

1) enabling legislation and a policy environment that sets up and empowers effective mechanisms for multi-stakeholder cross-sectoral dialogues at the country, regional, and local level;

2) an appropriate institutional framework composed of a mixture of local, riverbasin-specific, and public-private organizations that provide the governance arrangements for administering; and

3) a set of management instruments for gathering data and information, assessing resource levels and needs, and allocating resources for use (GWP-TAC, 2004). There is general recognition among practitioners and scholars that IWRM was spurred by the need for a paradigm shift in water management and governance because of climate change, variability, and growing uncertainty (Pahl-Wostl, 2007). Dealing with extremes in water management is not new, especially in the Western United States. In the past, technical infrastructure approaches were employed to address water variability issues; however, as Pahl-Wostl, (2007) observes, limits on the ability to control water variability by technical means created a need for adaptive management approaches such as IWRM. Government institutions utilizing an iron triangle mentality are not prepared to deliver innovative approaches or engage broadly with stakeholders. An integrated approach shifts the discourse from speaking of government to governance (Pahl-Wostl, 
Holtz, Kastens, \& Knieper, 2010), which is where many different institutions contribute to water policy development and implementation. This integrated model is characterized as polycentric, with horizontal and vertical interplay that involves both state and nonstate actors.

Critics of IWRM suggest that many barriers to success exist between the theory and practice of IWRM. Barriers include the ambiguity of definitions (Odendaal, 2002; Varis et al., 2006) and the lack of prescription for effective implementation (Medema et al., 2008). For example, integrated water resources management is not universally defined, and therefore lacks a common understanding among water policy actors, managers, and decision makers. Biwass and Kirpich (2004) raise the issue of institutional barriers and questions whether a single water management framework can be universally expedient across different physical, economic, social, cultural, and legal conditions. For example, overlapping governance, fragmented regulatory frameworks, legal constraints, or cultural issues may act as institutional barriers to a more integrated approach to water resources management.

Scholars have raised questions about the effectiveness of the cross-sector, multiple stakeholder approach given challenges such as ambiguous boundaries and complex links; difficulties with objectives, alternatives, and consequences; pervasive uncertainty; and multiple stakeholder conflict (Ohlson, 1999). Regarding capacity, Koudstaal, Rijsberman, and Savenije (1992) recognized that effective water governance is necessary for the successful implementation of IWRM plans. Whereas, Medema et al. (2008) assert that implementation challenges may preclude IWRM from serving as a 
useful tool unless strong underlying political, institutional, governance, and financial arrangements are present.

According to a U.S. Army Corps of Engineers (USACE) report on collaborative water governance (2010), the goal of IWRM is to manage water sustainably, which involves balancing objectives, coordination, and holistic management. Recognizing that water management must balance multiple objectives of different interests, the rationale for the IWRM approach has been accepted internationally as a more efficient, equitable, and sustainable management tool for managing water resources and for coping with conflicting demands (UNEP, 2009). Under the IWRM process, local stakeholders from all water use sectors are encouraged to participate. Finally, holistic management recognizes the interconnectedness of land and water, surface water and groundwater, water quantity and water quality, freshwater and coastal waters, and rivers and the broader watershed (USACE, 2010).

Recent literature on water management and governance frameworks identifies the need for a more integrated and holistic approach to water management due to increasing global uncertainties about water. Cortner and Moote (1994) observed that traditional water management regimes have focused on sustained yield of water supplies (predictable amounts of water) and are ill equipped to deal with emerging problems and uncertainties due to scarcity. They expressed the need for a new water paradigm that included two principles, including ecosystem management and collaborative decisionmaking. Gleick (2003) provides a characterization of the changes needed in water management approaches as a "soft path" approach. This implies a shift from the engineering-focus of building new water infrastructure to meet demands to "soft 
measures" such as pricing that involve changes to institutional mechanisms and new tools for allocation.

Mitchell (2005) characterizes IWRM as a holistic approach that attempts to work against the silo effect of existing water management programs that exhibit both vertical and horizontal fragmentation. He speaks to the need for devising mechanisms or processes that address the difficulties created by institutional boundary issues. In order to ensure legitimacy, he asserts that the process must be conceived, developed, and implemented with connection to statutory basis, meaning grounded in law (Mitchell, 2005).

Integrated and holistic water management approaches, like IWRM, are one avenue for addressing the complexity posed by climate and global change. Pahl-Wostl contributes extensively to the water governance literature. The author posits that traditional water management interventions that focus on water resource optimization using supply side solutions (e.g., building new storage) are no longer adequate to address changing global conditions (Pahl-Wostl, 2007). The author explains that historic approaches to solving complex water problems that utilize technical fixes are reaching their limits and a new water management paradigm is needed. Transition from a topdown, command and control water governance model to a horizontal, integrated, and polycentric approach with broad stakeholder involvement is warranted (Pahl-Wostl, 2007). The author suggests that a shift is occurring from a scientific management paradigm to one of collaborative governance to address complex water problems. This transition from technically-based management towards a more integrated approach 
typically involves a wide range of actors representing diverse interests and perspectives (Pahl-Wostl, 2015).

Pahl-Wostl (2009) developed a management and transition framework for addressing the dynamics and adaptive capacity of resource governance regimes as multilevel learning processes. In developing this framework, the author considered the influence of formal and informal institutions, the role of state and non-state actors, the nature of multi-level interactions, and the relative importance of bureaucratic hierarchies, markets, and networks. Pahl-Wostl (2009) tested this framework by reviewing 29 cases in Europe. Insights from these water governance studies suggest that the structural constraints from command and control governance arrangements and an iron triangle mentality are inadequate for dealing with uncertainties due to climate and global changes (Pahl-Wostl, 2009).

Broader stakeholder participation can help reduce uncertainties in policy implementation by bringing different perspectives and sources of knowledge to facilitate innovative solutions to water problems. The literature emphasizes that an important condition for improving performance is striving for more decentralized and polycentric governance structures. Pahl-Wostl, Lebel, Knieper, and Nikitina (2012) characterized IWRM as a "bold step forward in the direction to embrace complexity" which allows for the integrated and coordinated management of water and land (p. 25).

Medema et al. (2008) provide an extensive review of IWRM history, development, and efficacy. The authors compare IWRM to the concept of sustainability. IWRM promotes coordination and integration as a means of achieving more holistic water management and improving water resources' sustainability (Medema et al., 2008). 
Similar to the concept of sustainability, IWRM involves a continuous process of balancing and making trade-offs between goals in an informed manner rather than positing an end state to be reached (Medema et al., 2008). The authors caution that IWRM is primarily concerned with reform of water governance arrangements; however, effective water policy changes may require some degree of institutional reform (Medema et al., 2008).

Ludwig, Van Slobbe, and Cofino (2014) present a historical framework for the IWRM approach and explain that the process was introduced to better optimize water uses between diverse water-demanding sectors. However, since IWRM was introduced, water systems have become more complicated due to changes in the global water cycle from climate change. The realization that climate change will have a significant impact on water availability and flood risks has driven research and policy-making adaptation. Ludwig et al. (2014) assert that water problems are best understood as a product of human constructs and, in order to achieve success, planners and decision makers must consider alternative framings by different actors. Underlying norms and values are often not included in the planning and decision making process, thus posing challenges for public acceptance. The authors conclude that the IWRM model needs updating in order to effectively address uncertainties (Ludwig et al., 2014).

Olmstead (2014) conducted a comprehensive literature review on the role of water management institutions in addressing climate adaptation, with particular attention to economic impacts. As water tends to be managed at the local and regional scale, Omsted warns that national or sub-national institutional adaptations may or may not be ultimately adopted and implemented at the local or regional scale. The issue of 
appropriate scale is one that will be explored as part of the case study research.

In summary, several dominant themes emerge from the literature on IWRM and water governance. The literature speaks to the challenge of command and control approaches to water governance and suggests it is an inadequate method to respond to growing pressures on water resources. Scholars assert that historically, water resource management focused on technical solutions to well-defined problems; however, contemporary problems require a transformation of water management principles and policies to deal ever-growing and changing water resource challenges. The literature identifies a crisis of governance rather than of technical management of water, thus the need for a paradigm shift in water governance (Pahl-Wostl, Jeffrey, Isendahl, \& Brugnach, 2011). Gaps in the literature exist around detailed case studies assessing integrated water management network governance. This research and case study analysis will attempt to address this gap in policy research.

\subsection{Network Governance}

The role of collaborative network governance in integrated water management is a central focus of this dissertation along with exploration of tensions around the intersection of vertical and horizontal processes. This section includes definitions of the terms used to describe networks, presents prominent network theories, and reviews important contributions to the network governance theory policy domain.

A network is defined as "a set of goal-oriented interdependent actors that come together to produce a collective output (tangible or intangible) that no one actor could produce on his or her own" (Keast, Mandell, \& Agranoff, 2014, p. 16). Public sector networks are defined as "structures of interdependence involving multiple organizations, 
or part thereof, where one is not merely the subordinate of others in some hierarchical arrangement" (Keast et al., 2014, p. 16). Both of these definitions are relevant for this research

Network theory represents the first attempt to move beyond depictions of networks as a simplistic model of threads and nets (Keast et al., 2014). A key point of differentiation is that network theory "emphasizes relationships between actors rather than individual characteristics" (Keast et al., 2014, p. 17). It is grounded in the work of Moreno and Jennings, (1934), who introduced the "socio-gram" that depicts individuals as a set of nodes connected by lines in order to diagrammatically isolate relations among people and guide interventions (Keast et al., 2014, p. 17). Several decades after Moreno, Cartwright, and Harary (1956) connected social network theory with mathematics and graph theory, giving rise to a structured approach that remains current today (Keast et al., 2014, p. 18). An important aspect that differentiates network theory from other theories is the emphasis on the relationships between actors rather than on their individual characteristics. Social network theory posits that the position of the actors, and the type and nature of their relationship with other network actors, determines the outcomes (Borgatti and Foster, 2003; Kilduff and Tsai, 2003).

Several theorists have focused their efforts on network theory development and research on network management and performance. Most notably, Agranoff, and McGuire (2003), McGuire (2002), Mandell (1994), Meier and O’Toole (2001, 2005), and Koliba, Meek, and Zia (2011) have made significant advances in the field by explaining the differences between conventional management and network management (Keast et al., 2014). Around the same time, new theories about the role of networks in governance 
began emerging. Networks were likened to a new form of governance "arising in situations where hierarchical forms of command and control were no longer the most effective methods for policy development or implementation" (Keast et al., 2014, p. 22). This signified a shift from top-down government to governance by self-organizing interorganizational networks (Rhodes, 1997, p. 35). Kickert, Klijn, and Koppenjan (1997) defined governance networks as "more or less stable patterns of social relations between interdependent actors, which take shape around policy problems and/or policy programmes” (p. 6). Koppenjan and Klijn (2000, 2004) have made significant contributions in theorizing the role of networks actors and managers in shaping the conditions and context for effective network performance.

Powell (1990) was an early researcher of governance networks and conducted an in-depth comparative analysis of networks, markets, and hierarchical governance structures. He asserts that networks are more suited to entities involved in an "intricate latticework of collaborative ventures with other firms" (Powell, 1990, p. 303). Powell posits that "hierarchies are reliable and thus are suited to transactions that involve uncertainty, recur frequently, and require substantial transaction-specific investments" (Powell, 1990, p. 303). Markets, however, are suited to exchanges that are straightforward, non-repetitive, and require no transaction-specific investments. Powell observes that network organizations are more social than markets and hierarchies; they are dependent on relationships, mutual interests, and reputation. Some networks are less guided by a formal structure of authority and successful networks involve “complementarity and accommodation" (Powell, 1990, p. 304). Reputation, friendship, interdependence, and altruism are integral parts of the relationship (Powell, 1990). The 
author emphasizes that the most useful information comes from parties with pre-existing relationships and trust, rather than from the formal chain of command (Powell, 1990).

Network governance is emerging where hierarchical forms of control are no longer an effective method for policy development (Keast et al., 2014). Shifting from topdown governance to self-organizing interorganizational arrangements, networks provide a way to tackle complex problems in a multi-dimensional and flexible manner (Keast et al., 2014). The two main conceptualizations of networks, as suggested by Keast et al. (2014) are 1. interorganizational networks of independent organizations that come together for the purpose of advancing their own organizational goals (due to the selfinterest focus, these arrangements are mostly about cooperation and coordination); and 2. networks based on "interpersonal relationships, trust, mutuality and reciprocity with defining collaborative outcomes that move towards a more transformational network where new systems are created" (p. 8).

Koliba et al. (2011) provide an important theoretical and empirical foundation for network governance theory in their book, Governance Networks in Public Administration and Public Policy. The authors define governance networks as, "interorganizational networks comprised of multiple actors, often spanning sectors and scale, working together to influence the creation, implementation, and monitoring of public policies" (Koliba et al., 2011 p. xxv). Networks often involve actors, who relate to each other through a variety of ties, often with competing interests and priorities (Koliba et al., 2011). The authors present a conceptual framework of network governance and detail the skills and functions of public administrators in the context of networked relationships. They also present the theoretical foundations to analyze governance networks. Finally, 
Koliba et al. (2011) identify reforms and trends that led to governance networks, explain the roles that various actors take on through networked relationships, highlight the challenges involved in the failure of networked activities, and illustrate how policy tools are mobilized by these relationships.

Several key theoretical constructs outlined by Koliba et al. (2011) are relevant to this research. First, networks offer an approach to governance that can navigate complexity and address wicked public problems such as integrated water management to produce effective results. Second, networks provide a new framework for determining how government interacts with for-profits and NGOs to design and deliver public goods and services. Third, networks are aimed at coordinating strategies of actors with different goals and preferences, and often include a mixed form of administrative authority that involves both vertical and horizontal elements. Finally, Koliba et al. (2011) propose a conceptual framework for effective governance networks that engages all forms of public administration including command and control, competition, concession and compromise, collaboration, and cooperation.

This research study focuses on networks that are "designed to influence the framing of public problems and derivation of policy solutions” (Koliba et al., 2011, p. 23). The authors refer to this type of network as "interest group coalitions" which are “interorganizational networks of organized interest groups, advocacy organizations and collective interest groups" (Koliba et al., 2011, p. 23). The coalitions coordinate action to "influence the framing of public problems, the design and selection of policies, or the evaluation of policy implementation" rather than implementation or service delivery (Koliba et al., 2011, p. 23). In order to lend legitimacy, however, networks need to be 
democratically anchored (Koliba et al., 2011). Other elements of success include a high level of trust between network actors, strong ties within the network to assure accountability and performance, and the creation of social capital (Koliba et al., 2011).

Sorensen and Torfing (2005) posit that "governance networks are democratically anchored to the extent that they are properly linked to different political constituencies and to a relevant set of democratic norms that are part of the democratic ethos of society" (p. 201) The authors define democratic anchorage as comprising a combination of control by democratically elected politicians that are:

$>$ controlled by democratically elected politicians;

accountable to the territorially defined citizenry;

representative of the membership based on the participating groups and organizations; and

$>$ following democratic rules specified by a particular grammar of conduct.

Regarding the role of social capital in networks, Putnam's (1993) research centers on political arrangements of networks and asserts that social capital, as embodied in horizontal networks of civic engagement, bolsters the performance of the polity and economy. Social capital, as defined by Putnam (1993, p. 167), "refers to features of social organization, such as trust norms, and networks, that can improve the efficiency of society by facilitating coordinated actions." He emphasizes that "voluntary cooperation is easier in a community that has inherited a substantial stock of social capital, in the form of norms of reciprocity and networks of civic engagement” (Putnam, 1993, p. 167). Social capital also refers to the bonds formed between actors in networks and allows for the development of human knowledge (Koliba et al., 2011). 
Scholars note that implementation challenges can occur under network government approaches. In a vertical governance model, state actors establish the rules and determine when and how they are to be enforced whereas, under a horizontal model, governance is more diffuse (Cooper, 2003). Cooperation is not based on the legal authority paradigm, but relies on collaborative management based on information rather than authority (Agranoff and McGuire, 2003). State actors may perceive this type of governance as a hindrance if they no longer control all aspects of policy development or implementation. Under network governance, their authority to govern could be diminished or their ability to get the job done compromised. Conversely, their ability to deliver results may be enhanced by the additional resources brought to the table by the various network partners.

In summary, several different schools of thought have evolved around network governance theory. The existing literature provides important insights to various frameworks; however, gaps exist around what role networks play in water governance and what factors influence their effectiveness.

\subsection{Collaborative Governance}

Building on the previous discussion about network governance theory, collaborative networks are formed to deal with very complex problems that no single organization, agency, or group can deal with independently (Keast et al., 2014). Participants recognize that the current mechanisms are no longer working and new, innovative solutions that transcend information sharing and coordination are needed (Keast et al., 2007). 
The literature on collaboration highlights several common characteristics. First, collaboration involves a wide range of stakeholders representing a cross-section of organizations, interest groups, and people with a stake in the outcome (Healey, 1997; Innes \& Booher, 1999). Second, collaboration engages the participants in an intensive and creative process of consensus building (Gray, 1989; Wondolleck \& Yaffee, 2000), which leads to more creative solutions and increased likelihood of acceptance (Innes \& Booher, 1999; Susskind and Cruikshank 1987; Weber 2003). Third, collaboration works to achieve consensus on problems, goals, and proposed actions (Innes \& Booher, 1999; Sommarstrom, 1999; Weber 2003; Wondolleck \& Yaffee, 2000). Finally, collaboration requires a sustained commitment to problem solving (Gray 1989; Selin and Chavez, 1995; Weber, 2003).

Collaborative networks are formed to deal with complex problems that no one organization or group can solve on its own. They represent a unique type of network model that exhibits "complex reciprocal interdependencies and closer, denser relationships in which participants are engaging in system changes" (Keast et al., 2014, p. 34). Participants recognize that the current mechanisms are no longer working and new innovative solutions that transcend information sharing and coordination are needed (Keast, Brown, \& Mandell, 2007). Under a collaborative network, members are engaged in activities that go beyond making changes at the margins to creating "new collective value" by reframing the problem and developing alternatives that may not have been generated through existing interactions (Innes \& Booher, 1999, p. 15).

Keast et al. (2014) developed a composite theory of leadership management in collaborative networks. This composite theoretical model centers on concepts of process 
catalyst and strategic leveraging. The term "process catalyst" describes a new type of leadership that places greater value and emphasis on creating an environment for building strong relationships and securing a commitment to common goals rather than on achieving tasks (Keast et al., 2014). Strategic leveraging recognizes the worth of each participant and the importance of interactions among them (Keast et al., 2014). Most importantly, relationships must also be "mobilized, managed, and leveraged to secure value" (Keast et al., 2014, p. 227-228).

Benham et al. (2014) focus on factors for success in collaborative water governance frameworks. The authors lay out a theoretical frame for successful collaborative governance while utilizing the IWRM model. This includes the importance of building social capital and network linkages to effectively accomplish watershed activities. Benham et al. (2014) also research the effect of exogenous factors (i.e., historical, geographical, political and economic factors) on relationship development in collaborative IWRM planning. Their research shows that contextual factors must be taken into account if natural resource managers are to design collaborative processes that strengthen governance networks and improve water resources management outcomes.

Kemmis (1992) describes the need for collaborative community and public life in the rural West. He laments the frontier mentality of rugged individualism that runs counter to public life (referring to community responsibility) and trust in government institutions. Kemmis espouses that, without connection to the public thing or res publica (p. 6), the success of place-based water resources management efforts is challenging. He describes a collaborative, grassroots approach, exemplified in local and regional watershed groups in which stakeholders coalesce around a shared responsibility for a 
"public thing." As people learn to relate to each other in a different way, they discover a new competency and an unexpected capacity to get things done. "Only cooperative acts of the affected community can solve a problem, which is consistent with the concept of citizenship or "polis" that requires taking responsibility within a shared space, creating the possibilities for a shared inhabitation" (Kemmis, 1992, p. 118). This is in stark contrast to relying on government actors to resolve watershed management issues. Kemmis concludes that a strong sense of civic capacity, community buy-in, and support are key factors to lasting success for place-based water governance.

\subsection{Collaborative Watershed Movement}

One of the most important efforts to integrate water management is the creation of locally-based watershed councils. Beginning in the 1980s, locally organized, collaborative, non-regulatory groups began forming to improve watershed conditions in their local area. In Oregon, these groups have focused on restoring water quality, recovering native fish populations, and improving land management practices within their local watersheds. In 1999, the Oregon Watershed Enhancement Board (OWEB) was created to disperse grant funding and oversee watershed restoration efforts and has been a key institutional step forward towards integrating water management efforts. Although OWEB is not directly involved in managing water resources, it provides significant funding, and thus has a role to play in influencing the water planning process (Amos, 2009, p. 107). Described below are constructs around watershed-scale management that are relevant to this area of research.

Cortner and Moote (1999) advocate for a decentralized and participatory society organized around local ecological conditions. The authors raise the issue of appropriate 
geographic scale for ecosystems management and observe that, "the watershed is a more tenable unit of analysis because it is geographically recognizable and its boundaries can be used as a basis for organizing participation and governance institutions" (Cortner \& Moote, 1999, p. 46). The premise that decentralization, local control, and flexible management are the key to solving environmental problems underscores the watershed council approach.

In Swimming Upstream: Collaborative Approaches to Watershed Management, Sabatier et al. (2005) focus on collaborative approaches to watershed management that have dominated the landscape in recent years. The authors describe how water resource management has shifted away from top-down government agency-directed decision making to a more collaborative approach of negotiation and problem solving. Collaborative governance approaches are particularly important for the integrated management of water resources, which often span jurisdictional boundaries and are managed by multiple organizations.

The research and report findings outlined in Swimming Upstream make a significant contribution to the literature on water resources and governance in two ways. First, the study presents a fairly broad and elaborate conceptual framework for understanding collaborative watershed management. Second, the study analyzes a variety of collaborative watershed planning projects at the local and regional scale, using qualitative and quantitative mechanisms (Sabatier et al., 2005). The authors' framework for watershed management purports that one consequence of collaborative watershed management is change in the civic community of a particular watershed. They look at a variety of projects across the United States exploring issues of trust and legitimacy to test 
their hypothesis and present both normative and positive theoretical frameworks. This work contributed significantly to a broader understanding of collaborative water management mechanisms.

The National Policy Consensus Center (NPCC), located at Portland State University's Hatfield School of Government, advances the use of collaborative governance methods through innovative services, research, and education. As part of their research efforts, two published reports around collaborative watershed efforts are relevant to this research. The first report, Watershed Solutions: Collaborative Problem Solving for States and Communities (Marsh, 2002) is an outcome from a colloquium NPCC hosted for practitioners involved in watershed collaborations. It identifies lessons learned from successful watershed initiatives and develops recommendations to state officials on ways to enhance the use and effectiveness of watershed partnerships. The report identifies watershed collaboration best practices, identifies lessons learned and barriers to success, and provides recommendations directed at state-level actors.

Another NPCC report of particular relevance to this research is Factors of Successful Collaboration: Oregon's Watershed Councils as Collaborative Systems (Doherty, 2015). This research developed a construct for collaborative systems and tested it through application to Oregon's watershed councils. The author conducted an extensive literature review and summarized the benefits and challenges of collaborative processes at the watershed scale. In addition, based on her research findings, the author provides recommendations for enhancing collaborative performance among watershed councils (Doherty, 2015). This research provides important insights into factors for successful collaborations at the watershed scale. 


\subsection{New Public Governance}

The final area of literature reviews centers around a public administration framework known as New Public Governance (NPG). New Public Governance is one of two movements responding to questions about government's capacity as the primary actor to solve society's problems (Morgan \& Cook, 2014). Launched in the 1980s, the first movement, called New Public Management (NPM), utilizes the business or market model for the basis for measuring government success. Under the second movement, New Public Governance, the importance of applying a collaborative approach to providing public services is emphasized through partnerships with public, private and non-profit actors (Morgan \& Cook, 2014). NPG strongly builds upon governance network theory and developed as a response to shortcomings of New Public Management (Klijn \& Koppenjan, 2012).

New Public Governance emphasizes trust and legitimacy-building characteristics of public governance; it is value centered and emphasizes that the goal of government is to promote the larger common good (Morgan \& Cook, 2014). Second, NPG underscores creation of government processes that facilitate agreements among diverse stakeholders. Under NPG, politics is viewed as the "politically mediated expression of collectively determined preference that the citizenry deems valuable" (Morgan \& Cook, 2014, p. 5). Third, NPG facilitates the creation of a public good as a "co-production process involving the public, private and nonprofit sectors" (Morgan \& Cook, 2014, p. 6). Under the NPG framework, non-state actors are more invested in shared ownership of a public good than under top-down governance models. This creates opportunities to build capacity and civic infrastructure in a more holistic way. 
Representing a shift from governance through vertical structures of authority to working with horizontal structures, NPG offers a framework for identifying and reconciling conflicting values that dominate discussion under water policy development and governance. NPG emphasizes civic engagement and the role of engaging citizen and volunteer organizations to temper interest group conflicts and ideological differences (Morgan and Cook, 2014). (See Table 2.1 for key features of NPG framework.) However, many questions remain about what factors contribute to the success of "shared-power" arrangements under a NPG framework.

Some authors suggest that governance network theory has sparked ideas and management practices that have resulted in the rise of NPG. By building upon governance network theory, NPG has the potential to deal with the "complexities, interdependencies and dynamics of public problem solving and service delivery, which NPM failed to address" (Klijn \& Koppenjan, 2012, p 2). NPG may not replace hierarchical forms of government or network government arrangements created under NPM, but rather evolve into a hybrid arrangement combining these theoretical constructs (Klijn \& Koppenjan, 2012). 
Table 2.1 Characteristics of New Public Governance (Morgan and Cook, 2014)

- Theoretical basis: Institutional, network, theory of agency

- Concept of state: plural and pluralistic

- Management focus: values that are coproduced by networks and partners

- Leadership actions: interest-based conflict resolution

- Leadership scope: forging collective horizontal leadership

- Leadership archetype: strategic leadership

- Leadership results: agreement on actions

- Value orientation: limited explicit value conflicts

- Value arbitration: networks and relational contracts

- System orientation: mini-centric: external focus

- Performance unit of analysis: conflict resolution

\section{6 Summary}

In summary, several different schools of thought have evolved around network governance theory. The existing literature provides important insights to various governance networks models; however, gaps exist around what role networks play in water governance. The research builds upon these existing constructs by examining two cases of integrated water governance. The aim is to gain a better understanding of the governance network dynamics in water resources policy development and governance. 


\section{CHAPTER 3: RESEARCH DESIGN AND METHODS}

\subsection{Introduction}

This research study utilized case study and comparative analysis methods to gain a better understanding of collaborative, network governance approaches to integrated water resource management. I choose a comparative case study methodology to gain insights into and explain real-life situations in integrated water management. Through this study, I reviewed two collaborative water governance cases (New Zealand and the State of Oregon, USA) in order to assess how successful these institutional arrangements were in delivering an integrated approach to water management. Both cases were premised on an IWRM approach but with different legal and institutional frameworks. The practical goal for conducting this research was to gain a better understanding of network governance frameworks as applied to integrated water management. The intellectual goal was to gain insight into what was happening in these two integrated water case studies and why. By understanding the key defining elements, necessary conditions for collaboration, institutional barriers, and the primary factors for success, I aimed to expand knowledge about governance arrangements that can deliver integrated water management.

Working from the literature and the researcher's personal experience and knowledge on water policy issues, this study focused on the following seven research questions:

1. How are the different governance networks structured and how are their boundaries determined? 
2. How do the collaborative processes work, and what role do state and non-state actors play in setting water policies in New Zealand and Oregon?

3. What functions do they carry out? How are the networks governed, and how are policies developed in the collaborative?

4. How are these networks held accountable? To what extent are the networks democratically anchored?

5. How fully are surface water and groundwater, water quality and quantity, and land use integrated in management systems under New Zealand and Oregon governance structures?

6. What are the legal, political, and institutional barriers affecting water governance in New Zealand and Oregon?

7. How do issues such as climate change and water scarcity influence approaches to water management?

\subsection{Proposition at Risk}

Based on a review of relevant literature, personal experience, pre-research discussion, and related theoretical reasoning, I developed the following hypothesis for testing: I posit that the historic approaches to water governance approaches are inadequate to address wicked water problems, and thus collaborative networks involving public, private, and non-profit actors are better equipped to develop effective and durable outcomes. This involves a shift from a top-down, vertical command and control governance approach to a shared governance network that employs horizontal ties with partner organizations and interest groups. 


\subsection{Case Study Methodology}

I selected the case study approach for the following two reasons. First, this approach is pertinent when research addresses a descriptive or explanatory question such as "how or why did something happen." Second, it allows the researcher to cover contextual conditions and gain a better understanding and explanation of real-life situations (Maxwell, 2013, p. 97). Maxwell (2013) explains that the case study methodology serves to "elucidate processes, meanings, and contextual influences in particular cases" (p. 97). Furthermore, case studies provide a picture of "very complex interactions between interdependent actors with divergent interests and perceptions about desirable solutions" (Klijn \& Koppenjan, 2012, p 6).

According to Yin (2003), case study research "is an empirical inquiry that investigates a contemporary phenomenon within its real life context, especially when the boundaries between phenomenon and context are not clearly evident" (p. 13). It is also appropriate "when 'how' and 'why' questions are being asked about a contemporary set of events, over which the investigator has little or no control" (Yin, 2003, p. 9). Thus, I utilized the case study methodology to gain an in-depth understanding and develop insightful explanations of real-life situations that may not arise using other research methods.

The study consisted of a multiple-case design with the case serving as the unit of analysis. As Yin (2003) points out, the multiple-case design is more challenging to implement; however, the ensuing data can provide greater confidence in the findings. The search for appropriate case studies began with a review of the best practices landscape around collaborative network governance and integrated water management. This 
included a review of the literature and conference proceedings, current journals, discussions with academic peers, and discussions with academic advisors. The aim was to examine case studies in collaborative network governance using the analytical lens of network theories to unpack factors for success.

\subsection{Case Selection}

Two case studies were selected in New Zealand and Oregon, USA, that utilized IWRM principles, had comparable timeframes for adoption, and had similar geographic scales. Another key factor in the case study selection process was a practical one for the researcher -- I considered studying institutions where I had established contacts and access to information, and where government officials and other parties had expressed an interest in participating in case study research.

For the first case, I spent nine months in New Zealand, as a Fulbright Fellow, studying and researching their freshwater policy reforms. Traditional water management efforts in New Zealand were aimed at protecting water quality and managing water quantity through regional-level basin planning efforts. This research focused on reviewing the extensive work of a national level, independent-led group, called the Land and Water Forum, which had convened specifically to revisit New Zealand's existing water management framework and propose new water management policies that were "fair, efficient, and accountable" (Land and Water Forum Report, 2012a).

To gain a better understanding of the institutional arrangements and key decisionmaking drivers for integrated water management in New Zealand, this research focused on 1. documenting the collaborative, network national-level planning process led by the Land and Water Forum; 2. researching how the collaborative governance decision 
making process unfolded in New Zealand at both the national and regional scale; and 3. examining what counts for success in these governance networks.

The second case involved the study of Oregon's Integrated Water Resources Strategy (Strategy), a collaborative framework for developing a state water blueprint. As a former Oregon legislator, I had been directly involved in the development of the enabling legislation for the Strategy and the early years of policy development. The Strategy assessed the state of existing water resources management in Oregon, along with the impact of present and future demands on those resources.

\subsection{Case Study Design}

The first step in designing an effective case study involved developing a research design or plan. Research design is the logic that links the data to be collected, and the conclusions to be drawn to the initial questions of study (Yin, 2003). Every empirical study has an implicit, if not explicit, research design or articulating "theory" (Yin, 2003, p. 19). Yin's guidance on how to conduct case studies helped frame this research. I utilized Yin's (2003) five components of research design including (1) a study's questions, (2) a study's propositions, (3) a study's unit of analysis, (4) the logic linking the data to the propositions, and (5) the criteria for interpreting findings (p. 21).

Defining these five research design components served as an essential step for constructing preliminary theoretical concepts related to this research. Yin explains that the role of theory development prior to collecting data is a major difference between case studies and other related research methods such as ethnography and grounded theory. These methods typically avoid outlining theoretical propositions at the outset of an inquiry (Yin, 2003). In conducting these case studies, the choice of theory aided in 
defining the appropriate research design and data collection methods (Yin, 2003).

In order to ensure the quality of the research findings, I utilized the following four tests as outlined by Yin (2003):

1. Construct validity establishes the correct operational measures for the concepts being studied. Yin (2003) recommends applying multiple sources of evidence, keeping clear chains of evidence to connect the data with the concepts being scrutinized, and asking key informants to review case study analysis and findings. I employed all of these concepts to ensure construct validity. I relied on multiple sources of data to check the veracity of facts, and interviewed people with a range of perspectives to ensure that I was capturing events from different vantage points. The chain of evidence was comprised of case-organized field notebooks and databases that compiled information from multiple data sources to detail chronological histories, record meeting notes, and document my observations and reflections for each case study. Finally, I asked two key informants from each case to review draft dissertation sections for accuracy.

2. Internal validity refers to the accuracy of the causal relationships in each of these case studies. Do study findings make sense and are they credible? In order to promote internal validity, I employed the following methods as suggested by Miles and Huberman (1994). First, I utilized context-rich meaningful descriptions of the case by gathering evidence through semi-structured interviews. This provided a richer description and a greater contextual understanding than available through other data sources such as document and archival reviews or personal observation. Next, I employed triangulation of complementary methods and data sources to ensure converging lines of evidence. In addition, I sought rival explanations to test the validity of my findings and explore areas 
of uncertainty. Finally, I asked key informants to check the accuracy of the research conclusions and to ensure that the findings were internally coherent.

3. External validity references the domain to which a study's findings can be generalized. Yin (2003) discusses two types of generalizability: A) statistical generalizability draws inferences from the sampling data to a population; whereas B) analytical generalizability compares the case study findings to an established theory. This research focused on the latter, and Yin (2003) recommends using at least two case studies to show analytical generalizability. Specifically, the case study research tested the application of collaborative and network theories under two different cases. Qualitative data provided an in-depth understanding of collaborative and network theoretical processes in each case. Although use of only two case studies limits the explanatory potential of this research, trade-offs occur when including more cases. A multi-case analysis may have offered a greater range of collaborative network examples, but the opportunity to collect detailed and rich qualitative data would be more limited.

In order to promote external validity of the research findings, I employed several strategies. First, I provided ample 'thick descriptions' for readers to assess the potential transferability or appropriateness for their own setting (Miles \& Huberman, 1994). Second, I also attempted to describe the narrative sequences (antecedents, settings, histories) in a transparent manner so others could clearly understand the unfolding of events and causalities. Third, this research suggests settings where the theoretical findings could be fruitfully tested further in a case-to-case transfer.

4. Reliability pertains to whether the study process is consistent and can be repeated by other researchers with similar results. I employed a number of procedures to 
assure reliability and dependability of this research. First, I made sure that the research questions were understandable and that the study design features were congruent with the questions. Second, I engaged in a data collection process across a full range of appropriate settings, times, and respondents (to ensure a variety of perspectives). Third, a database was developed for each case study that included relevant documents, field notes of observations and reflections, memos, audio transcripts, and meeting notes to allow for other researchers to replicate study research procedures and assess case study findings. Fourth, data quality checks were used to address potential researcher bias (described in more detail later in this chapter) and informant reliability. Finally, I employed peer review of the coding process for each case study to check the dependability of coding results.

The next step in conducting the case study research involved preparing for data collection. Factors for success included prior research skills of the researcher, training and preparation for the specific case study, development of the case study protocol, and conducting a pilot case study (Yin, 2003). The case study protocol contained the following information:

$>\quad$ an overview of the case study project (project objectives, case study issues, relevant readings)

$>$ field procedures (credentials and access to case study sites, sources of information, procedural reminders)

$>$ case study questions (specific questions to consider when collecting data, sources of information) 
case study guide (outline, narrative format, documentation of information) (Yin, 2003, p. 70).

The heart of the protocol was the case study research questions reflecting the actual area of inquiry (Yin, 2003). Case studies differ from other research methods in that the questions are posed to the investigator rather than to a respondent. These questions served as a reminder to me as the researcher about information that needed to be collected and why. In addition, I associated each question with a list of probable sources of evidence such as individual interviewees, documents, or researcher observations (Yin, 2003).

Evidence for the case study research was gathered from the following sources: documents, archival records, key informant and participant interviews, direct observation, and participant-observation (detailed in Table 3.1). The case study research followed formal procedures to assure quality control during the data collection process. I applied the following three key principles of data collection in conducting the case study research:

use of multiple sources of evidence - that is, evidence from two or more sources, but converging on the same set of facts or findings

case study database - a formal assembly of evidence distinct from the final case study report chain of evidence - explicit links between the questions asked, the data collected, and the conclusions (Yin, 2003). 
Prior to conducting any research, I submitted a Human Subjects Review plan to the Portland State University Institutional Review Board and received approval for an exempt status in December 2015.

\subsection{Data Collection}

Employing Yin's suggested case study data collection techniques for conducting case study research, appropriate evidence was gathered to address the study research questions. Table 3.1 summarizes the data sources utilized for each case study. More detailed information on each of these sources is provided in the following sections. 


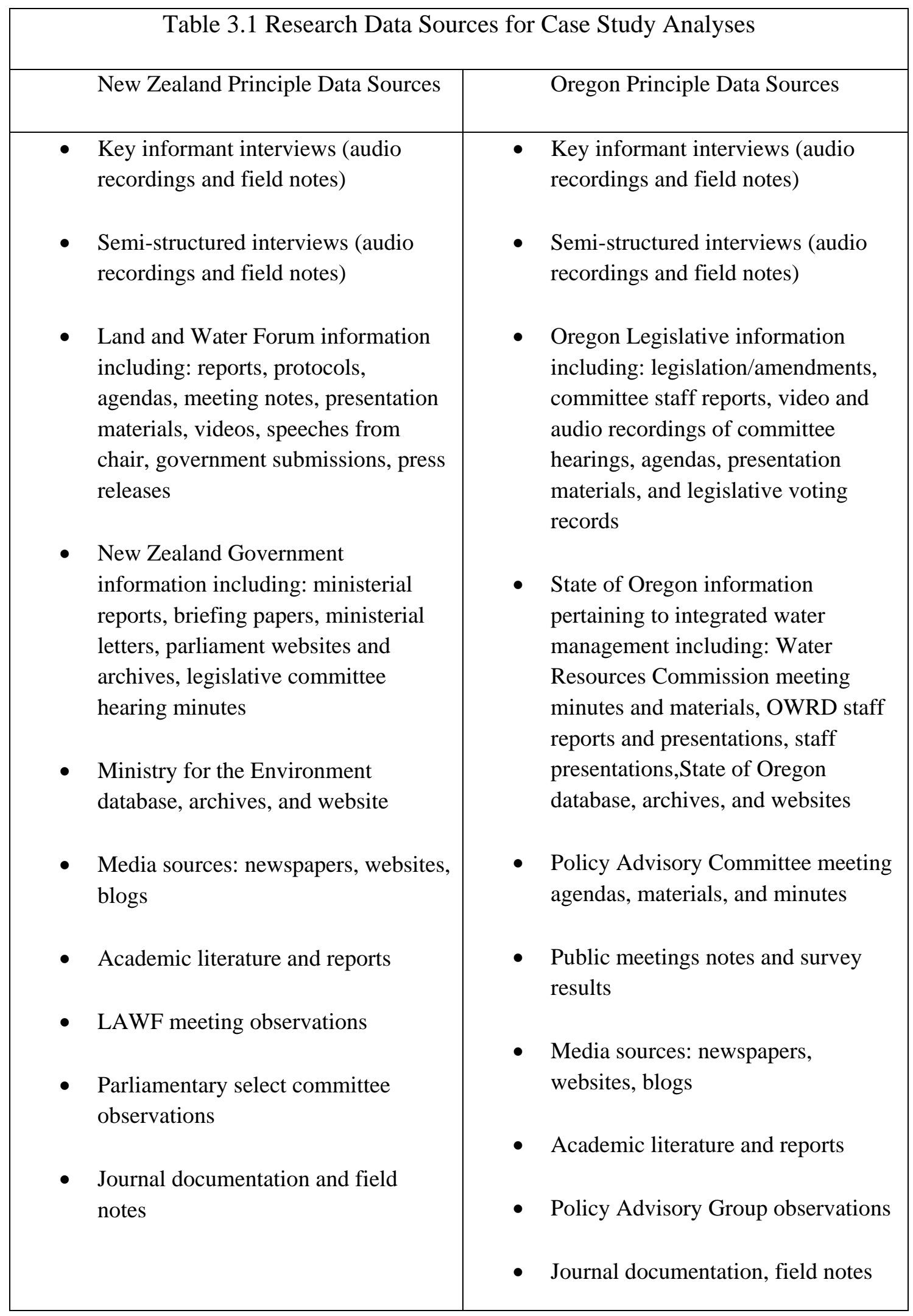




\subsubsection{Document Review}

In addition to reviewing scholarly literature as outlined in the literature review in Chapter 2, I conducted a thorough public document and archival review for each case study. The intent of this document review was to gather background information and familiarize myself with the past and current water policy landscape for each case study.

New Zealand. During the New Zealand case study, I was hosted by the Ministry for the Environment as part of a 2016 Fulbright Fellowship. Through this fellowship, I was afforded access to internal databases containing extensive amounts of current and archival information. Current materials reviewed include water-related legislation and rules, administrative records, ministerial reports and briefing papers, internal memos, policy papers, meeting minutes, ministerial briefing papers, select committee reports and presentations, and websites. Archival data included electronic and hardcopy versions of archived meeting minutes, draft reports, briefing memos, legislative history, newspapers articles, newsletters, and other similar materials.

I also reviewed Land and Water Forum-related published reports, plenary and small group meetings minutes, conference proceedings, Power Point presentations and videos, protocols, and internal briefing documents. I utilized databases from the Ministry for the Environment, New Zealand Parliament, New Zealand National Library archives, University of Victoria at Wellington, and New Zealand science-based research institutions as primary research sources. Documents relevant to the New Zealand case study were reviewed, summarized, and coded for content. The result of this analysis was used to identify potential data gaps, key informants, and develop a list of potential interview participants. 
Oregon. For the Oregon case study, I was more familiar with background information due to my direct legislative and professional experiences. However, since I had not worked directly in that space for a few years, I conducted a thorough document review to re-familiarize myself with all the information and materials associated with the Strategy. Documents reviewed included integrated water-related legislation and rules, legislative meeting minutes, agency reports, policy papers, memos, and newspaper articles. Oregon Water Resources Commission archival information included electronic and hard-copy versions of meeting minutes, memos, staff reports, issue papers, and other similar materials. Oregon legislative and agency databases accessed via the internet along with printed documents served as primary sources for this information. Information relevant to the Oregon case study were reviewed and synthesized, entered into a database, and analyzed for content.

\subsubsection{Semi-structured Interviews}

Semi-structured key informant interviews served as the primary data-gathering method to learn about the perspectives of state and non-state actors, gain a better understanding of collaborative network processes, fill data gaps, and triangulate evidence for both cases. During the early stages of the research, I started with key informants interviews, which were particularly valuable sources of information as they provided me with detailed knowledge about history, processes, and institutions, along with suggestions about other potential interview participants during the early stages of the research. Sampling was not designed to be random, but rather selective sampling of a range of policy makers and stakeholders involved in development of water policies. An effort was made to interview a variety of representative interest groups including: elected and 
agency officials from different levels of government; tribal interests; private interests from agriculture, industry, power generation, horticulture, forestry, tourism and recreation; non-governmental organizations from environmental, conservation, and fisheries, groups; and citizen groups.

The literature and document review aided in construction of the interview questions. Both scripts began with introductory questions to establish a rapport with the informant. When conducting interviews, I employed probing open-ended questions with follow-up prompts to focus the discussion, where needed. Interview protocols contained key questions and topics that I wanted to cover; however, I followed the participant's lead and let the interview veer "off topic" if a particularly interesting and relevant topic surfaced that was not included in the original set of questions. I listened intently to what the informant was saying, while attempting to view experiences through their eyes as much as possible. Throughout the process I asked clarifying questions if I was unsure exactly what they meant, or when they used a phrase or word that seems "loaded" with meaning for them. In order to unpack a loaded word or phrase and gain a better understanding of where they were coming from, I followed up with prompts such as "could you tell me a bit more about what you mean by xxx?" (See Appendices A and B for interview protocols.) The principle aim in collecting interview data was to let respondents tell their own story in their own terms.

New Zealand. In developing the New Zealand interview protocol, I consulted with Ministry for the Environment policy officials, Victoria University academic advisors, and other Ministry staff. The protocol consisted of twelve questions divided into four sections. The questions I posed to informants included a brief description of their 
background and how their interests or work experience relates to New Zealand water policy. I asked them to describe their involvement with the Land and Water Forum, their organization's role and how the Forum process has worked. Interviewees were asked about successes and challenges of the process as well as lessons learned. A series of questions about collaborative networks governance processes and outcomes were posed, and finally, the role of climate change in shaping the water reform process was explored.

Rather than employing random sampling techniques to select interview participants, I utilized intentional sampling. I began with interviewing the Land and Water Forum Chair, Alastair Bisley, and asked for his suggestions regarding other Land and Water forum participants to contact. I also used personal judgment and knowledge about the case history, context, and review of relevant information to develop a list of key informant interviews. I asked government officials and my New Zealand academic advisors to review the draft list to ensure that interview participants represented a range of interests, perspectives, and ideologies involved in water issues. Once the interview process was initiated, I used snowball sampling techniques to augment the interview list.

I conducted 24 interviews of Land and Water Forum members, indigenous leaders, central and regional elected officials, central and regional governement staff, and key interested parties as part of the research process. The interested parties represented a range of groups including: national and regional government, agriculture (dairy, ranching, horticultural, and irrigated agriculture), private energy providers, Maori, environmental and conservation, fishing, forestry, recreation, and scientific communities. Of the 24 people interviewed, half were audio recorded. For those not recorded (due to requests by interviewees or because they were via phone), detailed field notes were taken. 
After each interview, I drafted a memo documenting interview details and analytical insights for assistance during the data analysis phase. All interviews were transcribed and entered into a database for later coding analysis. (See New Zealand interview protocol attached as Appendix A).

Oregon. As I was more familiar with Oregon's history, context, and key players, I drafted a preliminary interview protocol based on personal knowledge and experience. In order to validate the objectivity of the interview protocol, I asked members of my dissertation committee, along with professional and academic peers familiar with Oregon water policies to review and provide feedback on the interview questions. The protocol consisted of eleven questions divided into four sections. To start off the interviews, I asked participants to share a brief description of their professional or personal background, and how their interests or experiences relate to Oregon water policy. Next, I asked interviewees to describe their involvement with the Integrated Water Resources Strategy, their organization's role, and how the Strategy design and development process had worked in their view. The next set of questions focused on successes and challenges of the process, and lessons learned. And finally, I posed a series of questions about collaborative network governance processes and outcomes and the role of climate change in shaping the water reform process. (See Oregon interview protocol attached as Appendix B).

For the Oregon case, I utilized intentional sampling techniques and interviewed 25 participants with past or current association with the Strategy process. Since I had been directly involved with the enabling legislation policy design, drafting, and ultimate adoption, I was already familiar with the key players, policy makers, and stakeholders. 
Although I had ideas about potential informants, I wanted to ensure that a range of interests were represented including government (tribal, state, and local), agriculture, ranching, environmental and conservation, recreation, and civic organizations. The first wave of interviews focused on the Policy Advisory Group members, as they had been deeply involved with development and updating of the Strategy. The next wave of interviews included the Governor's staff, state agency personnel, and other stakeholders. Finally, I interviewed Water Resources Commission members who played a key role in the Strategy policy guidance and development process.

Of the 25 participants interviewed, 22 were audio recorded. For those not recorded (due to requests by interviewees or because they were via phone), detailed field notes were taken. After each interview, I drafted a memo documenting interview details and analytical insights for assistance during the data analysis phase. All interviews were transcribed and entered into a database for later coding analysis. I began data analysis after the first interview, and continued to read and analyze interview data throughout the research process.

\subsubsection{Direct Observation}

I utilized direct observation of policy meetings for both cases to gain a better understanding of collaborative, network processes. In New Zealand, I attended six Land and Water Forum meetings and three public meetings on the freshwater reform process as a non-participant observer. I also attended two regional-level collaborative water forums. I documented all meetings, interviews, public forums, and one-on-one interactions with detailed field notes. Documentation in the form of notes, minutes, and memos were utilized for later coding. I utilized a recording device to document direct observations, 
where appropriate, and assist with the formal documentation process.

In the Oregon case, I engaged in both participant and non-participant observations. During my previous tenure in the Oregon Legislature, I was directly involved in policy development related to integrated water resources management. I attended meetings associated with development of Oregon's Integrated Water Resource Strategy in 2000-2002; however, at that time I was not engaged in active research for this dissertation. During field research conducted in late 2016, I attended policy meetings as a non-participant observer. Issues around potential bias as a participant observer are addressed in the validity section later in this chapter.

\subsubsection{Reflective Journal}

Use of a reflective journal helped capture my thoughts and insights while conducting research. Through journaling, I reflected on personal observations and analytical considerations of the research whether it was reviewing literature, conducting interviews, attending meetings as an observer, or during the writing and analysis phases. For example, I noted comments related to the sampling rationale, who to contact next, or which documents to search for. I also made extensive notes related to ideas under development, network graphics for the case studies, or comments regarding current practices. The use of a reflective journal helped add rigor to the qualitative analysis by recording assumptions, reactions, expectations, and biases throughout the research process. Field notes also afforded additional data for analysis.

\subsection{Data Analysis}

I employed a reflexive process in conducting the case study research focused on analyzing the case study evidence to facilitate answering the research questions. A good 
analysis should utilize all the relevant evidence, consider alternative interpretations, address the most significant elements of the case study, and draw on the researchers prior knowledge and experience (Yin, 2003). The analysis involved systematically organizing and transcribing interviews, document summaries, observations, field notes, and journal entries for later analysis. I looked at linkages to themes in literature and for emerging themes from the informant interviews.

\section{$\underline{\text { Inductive Coding Process }}$}

For coding and analyzing the data, I employed an iterative, inductive process to observe what new insights, themes, or theories emerged from the data (Starks \& Trinadad, 2007). Inductive reasoning is based on learning from experience, thus I looked for patterns and consistent themes that emerged in order to generate theoretical constructs. Throughout the research process, I made adjustments and modifications as new evidence was collected. The graphic below depicts the inductive reasoning approach I utilized for the case study analyses (See Figure 3.1).

Figure 3.1 Inductive/Deductive Reasoning Process

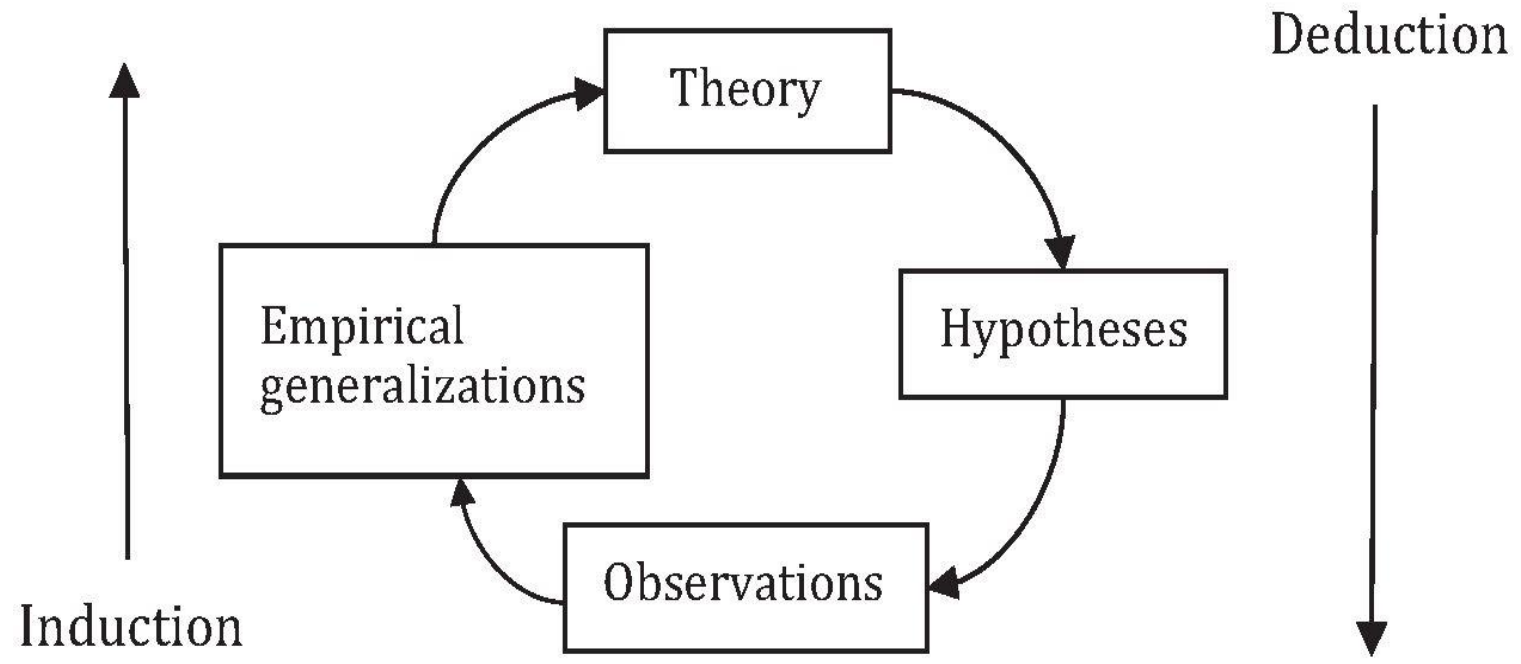


I began the data analysis process by reading through interview transcripts and field notes repeatedly to achieve greater familiarity and total immersion with the research data. After gaining a big picture perspective, I reviewed the data line by line to derive codes by highlighting the exact words and phrases that captured key themes or concepts. Coding is a process for assigning "units of meaning to the descriptive or inferential information compiled during a study" (Miles \& Huberman, 1994, p. 56).

I utilized Dedoose, an online qualitative coding software program, to assist with the coding process. I identified units of narrative data that seemed important or meaningful, or captured new insights, and assigned codes to the highlighted text. I endeavored to let ideas and themes emerge from the data alone, rather than imposing structure or a framework on the data. I adopted a "grounded approach," as I did not precode datum until I had collected it and observed how it nested in context (Miles \& Huberman, 1994, p. 58). The advantage of using a grounded theory approach was that, as the researcher, I was more open-minded and "context sensitive" (Miles \& Huberman, 1994, p. 58). The objective was to match observations with constructs found in network governance theory, or identify new themes that arose "in situ" or from the data alone to create a map of what was happening and why. Through this iterative process, labels for codes emerged that reflected key themes. I created a code book containing an exhaustive list of codes developed from this process (See Appendix C).

Following the initial data sorting and coding, I developed categories based on how the different codes were related and linked. I deconstructed and reconstructed data into categories to facilitate comparison and aid in development of theoretical concepts. I also examined the codes for patterns and distilled the textual data into a set of categories 
or concepts. This was an iterative process where I started with an extensive listing of all codes and eventually reduced this list to a smaller number of categories. I looked for "saturation," meaning that no significantly new explanations emerged from the data (Miles \& Huberman, 1994, p. 74). I identified major themes and sub-themes, ordinary themes, and unexpected and hard to classify themes. These final themes were intended to be exhaustive, sensitive to what was contained in the data, and reflect the purpose of the research (Miles \& Huberman, 1994). Next I looked at the relationship between these themes to help construct a narrative to explain what was emerging from the data.

Throughout the coding process, I documented impressions, thoughts and initial analyses, mainly in the form of memos. This technique proved especially helpful in tying together different pieces of data during the coding process. In order to be systematic and transparent, I followed the same steps and procedures throughout the data analysis process. The themes that emerged from the coding results for each case study are described in Chapters 3 and 4.

\section{Case Study Qualitative Comparative Methodology}

Once the data was analyzed for each of the two case studies, I initiated a comparative case study analysis process using Ragin's (2014) comparative method. Ragin (2014) describes that a key goal of comparative analysis is to interpret a common historical outcome or process across a limited range of cases. Comparison provides a basis for making statements about empirical regularities and for evaluation and interpreting cases relative to substantive and theoretical criteria (Ragin, 2014). This knowledge provides the basis for "understanding, explaining, and interpreting diverse historical outcomes and processes and their significance for current institutional 
arrangements" (Ragin, 2014, p. 6).

With the use of only two case studies, I was able to examine each case holistically, meaning that the casual significance of an event or structure was viewed in context, rather than a sum of collective parts (Ragin, 2014). In particular, I was interested in understanding historical sequences, the role of state and non-state actors, causal conditions, institutional barriers, decision-making process, and the role of leadership in each case. From the onset, both case studies appeared to be similar, yet they experienced different outcomes. Thus, I focused the analysis on how different conditions or causes fit together in the New Zealand case and contrasted them with how they fit together in the Oregon case (Ragin, 2014).

In conducting the case study comparison, I employed several elements of Ragin's comparative methodological approach. First, I recognized the holistic, case-based nature of comparative research and treated each case as a complex entity, rather than a sum of parts, throughout the course of analysis (Ragin \& Zaret, 1983). For each case, I studied the configuration of conditions to determine how the different combinations of conditions were associated with specific integrated water management outcomes. The effects of variables were also assessed in the context of the case, rather than detached from it, to facilitate linkage of causally relevant conditions to outcomes (Ragin, 2014).

Second, I adapted the use of Ragin's "truth table" to enable exploration of similarities and differences among the two cases. A "truth table" is an "analytical device that displays data in a matrix of logically possible configurations of causal conditions" (Ragin, 2014, p. xxi). The use of a truth table created a visual display of data that helped facilitate the analytical process through a side-by-side comparison for each research 
variable. This also helped uncover any patterns of invariance or consistent association (Ragin, 2014). By bringing the two cases together, I was able to assess where there was congruence or dissimilarities among causally relevant conditions in each case.

Third, I developed an explanatory model in an iterative, inductive manner (as described earlier in this chapter), to enable a dialogue between theory and evidence (Ragin, 2014). Through use of a truth table I was able to identify the presence or absence of certain conditions for each case. The goal was to identify the different causalities that were responsible for outcomes in each case. I used theory to aid in the identification of relevant differences and tested this with evidence generated for each case. Through a robust back-and-forth dialogue process between ideas and evidence, I was able to formulate a general explanatory model for each case.

\subsection{Validity}

In order to address research validity and reliability, I employed several strategies as outlined by Miles and Huberman (1994), including checking for representativeness, triangulation, addressing researcher effects or bias, checking for outliers, rival explanations, and soliciting feedback from informants. Table 3.2 depicts a summary of methods utilized to ensure research validity. 
Table 3.2 Methods Used for Addressing Quality and Validity Threats (Miles and Huberman, 1994)

- Checking for representativeness: assess whether findings are typical for the case

- Checking for researcher effects: methods to address possible researcher bias

- Triangulation: findings are more reliable if they can be buttressed from several independent sources

- Checking for outliers: strengthen and test findings by carefully examining exceptions or outliers

- Rival explanations: testing alternative explanations for the phenomena

- Soliciting feedback from informants: evaluation of major case study findings by key informants

Checking for Representativeness. Since I was not conducting random sampling

for interviews, I needed to avoid drawing inferences or generalizing from a select group that was not representative of a wide range of viewpoints. First, in order to avoid this pitfall, I interviewed 24-25 people in each case from a wide range of interest groups to ensure that the data wasn't skewed towards one perspective or another. I purposively contacted participants from industry, agriculture, forestry, tribes, conservation, tourism, recreation, public interest, and government to ensure a balance of perspectives in the interview process. Second, I asked colleagues to review the list of interviewees to confirm that a purposive sample represented a wide range of actors. This also held true for information gleaned from meeting observations. Since I was unable to personally 
observe all meetings for either case study, I reviewed available meeting minutes for each case. Under this scenario, I was able to compare and calibrate patterns or inferences developed through direct observations with information about other meetings that I was unable to attend.

Triangulation. Triangulation of evidence is "supposed to support a finding by showing that independent measures of it agree with it or, at least, do not contradict it" (Miles and Huberman, 1994, p. 266). Triangulation of data sources using different methods, with varying biases and strengths, helped confirm findings and facilitate a greater level of confidence in the research findings. For both case studies, data was triangulated from a variety of information sources (i.e., written documentation, interview data, observations, field notes, reflective journals, and peer review). In addition to reviewing copious reports, documents, and archival data for background information, I conducted semi-structured informant interviews to allow for participants themselves to provide rich data about the case. Attending meetings and workgroups allowed me to observe firsthand network governance processes in both cases. I also compared meeting notes with other peer observers to ground truth the observations. In addition to attending a variety of meetings, I carefully read and coded past meeting minutes and summaries. By using interviews, observation, and document reviews, I established a triangulation or converging lines of evidence to make certain there was a greater level of confidence in the study conclusions.

Addressing Researcher Bias. As a researcher, I brought personal experience and knowledge around water resources management and policy development to this research project. Additionally, I served as an elected official in the Oregon Legislature for over 
twelve years in both the Oregon House and Senate, where I was personally involved in developing water resource policy, legislation, and budgets. Direct experience with Oregon's Strategy helped inform this research and provide valuable insights and access to information about the Strategy's legislative history, policy development process, institutional and governance framework, state and non-state actor involvement. However, it also posed a potential objectivity challenge for the research and analysis process.

To address potential researcher bias, I used experiential knowledge as part of the inquiry process, but I did not view it as a license to impose personal values or assumptions on this research. I acknowledged that my prior professional and elected experiences, along with my personal values and beliefs, had the potential to affect the research in multiple ways. This is true not just for me, but for all researchers in general. Some sources (England, 1994; Rose, 1997) refer to this as "positionality" where researchers must especially take account of their own position in relation to the research participants and research setting. Thus, I took the following steps to ensure that the research was balanced and not considered biased by personal perspectives or political viewpoints.

First, I was cautious to keep an open mind, and listen carefully during interviews and meetings to capture important insights into what was happening in each case study, especially in Oregon where I had personal experience. In particular, I paid special attention during the interview process to my own internal filters and perceptions as I served as the data gathering instrument. By audio recording the interviews, I could check back and compare my field notes with the actual language used by interview participants. When conducting interviews for New Zealand, bias was not as much as an issue since I 
had not been previously involved in New Zealand water policy. For the Oregon case, however, potential bias was more of an issue. I was forthcoming about my background and past personal role in Oregon's water policy development in order to ensure transparency.

Second, when documenting the interviews, I carefully reflected on my own reactions and thoughts about the process and its content via detailed memos and log notes. For example, I considered ways in which my prior involvement may color an interviewee's response and how I interpreted them. To assure credibility and address concerns about potential bias, I tried to set aside my a priori knowledge and assumptions to listen to key informants' accounts with an open mind (Starks \& Trinadad, 2007).

Finally, through consultations with colleagues and mentors and drafting memos to keep track of emerging impressions, I was able to examine how my thoughts and ideas evolved as I dove deeper into the data. I exercised extensive reflection while proceeding through interviews, direct observation, data review, and data analysis phases of the research process. Also, I solicited direct feedback from my academic committee, and sought peer review input when interpreting findings. These actions helped identify and deter any biases or skewed logic that could threaten the study conclusions.

One final observation around potential bias is that throughout the interview processes for both case studies, I was struck by the candor and openness of key informants to share their stories and perspectives. Anticipating greater caution from the Oregon informants given my past personal experience, surprisingly, I found this not to be the case. Researchers conducting interviews sometimes face the naturally-occurring challenge of participants wanting to please interviewers by saying what they believe the 
interviewers want to hear, and thus I took this into account when analyzing the data. In particular, triangulation of data helped address this potential validity threat.

Checking for Meaning of Outliers. Throughout the research process, I looked for exceptions or outliers to test the generality of my findings and build a better explanation. When outliers in the research data arose, I attempted to work out the meaning of them by reviewing other different data sources to test what I knew about the case. It was important to understand what the outlier represented rather than discount it as an anomaly. For example, in both case studies, it was important to interview informants who had walked away from the collaborative network to understand why they were dissatisfied or had rejected the process rather than rely on informants that supported the collaborative processes.

Exploring Rival Explanations. Employing the tactic of searching for rival explanations offered another way to test my explanations for each case. When conducting field work, several possible explanations were developed to explain observations from the emerging research data. I evaluated the data and asked what kind of alternative case this information could build (Miles \& Huberman, 1994). These possibilities were maintained until one of them appeared increasingly more compelling due to additional sources of evidence. Once the most plausible reasoning was identified, it was validated by examining supporting evidence. Throughout this process, I sought to keep rival explanations in play for a practical period of time to avoid foreclosing too early on alternative reasoning.

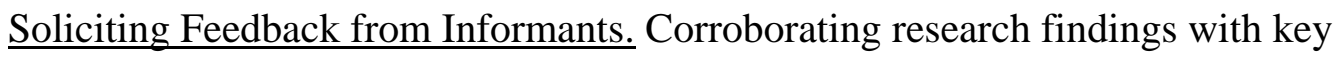
informants served as another method for evaluating case study findings. For both case 
studies, key informants were asked to evaluate the accuracy of the research findings. I checked with these key informants throughout the data collection process, and after final analysis. This process proved extremely helpful for soliciting feedback on main factors, causal relationships, and on interpretive conclusions. In addition, informants' comments and responses provided an opportunity for further reflection on my case study research findings. In sum, by utilizing multiple sources and modes of evidence, I collected and double-checked findings throughout the data collection and analysis process to buttress the explanatory power of my research findings.

\subsection{Limitations of Research Design and Methodology}

It is important to recognize limitations in the research design and methodology of this comparative case study analysis. First, this research involved two case studies and thus lacked the explanatory power of a multiple case study analysis. With that said this research was not focused on generalized theories but rather on understanding and applying theoretical concepts in two particular case study contexts. I applied a previously developed theory, network theory, as a template with which to compare the empirical results of my case study (Yin, 2003). The comparative analysis focused on adding to collaborative and network governance theory, rather than providing arguments challenging the validity of these theories.

Second, potential limitation pertains to the shorter amount of time I had to study and immerse myself in the New Zealand case versus the Oregon case. Put simply, given the shorter duration of my observations for the New Zealand case, was the data reliable and dependable? To overcome this possible weakness, I took extra care to employ a variety of data sources and conduct regular quality checks. Perhaps the most useful 
quality control method was engaging peers and academics familiar with the New Zealand case in a regular review process throughout the data collection and analysis process. The potential weakness pertains to objectivity and potential researcher bias due to my role as a participant observer in the Oregon case study. This limitation was discussed previously in Section 3.8 under Validity.

\subsection{Summary}

In this chapter, I presented my research questions, proposition at risk, and research methodologies for a conducting comparative case study analysis of how collaborative network governance performs in the integrated water management space. I laid out my case study selection rationale, case study design, and data collection techniques. Finally, I provided a detailed account of the data analysis process, methods for addressing research quality and validity, and limitations of my research design and methodology. In the next chapter, I present the first of my two detailed case studies by examining New Zealand's freshwater reform process. 


\section{CHAPTER 4: NEW ZEALAND FRESHWATER REFORMS CASE STUDY}

This chapter provides an in-depth case study of New Zealand's approach to integrated water management. As described in the literature review (Maxwell and Delaney, 1990; Yin 1994), the primary interest in studying this case was not to create generalizable research, but rather to develop rich description, interpretation, and explanation. The case study examines New Zealand's institutions, policies, and actors involved in integrated water management. Please note that in instances where I am quoting from a New Zealand source, I followed the New Zealand spelling.

In particular, the aim was to explore and understand the key institutions and actors shaping and constraining New Zealand's freshwater reform discussions. First, I set the stage by providing background information and a chronological history of New Zealand's integrated water management regime, including legislative and institutional frameworks. Next I unpack the collaborative Land and Water Forum process, an exemplar of network governance that focused on framing and developing integrated water policies and outcomes. Finally, I present an in-depth analysis and discussion of this case, including key findings and lessons learned.

\subsection{New Zealand: Clean and Green?}

New Zealand is located over 1000 miles south east of Australia (See Figure 4.1). Its three main islands are the North and South islands, and Stewart Island situated due south of the South Island. New Zealand is an archipelago with over 700 offshore islands; most are small and lie within 30 miles off of the coast (The New Zealand Encyclopedia). 
Figure 4.1 New Zealand Location Map (Source: World Atlas)

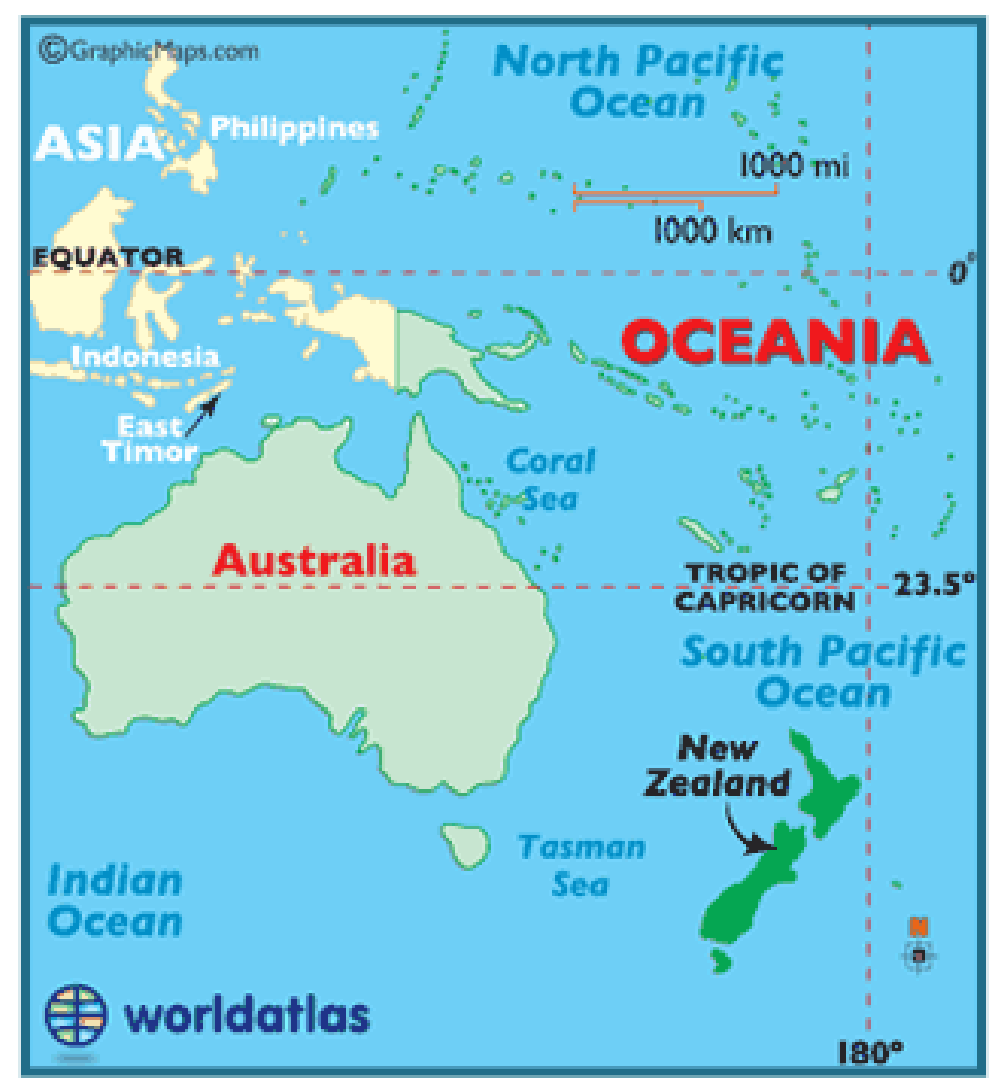

For a small country (103,517 square miles), New Zealand's geography is quite diverse. The North Island is mainly rolling hills, much of which is in agricultural production. A series of narrow mountain ranges run north-east along the North Island creating high country rising up to 5,500 feet (McLauchlan, 1989). The South Island is divided by the Southern Alps, which traverse most of its length and rise over 9,800 feet. To the west of the Alps lies coastal rainforest, and to the east, the Canterbury Plains formed by rivers flowing from the mountains (McLauchlan, 1989). This area supports extensive farmland and grazing areas. The climate is temperate, although weather in the 
far north is often subtropical during summer (December-March), and inland areas of the South Island can experience severe frosts in winter (June-August).

New Zealand supports a total population of approximately 4,766,700 (New Zealand's population clock, February 2017) and the majority of its residents live in urban areas on the North Island. Auckland is the largest city, with a population of about 1,415,550 (Statistics New Zealand, 2013 census). A multicultural country, New Zealand's population consists of the following ethnic groups: European descent (about 77 percent), Māori (15 percent), Asian (12 percent), and Pacific Islander (7 percent) (New Zealand Census, 2013). New Zealand is a constitutional monarchy with a parliamentary system of government comprised of three branches of government: the legislature (Parliament), the executive branch (government), and the judiciary (judges and courts).

New Zealanders are generally well educated and healthy, with a high standard of living. The country supports a market economy with a $\$$ U.S.182 billion gross domestic product (New Zealand Statistics, September 2016). For many years New Zealand's earnings were mainly from agriculture, primarily wool and dairy products. More recently, New Zealand's economy has diversified with industries such as tourism, film production, and winemaking becoming significant contributors to the economy. The country depends heavily on international trade, especially with Australia, China, the European Union, and the United States (Statistics New Zealand, 2016).

Plentiful water is an essential component of New Zealand's identity, and it is one of its greatest natural and economic assets. Geographically, water represents a large part of New Zealand's landscape, with over 264,000 miles of rivers and streams, 4,000 lakes, and approximately 200 groundwater aquifers (Ministry for the Environment, 2007). 
Freshwater is a key component of New Zealand's economy for urban water supplies, energy generation, agricultural production, viticulture, horticulture, and tourism. Freshwater is also critical to New Zealand's identity and unique ecosystems. New Zealand Tourism lauds its clean rivers as part of its marketing brand "100 percent Pure New Zealand."

Freshwater management is a highly contested issue in New Zealand in terms of both water quality and quantity. Despite its "100 percent Pure" image, New Zealand faces challenges when it comes to managing its freshwater resources. According to the Parliamentary Commissioner for the Environment (PCE), New Zealand's deteriorating water quality has become of great concern to many New Zealanders over the past two decades (PCE Water Quality Report, 2015 a). Water quality has been declining due to land use intensification, mainly from agricultural intensification and urban sprawl. Forest land conversions and large-scale dairy industry expansion has created pressures on surface and groundwater quality, and water quantity. Freshwater resources in the populated and intensely farmed areas of New Zealand will soon be fully "allocated" with limited ability to transfer water due to programmatic constraints.

Freshwater pressures have been exacerbated by increasingly variable weather patterns resulting in increased temperatures and higher rainfalls in the west, and less rainfall in the north and east (Royal Society of New Zealand, 2016). New Zealand has also experienced increased runoff from flooding due to increased rainfall and changing ${ }^{4}$ Tourism New Zealand's launched it "100 percent Pure New Zealand” marketing campaign in 1999
(Tourism New Zealand, n.d.). 
hydrological regimes, with increased drought in other areas (Royal Society of New

Zealand, 2016). It is important to note that impacts of climate change on water resources are being discussed at both the regional and central levels of government; however, it does not appear to be the major driver for reform in New Zealand, but rather one of many key factors.

\subsection{New Zealand's Institutional Framework, Legislation, and Policies}

New Zealand, like the United States, shares an English common law ${ }^{5}$ heritage. The common law tradition emerged in England during the middle ages and was applied within British colonies across continents. Regarding water use, medieval common law treated a stream as fixed, so adjacent landowners owned their portion of a stream and had full rights to the water (Guerin, 2003, p. 23). However, upstream diversion depriving the landowner of property allowed for damages to be sought (Guerin, 2003, p. 23). Rights gradually evolved from land-based to use-based, linked to the flow of the river rather than the presence of water on land (Guerin, 2003, p. 23). These approaches evolved to a reasonable use theory, a pre-cursor to what is now known as a riparian water rights system, similar to what is utilized in the Eastern United States. This policy continued in New Zealand (with the exception of mining rights) until the Water and Soil Conservation of 1967, which required the issuance of permits by regional governments for discharge and withdrawals. Under the Resource Management Act of 1991 (described in more detail

\footnotetext{
${ }^{5}$ Common law refers to the body of law developed in England primarily from judicial decisions based on custom and precedent, unwritten in statute or code, and constituting the basis of the English legal system and of the system in all of the U.S., except Louisiana (Merriam Webster dictionary).
} 
later in this chapter), a permitting system was established where water resource consents (equivalent to permits in the United States) were issued on a first come, first served basis (Guerin, 2003).

New Zealand represents one of a small number of countries that have organized governing institutions around natural catchment boundaries (with catchment being equivalent to the term watershed in the United States) and consider IWRM principles. New Zealand initiated IWRM principles to address early erosion and flood control problems in its newly colonized lands in the later part of the 19th Century (Davis and Threlfall, 2006). As early as 1868 , New Zealand began to organize around river basins with the establishment of river boards (Davis \& Threlfall, 2006). Erosion and flood problems in the 1930s led to the 1941 Soil Conservation and Rivers Control Act, one of the first pieces of legislation worldwide to link land and water resources (Davis \& Threlfall, 2006). Continuing soil erosion problems, non-point source pollution, and land use intensification created the need for more expansive legislation, and led to promulgation of the 1967 Water and Soil Conservation Act (Davis \& Threlfall, 2006). This Act introduced water quality as a water management objective and established 20 regional watershed-based boards (Davis \& Threlfall, 2006). By the 1980s, New Zealand had a plethora of laws directed at managing the environment, including fresh water (Warnock \& Baker-Galloway, 2015).

In 1991, the government enacted the Resource Management Act, which repealed over 60 Acts and amended more than 150 others, becoming New Zealand's primary environmental legislation (Davis \& Threlfall, 2006). Water in New Zealand is managed as a public resource. The Resource Management Act provides the legal framework for 
managing freshwater, both quality and quantity, with the intent to create a more sustainable, integrated, and holistic regulatory framework that covers air, land, and water. The Resource Management Act's emphasis on holistic resource management constitutes a strong foundation for IWRM (Davis \& Threlfall, 2006). At the time of its adoption, the Resource Management Act was lauded as a far-reaching approach to planning and environmental management (Warnock \& Baker-Galloway, 2015); however, implementation challenges have arisen.

The Resource Management Act is effects-based (impact-based) legislation that created a framework to manage and mitigate adverse environmental impacts of activities (Davis \& Threlfall, 2006). Permits for water uses and discharges are based on the impacts of the use (Howard-Williams, Bisley, \& Taylor, 2013); however, cumulative effects are not necessarily taken into account. The Act was also designed on the principle that decision-making is best carried out at the governance level closest to the resources affected, which better enables public participation in resource management decisionmaking (New Zealand Environment Guide). Consequently, responsibility for water resource management in New Zealand is shared between central government and local governments. The resulting governance structure is highly decentralized - with local planning and implementation at the district and regional level - guided by national-level directives (e.g., national policy statements or national environmental standards) that direct and bind local authorities' actions (Warnock \& Baker-Galloway, 2015). This was in line with many other reforms that were occurring in New Zealand government under the guise of New Public Management in the early 1990s. The government at the time focused on minimizing government functions, privatizing state-owned businesses, and 
relying on the market (Schick, 1996). It also resulted in a highly devolved system of environmental management in New Zealand, with limited direction from central government.

Until central government issued the National Policy Statement on Freshwater Management in 2011 (Sinner, 2011), New Zealand lacked mandatory nationwide water quality standards, except for drinking water. Prior to adoption of national-level guidance and regulations, each regional council established its own policies and regulations in order to implement to the Resource Management Act, with variable results. Central government preferred to grant regional governments the autonomy to tailor water policies to their watersheds. However, in the absence of national-level regulations and guidelines, a fragmented patchwork of regional water policies evolved. The lack of central government direction made it challenging for regions to effectively manage water resources, especially for those regions with limited financial resources. Listed below are the central government policy tools focused on freshwater regulation and management that have been issued to date:

1) National Policy Statement on Freshwater Management (NPS-FM 2011 and 2014) incorporating National Objectives Framework (NOF);

2) draft National Environmental Statement (NES) on Ecological Flows; 3) Water Conservation Orders (WCOs); ${ }^{6}$

\footnotetext{
${ }^{6}$ Water Conservation Orders (WCOs) are a national-level planning tool for recognising and protecting outstanding amenity and intrinsic characteristics of water bodies. Applications are made to the Minister for the Environment, but decisions on applications are made by special tribunals and may be appealed to the Environment Court and High Court. They can prohibit or restrict a regional council issuing new water and discharge permits, although it cannot affect an existing permit until it expires and the applicant applies for a
} 
4) Resource Management Regulations 2010 (Measurement and Reporting of Water Takes).

New Zealand's institutional water framework is depicted in Figure 4.2. The central government provides overarching directives through legislation, policy statements, and guidance, whereas regional and local councils are responsible for planning and directly administering most aspects of freshwater management, including water quality and water quantity allocation.

new permit. Regional policy statements, regional plans and district plans are supposed to be consistent with a WCO. 


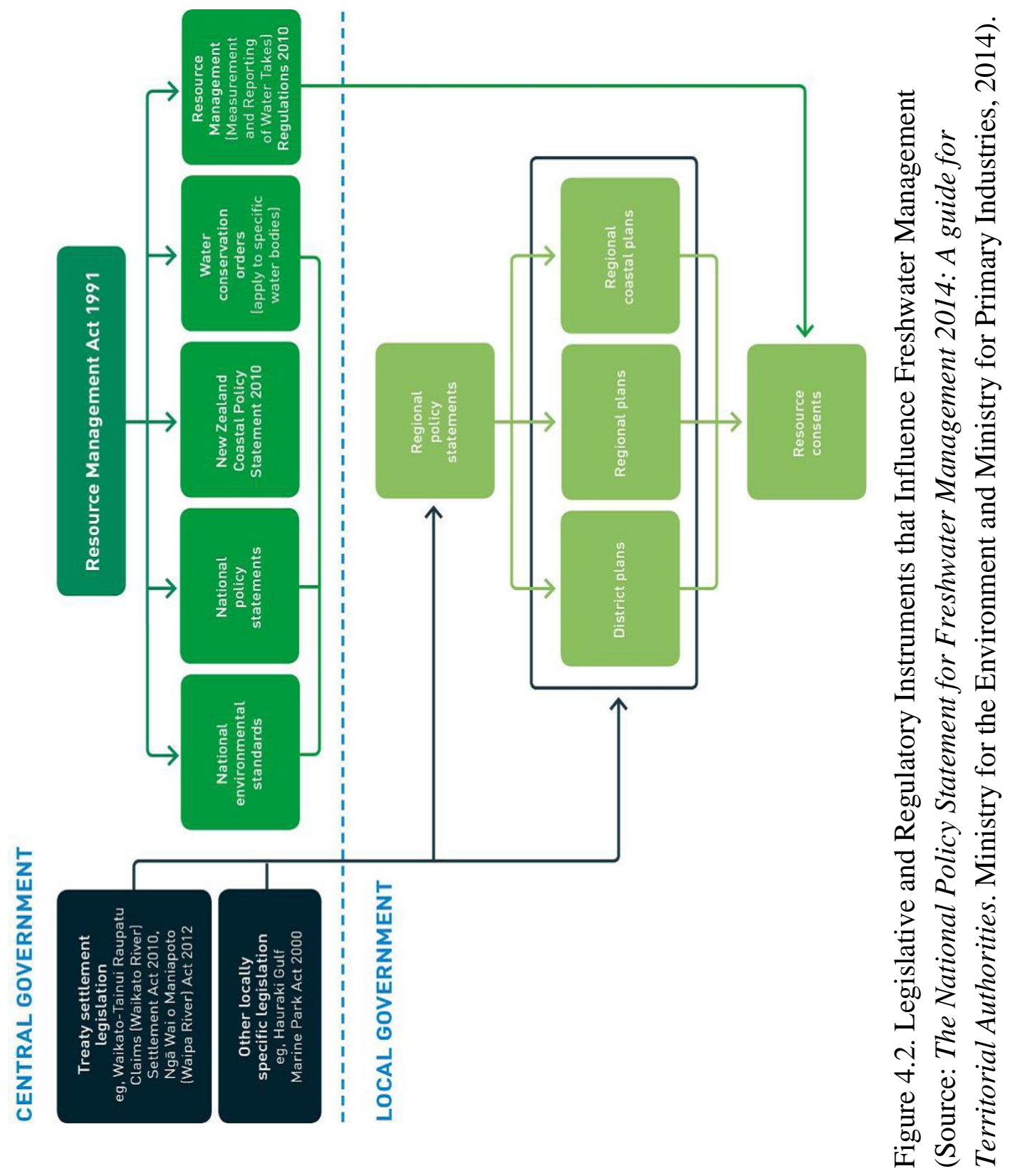


The role New Zealand's central and regional governments' play in freshwater management are described below.

Central Government Role. Under the Resource Management Act, the Minister for the Environment has the authority to promulgate regulations to guide and direct regional councils in their freshwater planning process. The Ministry for the Environment (Ministry for the Environment), established under the Environment Act of 1986, serves as the Government's principal adviser on environmental issues and, as the lead agency for freshwater policy development, holds primary responsibility for developing national policy statements and standards. MfE's mission is "Environmental stewardship for a prosperous New Zealand." Since 2009, the Ministry has operated under a collaborative governance model called the Natural Resources Sector (NRS). The NRS serves as a leadership team for central government natural resources policy work, and is led by the Chief Executives of the following government agencies:

$>$ Ministry for the Environment

Ministry of Business, Innovation and Employment

$>$ Ministry for Primary Industries

Land Information New Zealand

Department of Conservation

Ministry for Māori Development

Department of Internal Affairs

The Ministry of Health, although not part of the NRS, holds primary responsibility for setting drinking water standards.

An interesting feature of New Zealand government is the office of the 
Parliamentary Commissioner for the Environment (PCE). The PCE is an independent officer of Parliament with functions and powers granted by the Environment Act of 1986. Their role is to provide Parliament with independent advice on matters regarding the environment. On freshwater issues, the PCE has issued several reports examining different aspects of the government's reform process. In November 2013, the PCE issued a report entitled Water Quality in New Zealand: Land Use and Nutrient Pollution based on extensive research and scientific modelling. In that report, the Commissioner identified a clear link between expanding dairy farming and increasing stress on water quality. Subsequent reports have examined and made recommendations on the government's 2014 National Policy Statement, and have provided updates to the 2013 water quality report.

Another central government player in New Zealand's freshwater realm is the Environment Court (formally called the Planning Tribunal). Established under the Resource Management Act, this special court provides an avenue for citizens or parties to bring an appeal against the local government on environmental decisions (Warnock and Baker-Galloway, 2015). The Environment Court has fairly broad powers as it can make decisions on applications directly referred to it by the applicant (where agreed by the council), and proposals of national significance referred to it by the Minister for the Environment (Ministry for Environment, 2009). The Environment Court's jurisdiction includes Resource Management Act enforcement and the Court may issue enforcement orders to a citizen or an organization. The Court is comprised of environment judges and commissioners who possess knowledge and experience in areas such as local 
government, resource management, environmental science, and the Treaty of Waitangi (see section below on indigenous water rights).

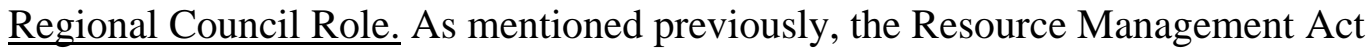
created a decentralized planning structure with local plan-making and implementation powers at the regional and local levels, and provided legislation and guidance nationally. There are 11 regional councils in New Zealand with boundaries broadly coinciding with water catchment areas. In addition, six unitary authorities function with combined regional council and district council duties. With regard to water, regional council responsibilities include managing the effects of using freshwater, coastal waters and land; developing regional policy statements; issuing of consents (e.g., for water takes or discharges to water); and managing rivers, mitigating soil erosion, and flood control.

Regional Councils must prepare Regional Policy Statements, which set the basic direction for environmental management in the region and "give effect" to National Policy Statements. Regional and district plans specify which activities are permitted and which activities require a consent. Under the Resource Management Act, regional councils and unitary authorities hold jurisdiction to make decisions about consent proposals. They must consider the environmental effects or impacts, which, as defined in the Resource Management Act, include effects on social, economic, and cultural conditions. Decisions are based on policy direction and rules specified in National Policy Statements, National Environmental Standards, Regional Plans, District Plans, and

\footnotetext{
${ }^{7}$ The words 'give effect' to are intended to convey that plans should actively implement a higher order plan or policy statement (e.g., a regional policy statement 'giving effect' or 'actively implementing a national policy statement) (Quality planning).
} 
Regional Coastal Plans.

Regional councils and unitary authorities authorize the resource consents ${ }^{8}$ for water takes and discharges into water unless plans specify otherwise. These consents are processed on a first-in-first-served basis, with the maximum duration of consent being 35 years. Consent-holders can apply to renew their consents on expiry. In 2004, this legislation was amended to give priority to existing consent holders in the event of a new entrant seeking access to a limited resource.

\subsubsection{Indigenous Water Rights}

"Ko au te wai, ko te wai ko au...I am the water, the water is me..." - Māori Proverb

New Zealand's Resource Management Act created, inter alia, a framework for an integrated approach to freshwater planning. However, the incorporation of Māori perspectives in freshwater planning and implementation poses one of the greatest challenges for effective water management in New Zealand (Durette \& Barcham, 2009). The New Zealand Government has publicly acknowledged that $i w i^{9}$ have rights and interests in fresh water; however, the government's position is that no one owns fresh water, and that freshwater resources need to be managed locally on a catchment-bycatchment basis within the national freshwater management framework. This section provides background information on $i w i$ values and perspectives in freshwater planning,

\footnotetext{
${ }^{8}$ A resource consent is the authorization given to certain activities or uses of natural and physical resources required under the RMA s77B (1). It is similar to a permit in the United States.

${ }^{9}$ Iwi are extended kinship group, tribe, nation, people, nationality, race - often refers to a large group of people descended from a common ancestor and associated with a distinct territory (Maori Dictionary online).
} 
including a brief overview of key statutes providing a framework in the freshwater space: the Treaty of Waitangi and the Waitangi Tribunal, and the Government's engagement with $i w i$ in the freshwater reform process.

Treaty of Waitangi, Statutory, and Policy Framework

The Treaty of Waitangi (Treaty), signed in 1840 between over 500 Māori chiefs and the British Crown, provides the foundation for the Crown-Māori relationship in New Zealand. The Treaty contains three articles that were written in both English and Te Reo Māori (Māori language). Translation issues have resulted in different interpretations of the two versions of the Treaty, a discrepancy that has underpinned long-lasting conflict between Māori and the Crown. According to the English version, Māori ceded to the Crown absolutely and without reservation all the rights and powers of sovereignty (Article 1) but retained full exclusive and undisturbed possession of their lands and estates, forests, fisheries and other properties (Article 2) (Ruru, 2009). Under the Māori language version of the Treaty, Māori ceded only governance to the Crown (Article 1) but confirmed and guaranteed the chiefs "te tino rangatiratanga"-- the exercise of chieftainship - over their lands, villages and "taonga katoa" - all treasured things (Ruru, 2009). Article 2 granted the Crown a pre-emptive right to deal with Māori over land transactions, and Article 3 granted Māori the same rights and privileges as British citizens living in New Zealand (Ruru, 2009). In regards to fresh water, Māori argue that under Article 2 of the Treaty they never ceded ownership or governance rights over water during the process of nineteenth century land sales to settlers; therefore, their customary water rights are still intact (Memon \& Kirk, 2011).

In the years following the signing of the Treaty, settlers expanded in areas 
throughout the country, altering New Zealand's landscape by clearing native forests for agriculture production and pastures, draining wetlands, dredging waterways for mining, urban development, and diverting water for drinking water, irrigation, and hydropower schemes. Along with settlement, Māori land was confiscated or purchased, displacing iwi from their land and nearby rivers, disrupting their sense of place, along with their economic, social, and cultural vitality.

Waitangi Tribunal. In the 1960s and 70s, Māori began organizing politically and exerting demands for redress from the Crown for land that was unjustly confiscated or bought without observation of agreed terms of sale (King, 2003). These amends were not fully realized until years later, when in 1975, under the Treaty of Waitangi Act, the New Zealand Government created the Waitangi Tribunal, a legal avenue for Māori to seek redress for Treaty breaches by the Crown (New Zealand Encyclopedia, accessed May 12, 2016). Set up by the Treaty of Waitangi Act 1975, the Waitangi Tribunal is a permanent commission of inquiry that makes recommendations on claims brought by Māori relating to Crown actions which breach the promises made in the Treaty of Waitangi (New Zealand Ministry of Justice, Treaty of Waitangi website).

The Waitangi Tribunal's recommendations are mainly non-binding; however, Tribunal reports can assist parties in their settlement negotiations (New Zealand Ministry of Justice, Treaty of Waitangi website). Rights of individual iwi vary according to Treaty negotiations that reflect historical, cultural, and geographic features unique to an area (Ministry of Justice, Treaty of Waitangi website). It is important to note that, although New Zealand's Treaty settlement process provides redress for grievances, which may include the transfer or returns of land to $i w i$ within their areas of interest, including the 
beds of lakes and rivers, water allocation has not been a feature of that process. To date, no $i w i$-specific water allocation has been promulgated as part of the Treaty settlement; however, over twenty-five co-governance and co-management arrangements have been agreed between the Crown and $i w i$, including joint committees, statutory boards, regional council committees, and WCOs (Ministry for Environment/Ministry for Primary Industries Report, 2014, p. 40).

Currently before the Tribunal is the National Freshwater and Geothermal Resources claim (WAI 2358), an important claim in regards to Māori economic rights and interests in fresh water. Under WAI 2358, a claim brought forward by the New Zealand Māori Council in response to the Government's proposal to partially privatize state-owned power-generating enterprises (approximately 75 per cent of New Zealand's energy comes from hydropower and geothermal energy), the claimants assert that Māori have unrecognized proprietary water rights that should be recognized by the Crown or compensated economically. Māori claim that there is an ongoing breach of their residual proprietary rights, which were guaranteed and protected by the Treaty of Waitangi from 1840 onwards. The inquiry was split into two stages with the Tribunal finding under stage one:

...that the proprietary right guaranteed to $h a p \bar{u}^{10}$ and $i w i$ by the Treaty in 1840 was the exclusive right to control access to and use of the water while it was in their rohe (territory). The closest English equivalent in

\footnotetext{
${ }^{10}$ Iwi are extended kinship group, tribe, nation, people, nationality, race - often refers to a large group of people descended from a common ancestor and associated with a distinct territory. Hapu are kinship group, clan, tribe, subtribe - section of a large kinship group and the primary political unit in traditional Māori society. (Maori Dictionary: April 16, 2016)
} 
1840 was ownership; the closest New Zealand law equivalent today is residual property right. (Ministry of Justice, Treaty of Waitangi)

The Tribunal had initiated the second stage of WAI 2358 as of the writing of this report. Under stage two, it has stated that it will consider whether the rights found to exist in stage one are adequately recognized and provided for in current and proposed laws and policies (including the freshwater reforms).

To date, the government's response to the stage one findings and stage two approach has been to acknowledge that $i w i$ have rights and interests in freshwater resources (Wai closing submission Wai 2358, \#3.3.15, Crown Closing Submissions for Stage One, 20 July 2012), albeit not ownership of the water itself. The government has been discussing appropriate mechanisms for redress of breaches around $i w i$ water rights and interests, and proposes strengthening the role and authority of $i w i$ in the freshwater planning process, rather than developing a separate framework for proprietary water rights. For a more detailed report on New Zealand's approach to freshwater management and indigenous water rights, please refer to this Fulbright report:

http://fulbright.org.nz/publications/new-zealands-approach-to-integrated-freshwatermanagement-with-a-focus-on-indigenous-interests/.

\subsection{Setting the Stage for a Collaborative Process in New Zealand}

New Zealand's Resource Management Act provides the foundation and framework for managing water in a sustainable and integrated manner. However, the government initially delegated its policy-making role, as well as implementation, to the regional councils. This resulting lack of central government direction and strategic guidance led to fragmented water policies, with each region producing different water 
quality regulations and water allocation outcomes. Over the past two decades, non-point (diffuse) source pollution from urbanization, agriculture practices, dairy intensification, and conversion of forest lands accelerated, thereby degrading freshwater quality in New Zealand's rivers, streams, and lakes. In addition, certain parts of the country faced overallocation of water resource consents to private users due to competing demands of population growth, irrigation, economic development, and hydropower generation. Pressure from New Zealand farmers, businesses, and the public grew in response to these issues.

New Zealand has engaged in a series of efforts over the past two decades to address water issues. In 2000, the Minister for the Environment at the time, Marion Hobbes, gave a call to action at the Water 2000 conference in Auckland. The Minister emphasized the need for a new governance approach around water management that balances the environment with economic development:

We need to think about water and the environment differently. For too long we have thought about water and the environment as a problem, as a constraint to development, something that stood in the way of progress in New Zealand. We need to turn this thinking on its head. We need to think of the environment as one of New Zealand's strategic opportunities. We need to think about the concept of sustainable development. I put this change of thinking to you as a challenge today and ask you to think through how we can put into effect this paradigm shift that is needed (New Zealand Parliament website).

In response to growing pressures and concerns about water quality and quantity, New Zealand's Government recognized a need for a more effective freshwater governance framework. Government Ministers proposed the "Sustainable Water Programme of Action" in 2003 as a priority under the "Sustainable Development 
Programme of Action," a government-led approach to sustainable development in New Zealand. The Sustainable Water Programme of Action identified three national outcomes for freshwater:

1. Improve the quality and efficient use of freshwater by building and enhancing partnerships with local government, industry, Māori, science agencies and providers, and rural and urban communities.

2. Improve the management of the undesirable effects of land-use on water quality through increased national direction and partnerships with communities and resource users.

3. Provide for increasing demands on water resources and encourage efficient water management through national direction, working with local government on options for supporting and enhancing local decision making, and developing best practice (Ministry for the Environment, Briefing Paper, 2007).

The program recommended specific actions for achieving national outcomes including: fostering leadership and partnership, providing national direction to regional and local governments, and setting national priorities. The strategy recommended a governmentled process developed in consultation with stakeholders.

Government officials developed policy proposals and held public consultations on the proposals in 2004 and 2005. According to former government officials who were involved in the process at the time, the proposals failed to garner strong support from stakeholders on either end of the political spectrum. Environmental and conservation organizations called for more stringent regulations from central government. Industry and agricultural users were concerned about tough new regulations, but they recognized that 
with growing concerns about water quality and over-allocation, some type of action was needed. Regional governments were hesitant to give up control to central government, and Māori were beginning to assert their interest in freshwater planning and access to water rights.

The Government's Sustainable Water Programme of Action failed to gain political traction, and implementation stalled in 2008. Interviews with former government officials suggested a number of reasons for this failure. First, the proposal was crafted mainly by public officials and Ministers with limited input from outside groups. Buy-in from the public and water user community was minimal, with little support for moving forward. Second, the freshwater reform process operated under limited agency staffing and resources for a complex and demanding task. This hindered the staff's ability to fully vet the proposals, especially given the complexity and political sensitivity of water issues. Third, the proposal was criticized by influential environmental and conservation groups as producing "an insipid and an environmentally ineffective document” (Logan, 2013). And fourth, competition among governmental agencies and bureaucratic inertia was a factor in poor reception of the proposal. "There seemed to be intra-government constraints in departments' capacities to advance the environmental components of water policy" (Logan, 2013). Reflecting on this effort, the program was re-dubbed by observers as the "National Programme of INaction."

Meanwhile, politically charged efforts highlighting non-point source pollution issues (e.g., the "Dirty Dairying" and "Choose Clean Water" campaigns) continued to raise public awareness about and interest in freshwater issues. Litigation challenging resource consents also become more commonplace, escalating concerns about increasing 
costs and longer resource consent processing timeframes. Public concern about New Zealand's degrading water quality and competing demand for limited resources continued to grow.

In 2008, a new center-right Government took the helm in New Zealand. In response to New Zealanders' growing frustration around the lack of progress on freshwater reforms, a new stakeholder-led approach was initiated called the Land and Water Forum (LAWF). This collaborative approach was sparked by a small group of influential leaders concerned about freshwater issues who had convened at an Environmental Defence Society conference.

Guy Salmon, a well-known and widely respected environment advocate, had been observing Scandinavian collaborative approaches to resolve complex and contentious environmental issues. He suggested that it might be applied in New Zealand to address freshwater management (Howard-Williams et al., 2013). Other NGOs, including the Environmental Defence Society, supported Guy Salmon's suggestion for creating a collaborative forum around freshwater policy development. At the same time, the government recognized the need to respond to public demands for action around freshwater management; however, reaching consensus on polarizing water issues was challenging. There was a sense that unless a network of interested parties participated actively and directly with each other, conflict and stalemate would persist, with damaging consequences for the environment and economy (Howard-Williams et al., 2013). Thus, LAWF grew out of this agreement by the Minister for Environment, environmental, and farming interests to work collaboratively to improve freshwater management and governance. 


\subsection{The Land and Water Forum: A collaborative, network approach to water policy development and governance}

The Land and Water Forum Trust is an incorporated entity that was created "for the understanding of land and water use in New Zealand including social, economic, cultural and environmental implications of land and water use and effect of such use..." as laid out in the Land and Water Forum Terms of Reference document (2011, p. 1). LAWF was "established in the belief that the stakeholders in water management need to directly engage directly with each other if a sustainable way forward was to be found for better water management in New Zealand” (LAWF Terms of Reference, 2011, p. 1). LAWF brought together an array of stakeholders from industry groups, agriculture, power generation, environmental and recreational NGOs, iwi, forestry, horticulture, tourism and urban water interests to "develop shared outcomes, goals and long-term strategies" for freshwater management in New Zealand (LAWF Terms of Reference, 2011, p. 1.).

LAWF's Terms of Reference document (2011) states that the government Cabinet "agreed to a new strategic direction for fresh water, including a stakeholder-led collaborative process run by the Forum." Hence, the Cabinet Ministers at the time provided political support and legitimacy for LAWF. It is important to note, however, that with respect to decision-making and implementation responsibilities, the document emphasizes that "for the avoidance of doubt, the design of specific policy instruments, detailed design and drafting of legislative amendments or regulations, and the actual implementation of government decisions are specifically excluded from the scope of the project” (LAWF Terms of Reference, 2011, p. 2). 
LAWF's structure consists of 67 organizations assisted by central and local government active observers ${ }^{11}$ and members of New Zealand's academic, scientific, and policy community. (See Appendix C for a list of LAWF members.) Alastair Bisley, a former foreign trade negotiator with extensive government experience, was selected to chair the Forum. Mr. Bisley characterized LAWF as "an exercise in collaborative governance - addressing complex and intractable issues by bringing together the principal stakeholders, including from the private sector and civil society, to seek agreement/consensus on a way forward" (Eppel, 2013). Protocols for participation were established and all LAWF participants were required to accept these protocols as the basis for their involvement.

A smaller group of 30 major stakeholders was formed to generate specific policy proposals around key issues, report back regularly to the larger plenary group on progress, and assist in preparation of LAWF reports. Participants in the small group include representatives from agriculture (pastoral and horticulture), iwi, forestry, power generation, environmental groups, recreationalists, and tourism, and (See Appendix D for the full LAWF member list.) This small group proved instrumental in working through and achieving consensus on tough water policy issues. Recommendations brought forth from the small group were presented to the full LAWF for vetting and ultimate approval.

\footnotetext{
11 "Active observers" are parties that attend the LAWF meetings but are not directly involved in the consensus process. Central and local government representatives served as active observers (LAWF Protocols for Participation).
} 
The chair and three members, representing iwi, conservation interests, and New Zealand's primary industry sector, serve as the trustees for LAWF.

Cabinet Ministers tasked the Forum with conducting a stakeholder-led collaborative process to recommend freshwater policy reforms and provided partial funding and staff resources to help LAWF implement its charge. LAWF approached their work by setting up seven "flexi-groups" that were tasked with unpacking key policy issues and reporting their findings to the smaller group. Unlike the smaller group, the flexi-groups were not required to reach consensus. The following policy focused groups were established as part of the LAWF collaborative process:

1. Core elements and the nature of water rights

2. Water quality allocation

3. Water quantity

4. Urban Issues

5. Implementation of water allocation

6. Stock exclusion

7. Water quantity over-allocation LAWF established suggested terms of reference for these working groups specifically outlining operating procedures, administrative functions, detailed scopes of work, and membership requirements for each flexi-group.

LAWF has been meeting regularly since 2009 and to date has issued four reports. The first phase of the Forum's work lasted from August 2009 to August 2010 and resulted in A Fresh Start for Freshwater. This report, issued in September 2010, identified a set of outcomes and goals for freshwater management and recommends a 
number of policy changes to achieve those. Public meetings to present and discuss the Forum's recommendations were held around the country in late 2010 and the beginning of 2011, and involved 1,200 people (Land and Water Forum, 2011).

A Fresh Start for Freshwater, lays out why a new form of governance was needed:

The Land and Water Forum came together because we knew that water provides great opportunities for all of us - our ecologies and our environments, our farms and our cities, our recreation and our tourists, and for energy production and industry. It is a source of life and food, and for $i w i$ it is also central to their identity. To maximise these opportunities for us all, and for future generations, we needed a better way to manage water in New Zealand - less confrontational, more collaborative, and more effective. (Land and Water Forum, 2010, p. v.)

It also explained the importance of reaching consensus around freshwater policies:

It has become increasingly difficult to establish a consensus in New Zealand about what constitutes sustainable land use and its implications for freshwater. This difficulty hampers our economic development and damages our environment. It also creates antagonisms between different groups in our society. (Land and Water Forum, 2010, p. 59.)

Regarding the process, the report stated:

The Forum will use a collaborative governance process to carry out the project. Membership of the Forum comprises stakeholders outside of the government with a major interest in fresh water. (Land and Water Forum, 2010, p. 59.)

In their first report, LAWF offered 53 recommendations, including setting limits for water quality and quantity; achieving water quality targets; improving water quantity allocation; establishing a National Land and Water Commission on a co-governance basis 
with $i w i$ and developing a National Land and Water Strategy; and seeking science and knowledge for water management.

The government issued a response to the Forum's recommendations in September 2011, and asked it to carry on its consensus-building work and develop recommendations on the methods, tools and governance processes required for setting and managing limits on water quality and quantity (Land and Water Forum, 2016). The Land and Water Forum was given a second mandate and reported to Government in 2012 through two subsequent reports. These reports provided more detailed recommendations on how freshwater objectives and limits should be met, approaches for improving land and water management practices, strategies to address allocation of both water discharges including changes in the resource consenting system and the facilitation of water transfers and trades of both water and discharges, along with detailed recommendations for collaborative processes in freshwater management at the local level.

LAWF met regularly in 2013 and 2014 to assess the government's response to their reports. It also considered what future role, if any, it might seek to play in relation to land and water management, and how it might best constitute itself in order to do so (Land and Water Forum, 2016). The Forum issued its fourth major report in 2015. This report focused on maximizing the economic benefits of fresh water while managing within water quality and quantity limits established under the 2014 National Policy Statement on Freshwater Management. Recommendations called for exclusion of livestock from waterways on plains and lowland hills and presented a number of recommendations regarding urban water issues. LAWF was able to reach consensus on options for addressing $i w i$ rights and interests in freshwater, and the use of market 
mechanisms to address water transfers and over-allocation of water. According to LAWF staff, the only major issue on which the Forum did not reach consensus was water pricing. (See link to Analysis of LAWF recommendations:

http://www.landandwater.org.nz/Site/Resources.aspx for a 2016 status report on government implementation of LAWF's recommendations.) The Forum is engaging through 2017 on Phase 3, which entails formulating advice to Ministers on managing within water quality and quantity limits, further development of the National Objectives Framework, and review of overall changes to water policy and implementation.

\subsection{New Zealand's "Fresh Start" to Water Governance Reform}

Soon after the LAWF process was underway, the Government embarked on a series of reforms known as the "Fresh Start for Fresh Water" program (Ministry for the Environment, 2013). Policy work on the reforms, co-led by the Ministry for the Environment and the Ministry for Primary Industries, was focused on improving the way New Zealand manages its freshwater resources. Although New Zealand's central government led the reforms, ministers underscored that local communities, through their directly-elected councils, are best suited for making decisions about freshwater management in their region as they take into account local conditions, needs, and aspirations (Ministry for the Environment, 2013).

As described in the previous section, in 2009 the New Zealand national government tasked LAWF with developing recommendations for overhauling New Zealand's land and water management scheme. In response to LAWF's recommendations, the government developed and issued the first National Policy 
Statement for Freshwater Management in 2011 (NPS-FM 2011) that identified five matters of national significance:

1) over-allocation of fresh water

2) contamination of fresh water

3) loss of wetlands

4) incomplete integrated management

5) protection of wetlands.

It directed regional councils to manage water in an integrated manner while providing for economic growth within set water quality and quantity limits (Ministry for the Environment, 2013). Specifically, the NPS-FM 2011 mandated that regional councils set objectives for freshwater bodies that reflect national and local goals as well as establishing flow, allocation, and water quality limits to ensure those objectives are achieved. It also required councils to ensure $i w i$ involvement in freshwater planning, and that their values are reflected in decisions about freshwater management (Ministry for the Environment, 2013).

Prior to the release of the NPS-FM 2011, the government introduced the Resource Management Regulations (Measurement and Reporting of Water Takes) to collect better information about how much water New Zealanders are using. These regulations apply to about 98 per cent of total national volume of water use authorised through resource consents (Ministry for the Environment 2016). Water diversions of more than 5 litres per second were required to install water meters by November 2016 (Ministry for the Environment 2016).

In 2013, the government initiated a process to amend the NPS-FM 2011, once 
again based on LAWF's recommendations, to improve the freshwater management system, and to provide clarity around a number of issues. These reforms are outlined in the March 2013 proposal paper "Freshwater reform 2013 and beyond." The key elements in the proposal included:

1) strengthening national direction through amendments to the National Policy Statement on Freshwater Management to introduce a National Objectives Framework and better water accounting;

2) improving scientific and economic information to support community discussions on fresh water; and

3) improving the quality of decision-making through collaborative planning. (Ministry for the Environment, 2013).

In 2014, the NPS-FM was amended to adopt the National Objectives Framework (NOF), built on LAWF's recommendations and the work of a Science Review Panel. This effort established a list of national freshwater values and described attributes associated with them. The NOF establishes numeric values, or minimum standards, for ecosystem health and human health. It was intended as a decision support tool to assist regional councils in setting freshwater objectives and limits in their regional plans. Under the NPS-FM 2014, all councils are required to set quality and quantity objectives and limits for water bodies by 2025 , although some exceptions do apply.

In February 2016, the government released another consultation document, Next Steps for Fresh Water, proposing additional freshwater reforms including the use of a Macroinvertebrate Community Index as a measure for water quality; a phased stock exclusion requirement from waterways; technical efficiencies and development of good 
management practices for non-point source water pollution; a \$100 million freshwater improvement fund; and policies intended to improve $i w i$ participation in freshwater decision-making. All of these proposals were informed by policies discussions developed through the LAWF process. The Environment Minister and Ministry for the Environment staff held a series of public forums and hui (public meetings hosted by local $i w i$ ) around the country to solicit feedback on the proposed reforms.

\subsection{New Zealand Regional Planning Framework}

It is important to note that LAWF's work focused on policy changes that needed to occur at both the central and regional levels. New Zealand's integrated management framework is primarily delivered at the regional level by the 11 regional councils and six unitary authorities, who are responsible for planning, implementing, and enforcing policies and programs around fresh water, land use, soil conservation, and the coastal marine area (RMA $\S 14(1))$.

For the first two decades of the Resource Management Act's operation, part of the statutory regime that was meant to guide regional councils in freshwater planning and management was not yet in place (Warner \& Baker-Galloway, 2015). This meant that, prior to the promulgation of the first NPS in 2011, each regional council established its own policies to enact the Resource Management Act—with variable results (Eppel, 2016). The NPS-FM was introduced in 2011 to give national direction to regional councils managing freshwater resources. It required that overall water quality must be “maintained or improved" within a region (Ministry for the Environment, 2016, p. 8). It also required that councils adopt water quality and quantity objectives and limits for water bodies by 2025 (or 2030 in certain circumstances) as part of their regional plans. 
The consequence of not having limits was a failure to protect in-stream interests, overallocation of water quantity, and a reduction in water quality (e.g., assimilated capacity).

Prior to promulgation of the NPS-FM, almost all regional councils had developed regional plans or proposed plans relating to freshwater. However, it is significant to note that very few regional councils had established numerical freshwater objectives or limits as part of their plans. Research on reasons for lack of progress revealed that local governments struggled to undertake their water planning functions on account of lack of resources, capacity, and political capability (Memon \& Kirk, 2011).

The success of freshwater reforms relies heavily on the buy-in and support of regional governments. LAWF included representatives from regional governments to ensure that their perspectives were included. Capacity and adequate resourcing of regional government efforts was an issue that was arose frequently at LAWF discussions. LAWF emphasized that New Zealand's integrated water management framework relies heavily on a partnership of central government guidance and support with regional government implementation.

\subsection{Discussion and Analysis of New Zealand Case Study Findings}

A key focus on this case study research was to gain a better understanding of the role of New Zealand's collaborative governance network in transforming integrated water management policies. I was particularly interested in understanding the determinants that led to the success of the Land and Water Forum when previous attempts by the government had failed. In order to gain a more in-depth understanding of the Land and Water Forum process, extensive document and archival research was conducted along with direct observation through attendance at multiple LAWF meetings (both of the 
plenary and small groups), public meetings, and agency discussions around the freshwater reform process. I conducted 24 key informant and participant semi-structured interviews to provide an additional source of evidence to test my initial observations and interpretations. A detailed description of specific methods is provided in Chapter 3. Outlined below are the research findings, key themes, and lessons learned that emerged from the research evidence.

To validate findings gleaned through direct observation, extensive document research, and archival research, I conducted semi-structured interviews to gain a more indepth understanding of New Zealand's freshwater reform process and the role of networks in water governance. As described in Chapter 3, Research Design and Methods, a purposive sample of key informants and government officials involved in freshwater policy development was employed for the interviews. This involved sampling a broad cross-section of Land and Water Forum members to ensure a diverse range of viewpoints and perspectives including the following interests areas: agricultural (horticultural, ranching, and dairy operations); forest management; hydropower generators; Maori (indigenous perspectives); environmental and conservation; science researchers and academics; and regional governments. Ten public officials (policy makers and regulators from central and regional governments) who served as "active observer" participants in the LAWF process were also interviewed.

To develop the interview protocol, I relied upon the information gleaned through extensive document reviews, direct observations from attending LAWF meetings, consultation with public officials familiar with the Forum process and players, and input from academic advisors in New Zealand. Semi-structured interviews provided rich data 
about the LAWF process and network governance approach to freshwater policy development in New Zealand. The following key themes emerged from the LAWF interview data:

$>$ legitimacy and authority of the LAWF governance network

mutual learning and knowledge transfer fostered through the collaborative processes

$>$ the importance of building trust and social capital the essential role of leadership

$>$ limitations and constraints on decision-making process

Drawing on information from the interviews, I discuss these key themes in more detail below.

Legitimacy and Authority

As noted in the background section above, New Zealand's government-led freshwater reform process had stalled around 2008. Key informants and all interviewees spoke to the creation of LAWF's network governance approach as a key turning point.

As one interviewee noted:

LAWF broke the political stalemate and created a mandate for the government to Act. LAWF was instrumental in getting the government to move on water issues. Before LAWF there was an inability for bureaucratic institutions to work collaboratively and they failed to bring together stakeholders.

Although LAWF was a group of interested parties, it needed to be democratically anchored with power and authority (Koliba et al., 2011). Another LAWF member 
observed that the Ministers bestowed LAWF with authority and thus provided the legitimacy LAWF needed to keep actors working together in the network:

One of the most critical elements of the LAWF process was having a mandate from government. Previous efforts had waxed and waned depending on the government in power at the time. LAWF was autonomous and nested: two critical elements to LAWF's success. The Ministers provided legitimacy for the process which was essential for making progress on freshwater reforms.

Four interviewees noted the importance of LAWF's autonomy as a critical element. One shared that:

Government allowed LAWF autonomy which was critical to the process. This independence created the space to enable dialogue among key actors. LAWF helped move the freshwater reform process from inertia to action.

The legitimacy of networks is a key theme that arose from both the literature (Koliba et al., 2011, Keast et al., 2014) and interview data. LAWF represented a collaborative network of mainly non-state actors that managed to achieve broader public goals. Political leaders created the charge and granted LAWF the authority and support it needed to function autonomously. The authority not only resided with LAWF as an organization, but with each group involved in the network. It is also important to note that LAWF addressed very similar problems that the New Zealand Government had failed to address almost a decade before. By involving stakeholders and the public in the design and development of integrated water policies, LAWF was able to break down institutional barriers and facilitate change in the policy making process. Collaborative Learning Process

A theme that strongly emerged from the interview data pertained to LAWF's role 
in fostering a collaborative forum for constructive dialogue, knowledge transfer, and mutual learning. The literature also points out that networks are regarded as a more effective means of governance with a potential to foster learning both on a collective and individual level (Schusler \& Krasny, 2008). LAWF represented a wide range of organizations and interested parties with stakes in the outcome of integrated water management. The Forum engaged the participants in an intensive and creative process of consensus building (Gray, 1989; Wondolleck \& Yaffee, 2000) that led to more creative solutions and increased the likelihood of reaching consensus. The interview data showed that LAWF participants viewed the collaborative learning process as beneficial for fostering a greater understanding of recognition of New Zealand's water problems. The following quotes gleaned from interviews illustrate the high regard for the collaborative learning process:

Through LAWF, I recognized the need to work collectively instead of competitively.

$>$ It got people talking to each other instead of litigation.

$>$ LAWF created cross-sector conversations that fostered a greater understanding of each other's perspectives on water management. This led to more meaningful conversations with a share language.

LAWF created a 'safe space' for dialogue and allowed us to walk in each other's shoes.

This new governance paradigm in New Zealand demonstrated that a polycentric organization like LAWF, where multiple actors from different institutions contributed to water policy development, was a more effective way to move forward freshwater reforms 
than through a single-decision making authority (Pahl-Wostl et al., 2011).

Mutual learning and understanding of each group's value, interests and motivations created a space where collaboration was possible, even around challenging water issues. Based on discussions with key informants, interview data and direct observation, it appears that reaching a common understanding on water issues was a key factor in LAWF's success in developing a wide array of consensus-based policy recommendations. By reading media accounts, attending public meetings, and discussions with key informants, LAWF appeared to be instrumental in changing public views about freshwater management across New Zealand. This is in stark contrast to the government-led efforts that were perceived as a "government knows best" approach and failed to garner public or stakeholder support.

Iwi involved in LAWF also identified collaborative learning as a key element to LAWF's success. In the past, iwi had not been at the table with non-state actors but interacted predominantly with government officials. According to discussions with key informants, iwi rights and interests in water is a critical piece of New Zealand's freshwater reforms that LAWF successfully reached consensus on. Two of the $i w i$ interviewed for this research emphasized that a network governance approach proved beneficial in fostering a common language and more constructive conversations around integrated water management. One specifically commented:

The LAWF process operates under a different paradigm that involves engaging, educating, deliberating, and deciding among the different stakeholders groups. LAWF clearly helped raise the profile of Māori engagement. Māori have real strength in collaboration and thus the LAWF process has worked well for Māori. We see a benefit to having everyone at the table engaged in policy formulation. The LAWF 
process is different from business as usual where the government decides, announces, and then defends it method of decision-making.

Iwi viewpoints around managing water systems holistically, and balancing economic with ecological interests were incorporated into the LAWF's governance principles and are reflected in many of their specific recommendations.

\section{LAWF Process Built Trust and Social Capital}

LAWF built a pattern of trust and interdependence between actors to coalesce around water policy problems. It "emphasized relationships between actors rather than individual characteristics" (Keast et al., 2014, p. 17). Interview data revealed that the collaborative learning process broke down barriers and created new working relationships that fostered trust among the different actors. Actors were able to move beyond their own self-interest to promote shared interests. Consistent with the network literature, LAWF created a "purposive collaborative network to leverage relationship assets" (Keast and Mandell, 2014). Based on research findings from discussions with key informants, interview data, and direct observations, LAWF enabled development of social capital that lead to development of innovative solutions on tough water policies.

Respect for the process and the ability to build trust were important factors in LAWF's ability to reach consensus on many challenging water policies. All but one person interviewed shared this perspective:

Personal relationships formed between interested parties that broke down communication barriers. These relationships are important for building change over the long term. Collaboration is a relatively new process for New Zealand, and LAWF has proved more successful than bureaucratic-driven processes to date. 
Prior to LAWF, many of the parties around the table were involved in contentious debates or litigation. LAWF provided a "safe space," as one interviewee described, for conversations and deliberations on often divisive issues. Discussions with key informants revealed that the Forum created a more transparent process for decisionmaking versus a "black box" government-led approach. This appeared to engender a greater sense of trust and acceptance on policy outcomes since all parties were informed and engaged throughout the decision making process. As one interviewee explained:

LAWF was able solve the political compromise problem by having the right people around that table. It's about talking to people you don't necessarily agree with. These relationships took time to develop, but eventually the dividends paid off through mutual cooperation and collaboration. LAWF produced a socialization process that developed strong emotional connections among the member group.

Through this process of building trust and social capital, LAWF was able to generate more creative and viable outcomes than prior efforts. Grounded in a horizontal, network governance approach, LAWF reduced competitiveness and increased cooperation.

\section{$\underline{\text { Strong Leadership and Commitment }}$}

Strong leadership and vision surfaced as another important theme from the interview data. As a former foreign trade negotiator and public official, the chair of LAWF played an important role in keeping the collaborative network approach moving forward and ensuring a convergence of viewpoints. One interviewee shared that:

The chair provided skilful leadership with expertise in negotiating and mediating that served the LAWF process well. Mr. Bisley kept the process moving forward even during some contentious discussions. He 
served as the 'broker of the collaborative' and was paramount to

LAWF's ability to reach consensus on tough water policy issues.

Water issues are very politically sensitive and in order to succeed, the network needed a strong chair to ensure the integrity of the process, build a shared framework of understanding, and foster inclusive solutions. The chair's previous experience of working on contentious and complex issues gave him the credibility to serve as a "change agent." These skills were necessary to develop policies and decisions acceptable to all stakeholders.

LAWF reports, government documents, and media accounts detail that the Ministers for the Environment and Primary Industries granted power and authority to LAWF to develop freshwater reform policy recommendations. Key informants commented that government Ministers' endorsement of the process was a key factor in keeping people at the table. In past efforts, the government made it clear that LAWF was the "only game in town," and advised stakeholders not to lobby Ministers or government officials directly. The LAWF process was viewed as the "go to" body to resolve differences and develop freshwater policy recommendations. Although state actors primarily served as "active observers" in the LAWF process, it is important to note that the chair possessed behind the scenes credibility and direct connection with Ministers. This allowed the chair flexibility to steer the process since Ministers had full confidence in his ability to facilitate sustainable agreements and deliver outcomes.

\section{Constraints on Decision Making}

According to LAWF reports and discussions with key informants, the Forum reached consensus on over 230 recommendations around freshwater policy reforms. 
Central and regional governments have acted on some but not all of these policy recommendations. (See link to Analysis of LAWF recommendations: http://www.landandwater.org.nz/Site/Resources.aspx.) An unexpected finding that was not well defined in the network literature was the concern that Government was "cherry picking" recommendations rather than trusting the consensus-based collaborative process. The perception was that the "rules of engagement" had somehow changed and that a political lens was being applied to LAWF's recommendations. This dynamic created tension between LAWF members and government officials during the later phase of the process, especially around the issue of water allocation.

Key informant discussions and interview data revealed that LAWF members recognized that policy trade-offs occur as part of a network, collaborative approach; however, there appeared to be a lack of clarity around the ultimate decision making process for moving recommendations forward. Four LAWF members interviewed expressed frustration with the lack of control over the implementation process at both the central and regional level. This raised questions, in their mind, about the legitimacy of the policy outcomes. Table 4.1 provides a summary of strengths and weaknesses of New Zealand's collaborative network process around integrated water management. 
Table 4.1 Strengths and Weaknesses of New Zealand's Land and Water Forum

\begin{tabular}{|c|c|}
\hline \multicolumn{2}{|c|}{$\begin{array}{l}\text { Strengths of Collaborative Network } \\
\text { Process }\end{array}$} \\
\hline & $\begin{array}{l}\text { Broad range of stakeholders } \\
\text { representing range of viewpoi } \\
\text { opportunities for knowledge } \\
\text { transfer and shared learnings }\end{array}$ \\
\hline & $\begin{array}{l}\text { Small groups served as steerin } \\
\text { committee to shape policies fo } \\
\text { vetting with larger group }\end{array}$ \\
\hline & $\begin{array}{l}\text { Consensus decision making } \\
\text { process }\end{array}$ \\
\hline & $\begin{array}{l}\text { Strong leadership model with } \\
\text { independent chair serving as }\end{array}$ \\
\hline
\end{tabular}

- Long-term commitment by network members. Result in strong ties and interdependencies; builds social capital and high levels of trust that kept majority of parties at the table

- Separate Secretariat; not dependent on Ministry for staffing

- Developed extensive list of water policy recommendations

- Democratic anchorage from elected leaders and interests represented on LAWF
Weaknesses of Collaborative Network Process

- State actors have limited role, mainly as active observers; creates tension between horizontal and vertical lines of control

- Recommendations crafted mainly by select group of members; lack of transparency on how groups were selected and how decisions in small groups were made

- Challenging to reach consensus on some issues like water pricing

- Network not an elected entity lines of accountability are unclear

- Resources provided by Ministries; not completely independent

- Reliant on government for prioritization and decision making

- Recommended actions need government support to move forward 


\subsection{Comparison of New Zealand Study to Network Governance Literature}

Network theory and New Public Governance framework provided useful constructs for understanding the factors at play in the LAWF process. What I observed around the LAWF process is consistent with key themes that emerged in the literature; however, a few new themes surfaced through the interview data. The following section includes a discussion of how network governance theoretical constructs performed in the New Zealand case. For each topic below, I present a brief review of the applicable theory, an application of the theory in the New Zealand case, and the resulting lessons learned.

Collaborative processes. This case study research revealed that, in regards to shaping New Zealand's national water policy, LAWF's collaborative network governance was highly influential in advancing their freshwater reform process where previous efforts by the government had failed. New Zealand's government's attempt to move water policy reforms forward had stalled for a number of reasons including: a delivery through a top-down, bureaucratic approach; lack of stakeholder involvement in crafting policies; weak political leadership; insufficient resourcing; and lack of political acceptance. The Land and Water Forum was subsequently created to deal with a very complex, "wicked problem" that no one agency, organization, or group could deal with independently (Keast et al., 2014). It proved successful in reaching consensus on challenging water issues where previous agency-dominated efforts had failed. The Forum was established in the belief that this collaborative effort should not be steered by government officials. Instead, stakeholders needed to engage directly with each other if they were to find a way forward (Land and Water Forum, 2010).

Building on network and collaborative theories, the LAWF process represented a 
pluralistic, process model of public policy decision making that was "democratically anchored" with power and authority by key government ministers to lend legitimacy (Koliba et al., 2011). The research proposition at risk posited that shared power and horizontal relations are better suited to dealing with "wicked problems" such as integrated water management than a more vertical, command and control approach. This New Zealand case study demonstrates a shift from an "Iron Triangle" bureaucratic-led policy model to a structure and process that facilitated more expansive participation by a wide range of actors and interests. The Land and Water Forum process emphasizes the importance of building relationships and shared learning among key policy actors involved in water use and management. It represents a mixed form of administrative authority, and works across horizontal and vertical lines (Agranoff \& McGuire, 2010). This network governance approach changed the dynamics around New Zealand's freshwater reforms and proved successful at developing broad consensus on a wide range of policy options, many of which have been adopted by regional and central governments.

Interdependencies and strength of network ties. The network governance scholarship emphasizes that policy is formed in a network of interdependent actors and that interdependency is the core factor that initiates and sustains networks (Koliba et al., 2011; Klijn \& Koopernjan, 2012). When two actors enter into horizontal relationships, they break the traditional principal-agent dynamic of vertically arranged relationships (Koliba et al., 2011). Network theorists have equated the development of interpersonal relationships with cooperative behaviors, norms of trust, and reciprocity (Koliba et al., 2011). 
Consistent with themes from the literature, participants in New Zealand's collaborative process recognized that the current policy process mechanisms were no longer working and new innovative solutions were needed. After years of effort, government officials had failed to move freshwater policies forward in New Zealand. Political stalemate coupled with intense public pressure contributed to the conditions for establishing a collaborative, network approach.

The creation of LAWF shifted responsibility for developing policy recommendations to a network of influential non-state actors, although it did not exhibit a true power-sharing relationship as outlined in the New Public Governance literature as the government maintained decision-making authority. The LAWF process did, however, create interdependencies among actors that led to a new way of framing the problem and developing policy recommendations that differed from previous attempts.

Through its extensive collaborative process, LAWF built substantial agreement among national-level stakeholders for addressing long-standing fresh water policy issues. Members were engaged in activities that went beyond making incremental changes to policies and institutions. Rather than finding compromises or quid pro quo arrangements, LAWF was able to create "new collective value" through mutual understanding and deliberation (Innes \& Booher, 1999, p. 15). By focusing on relationships, rather than positions, the LAWF collaborative network emphasized building trust and mutual understanding and created new frames that allowed participants to find a new way of working together. Collaborative networks can "leverage relationship assets" to meet future outcomes by developing more innovative solutions (Innes \& Booher, 1999, p. 35). 
LAWF was able to tackle complex problems in a more flexible and multidimensional manner.

Trust in networks. Trust is cited often in the literature as a core coordination mechanism of networks (Klijn \& Koopernjan, 2012; Keast et al., 2011; Provan \& Kenis, 2007; Ansell \& Gash, 2008). Trust is an important asset to achieve in networks as it "reduces uncertainty and facilitates investments in collaborative processes among interdependent actors with diverging and sometimes conflicting interests" (Klijn \& Koopernjan, 2012, p. 8). The literature also stresses that trust enhances the possibility that network actors will share information and develop innovative solutions (Klijn \& Koppenjan, 2012).

My research findings revealed that LAWF built a high level of trust among its members. Essential to LAWF's success was its autonomy from government and the ability to remove policy blind spots affording non-state actors the opportunity to develop innovative solutions through a collaborative process. I posit that LAWF represents a New Public Governance approach as a multi-actor network operating through collaborative, horizontal ties. Through LAWF, there was a shift in responsibility for developing policy recommendations from state to non-state actors. Government agencies were no longer steering but served as "active observers" throughout the LAWF process. This created tension as government officials preferred to be in the driver's seat for developing policy options. In essence, LAWF constituted a new form of collaborative network governance created to solve problems that could not be solved by one organization. As one LAWF participant reflected, “one of the Forum's greatest strengths is its ability to move beyond political and bureaucratic inertia." 
Democratic anchorage. As noted in the literature, accountability plays a key role in the success of networks. Sorensen and Torfing (2005) posit that "governance networks are democratically anchored to the extent that they are properly linked to different political constituencies and to a relevant set of democratic norms that are part of the democratic ethos of society" (p. 201). New Zealand's case did lend legitimacy to the policy network both formally (via elected officials) and informally (via bureaucrats) representing citizens as well as particular interest groups.

Research findings indicate that LAWF created a new legitimate claim to authority in the policy making arena. Interview data revealed that there was strong allegiance to this new networked institution and associated outcomes that were deficient in previous government-led incarnations. Diverse groups worked together with a commitment to solving problems that government could not solve on its own. The external situation around rapidly declining water quality and unresolved water allocation problems placed an intense amount of pressure on LAWF to reach consensus. Political leadership also played a key role in moving the process forward. The LAWF chair, a former foreign trade negotiator with extensive government experience, exerted influential leadership with stakeholders, government Ministers, and agency officials. At least at the beginning, the Ministers were committed to the LAWF policy process and saw it as a way to work through thorny water issues that government could not do on its own.

One area of tension that emerged involved the extent of public involvement. Initially, LAWF engaged in an extensive public consultation effort. Prior to the release of its first report, Report of the Land and Water Forum: A Fresh Start for Fresh Water in 2010, the Forum conducted public hearings around the country to gain public input and 
feedback on its recommended proposals. The Forum's efforts helped educate New Zealanders about water issues and raise awareness about the Land and Water Forum's efforts to reform freshwater management. However, public engagement efforts declined as subsequent reports were developed. Some participants interviewed expressed concern about how the LAWF process had become more insular over the years as the LAWF process was not easily accessible to the public. Through my own experience, I found it challenging to locate agendas and meeting locations on the LAWF webpage. Concerns that LAWF had become an elite body of special interests with direct connection to the government could jeopardize its future legitimacy.

Social capital. This is formed in the bonds between actors and linked to organizational learning and knowledge transfer (Keast et al., 2011). Social capital, as defined by Putnam (1993), "refers to features of social organization, such as trust norms, and networks, that can improve the efficiency of society by facilitating coordinated actions” (p. 167). Koliba, DeMenno, Brune, \& Zia (2014) refer to social capital as a byproduct of horizontal relationships in networks and acknowledge that it may be cycled back into the network as an input. The case study research revealed that New Zealand's collaborative network process developed strong ties between non-state actors and in turn did generate high levels of internal (within network) social capital. This dynamic created opportunities to frame a wide range of recommendations around integrated water policies.

Although LAWF exhibited strong internal social capital among non-state actors, the process did not appear to engender strong social capital with the state actors. Thus, while LAWF played a significant role in policy development, its influence around final 
adoption and implementation of policies appeared limited. Ultimately, decisions on what policies to adopt and move forward remained with the government ministers and officials who were responsible for adopting and implementing LAWF's policy recommendations (See link to Analysis of LAWF recommendations: http://www.landandwater.org.nz/Site/Resources.aspx.)

This dynamic created tension between LAWF and government officials. Even though LAWF viewed itself as an autonomous network governance institution with independent staff, it still relied on state actors as they maintained legal and fiscal controls and functions (McGuire \& Agranoff, 2010). LAWF had been granted legitimate power and authority to develop a new strategic direction for fresh water, and it appeared that some members were under the impression that if they were able to reach consensus, the government would support their policy recommendations.

\subsection{Summary}

This in-depth case study analysis demonstrated how a network approach to integrated water management moved the freshwater policy discussions forward in New Zealand. The research presented in this chapter supports the proposition that networks are better suited than bureaucratic organizations to deal with wicked issues like water management. Networks have a greater potential than hierarchies to function as complex adaptive systems with capabilities for coordination between many different actors and organizations (Bennington, 2011). In the next chapter, I will present my Oregon case study along with the research analysis and findings. 


\section{CHAPTER 5: OREGON CASE STUDY}

This chapter presents an in-depth case study examining Oregon's institutions, policies, and actors involved in integrated water management, including the development of a statewide integrated water resources strategy. A focus of this case study research is to gain a better understanding of factors for success in collaborative networks engaged in developing integrated water policies. In particular, the aim was to gain a better understanding of the key institutions and actors shaping and constraining Oregon's integrated water policy discussions. First, I set the stage with background information on Oregon water policies including a chronological history of water management, and an overview of Oregon's legal and institutional frameworks. Next I provide a detailed account of Oregon's Integrated Water Management Strategy development process through a collaborative, network governance approach. Finally, I present an in-depth case study discussion and analysis, including key research findings, an assessment using network governance theoretical constructs, and reflections on lessons learned.

\subsection{Water Management Challenges}

Oregon is a coastal state located in the Pacific Northwest of the United States and known for its diverse landscape of forests, mountains, rivers, and beaches. The Cascade Mountains stretch across the entire state from north to south, producing areas with two distinct climates. West of the Cascades, a mild, moist marine climate prevails, while east of the Cascades lies Oregon's high desert country with sparse rainfall and an extreme climate (See Figure 5.1). With more than 100,000 miles of rivers and streams, 360 miles of coastline, and more than 1,400 named lakes, Oregon is renowned for its water and 
natural beauty (Oregon Water Resources Department, 2012). Oregon boasts ample public lands with the federal government managing about 53 percent of the land in Oregon (Oregon Water Resources Department, 2017).

Figure 5.1 Map of Oregon, USA (Source: One World - Nations Online)

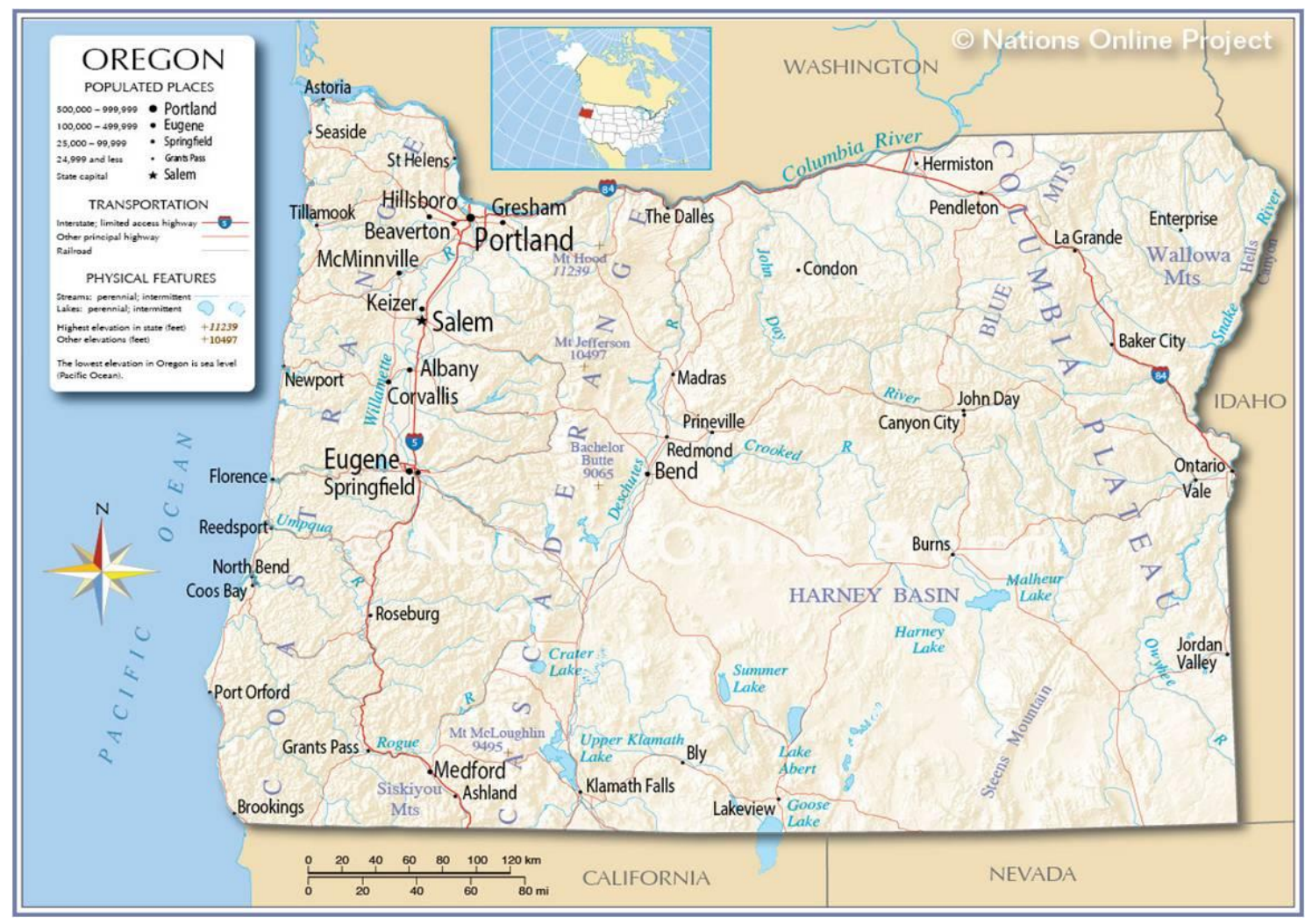

Oregon's water resources are an essential part of the state's ecological and economic well-being for drinking water, recreation, industry, agriculture, and fish and wildlife. However, Oregon is facing a number of significant water resource management challenges. More than 1,861 water bodies are impaired and not meeting water quality standards (Department of Environmental Quality, 2010). Degradation of water quality 
impacts public and watershed health, and diminishes the amount of fresh water immediately available to water users and the environment, and water quality degradation also contributes to water scarcity (Oregon Water Resources Department, 2010).

Regarding water quantity, nearly all of Oregon's surface water is fully allocated during the summer months (irrigation season), with declining groundwater resources in some areas of the state (Oregon Water Resources Department, 2010). Opportunities for additional groundwater uses are limited by hydrologic connection to fully appropriated surface water, declining aquifers, and water quality issues (Oregon Water Resources Department, 2010). Some water is available during the winter months for storage; however, opportunities may be limited by the need to ensure ecological flows, environmental protections and minimum impacts to endangered species (Oregon Water Resources Department, 2010). There are also threats facing Oregon's watershed ecosystems. Oregon's streams and lakes provide substantial habitat and are vital for fish and wildlife to reside and reproduce. However, 24 fish populations have been identified as threatened or endangered under the Federal Endangered Species Act, while another 31 are listed as state sensitive species (Water Resources Department, 2010). Managing the state's water resources to protect and restore these species needs to be considered as part of integrated water management.

Lastly, Oregon also faces governance challenges in that water is rarely dealt with at one spatial or institutional level, and current approaches to water resource management make integration across spatial scales and institutions challenging. In addition, lack of funding for data collection and management and adequate agency staffing presents a key challenge to adequately manage water in Oregon. In this next section, I will provide a 
more detailed overview of the complexities and challenges of Oregon's water governance framework.

\subsection{Water Governance in Oregon}

Water resources in the United States are typically managed under the model of American federalism with a sharing of power between the federal and state governments. Water governance in the United States is highly complex and fragmented. At the federal level, multiple federal agencies oversee implementation of federal statutes including the Clean Water Act and Safe Drinking Water Act (U.S. EPA), the Endangered Species Act (U.S. Fish and Wildlife and the National Marine Fisheries Service) and the Harbors and Rivers Act of 1899 (U.S. Army Corps of Engineers). Even though these federal laws provide overarching policy directives, each state supports their own water governance framework due to differing state government structures, policies, and implementation mechanisms. In Oregon, multiple state and local entities operate under a combination of federal and state laws, policies, administrative rules, and case law.

Historically, all of the state agencies involved in natural resource and environmental management have been organized along traditional resource allocation, management, and regulatory lines: agriculture, energy, environmental quality, fish and wildlife, forestry, geology, parks, state lands, and water. To illustrate the complexity of Oregon's water governance framework, ten out of these fourteen state natural resource agencies $^{12}$ manage some aspect of water. In addition to following federal and state

\footnotetext{
${ }^{12}$ Water Resources Department, Department of Environmental Quality, Department of Agriculture, Department of Fish and Wildlife Department of Land Conservation Development, Department of Energy,
} 
legislative and executive directives, these state agencies receive guidance and direction from a myriad of citizen boards and commissions that sometimes result in conflicting water policies.

At the local level, hundreds of authorities known as special districts are involved in water management; these districts include, for example, water control, domestic water supply, irrigation, sanitary districts, water improvement, diking, ports, and soil and water conservation districts (Special Districts Association of Oregon, 2016). Most special districts are directed by a governing board elected by voters with financing through property taxes, fees for services, or a combination of both (Oregon Blue Book, 2015). This fragmented approach to water governance, at both the policy level and geographical scale, has resulted in organizational challenges, inefficiencies of scale, and ineffective mechanisms for managing water resources in an integrated way. This is of concern given increasing pressures from a growing population, physical scarcity, and climate change.

Another factor at play is that Oregon's geopolitical boundaries, similar to many Western states, are not well suited for fostering integrated water management. In 1878, John Wesley Powell published his landmark Report on the Lands of the Arid Region (Powell, 1878) where he laid out a strategy for settling the West to minimize conflicts over scarce water. Powell suggested organizing settlements around watersheds as he believed that would force water users to conserve scarce water resources. Powell thought this arrangement would also make communities better prepared to deal with attempts to

Marine Board, Department of Parks and Recreation, Department of Forestry, Department of Geology and Mineral Industries, and the Watershed Enhancement Board. 
usurp their water. Unfortunately, policy makers ignored Powell's advice and instead, organized Western states by political boundaries (i.e., township and section lines) that disregard natural river basin areas. The absence of planning on a basin scale has posed enormous challenges for managing water resources, especially in the Western United States. Many states lack a governance framework that integrates water resources (quality and quantity, groundwater and surface water) and land use policies, and Oregon is no exception. Land use policies are included in my analysis to recognize the strong connection between water and land use. Proper land use management plays a role in minimizing development impacts to protect water quality. Moreover, with the pressures of an increasing population, Oregon's communities need to adequately plan and prepare for meeting growing demands on a shared resource (Oregon Water Resources Department, 2012).

By the late 1800 s, concerns around water availability had already created contention among Oregon farmers, fisherman, ranchers, and growing urban areas (Bastasch, 2006). The legendary quote attributed to Mark Twain, "whisky is for drinking; water is for fighting over" rang true. In Oregon prior to 1909, two competing approaches to water use co-existed, the riparian system and prior appropriation (Bastasch, 2006). Under the riparian system, based on English common law and widely used in the Eastern United States, only landowners with water flowing through their property have claims to the water. Riparian systems worked well in humid growing areas like the Eastern United States and England, where access to flowing water was not essential, nor limited, for agriculture. However, it does not work well in Western arid areas of the United States, where land is often located far away from water sources and irrigation is needed to grow 
crops (Bastasch, 2006). In order to optimize use of scarce water resources in the west, a different system of water use emerged.

Since 1909, the prior appropriation system has been in effect when passage of the first unified water code introduced state control over the right to use water (Oregon Water Resources Department, 2013). The principle of prior appropriation allocates water to users based on the order in which water rights were acquired. This means the first person to obtain a water right on a stream is the last to be shut off in times of low streamflows (Oregon Water Resources Department, 2013). Under drought or water-short times, the water right holder with the oldest date of priority can demand the water specified in his or her water right without consideration for the needs of junior users (Oregon Water Resources Department, 2013). If there is a surplus beyond what is necessary to fulfill the senior right, the water right holder with the next oldest priority date can take what is available to satisfy needs under his or her right (Oregon Water Resources Department, 2013). This continues down the line until there is no surplus or until all rights are satisfied, and the water permit application date usually becomes the priority date of the right (Oregon Water Resources Department, 2013).

The Oregon water code established four general principles that still are valid today: (1) "water belongs to the public; (2) any right to use it is assigned by the State through a permit system; (3) water use under that permit system follows the prior appropriation doctrine under which older water uses are entitled to water before newer uses; and (4) permits may be issued only for beneficial use without waste" (Bastasch, 2006 , p. 55). When the water code was ratified in 1909, the code's provisions pertained only to surface waters, not groundwater (Bastasch, 2006). Starting in 1927, the state 
required permits to use groundwater east of the Cascades; however, the Oregon

Legislature did not authorize a statewide groundwater permitting system until the passage of the Groundwater Act of 1955 (Bastasch, 2006). In 1975, the Oregon Legislature created the Water Policy Review Board and merged the State Engineer's Office with the State Water Resources Board to create the Oregon Water Resources Department (Oregon Water Resources Department, 2013).

The Oregon Water Resources Department implements the water rights permitting process. First, Department staff reviews the water rights application to ensure it is complete. Next, staff at the Department's water rights section reviews the application to determine: "whether a statute or rule restricts the proposed use; whether the requested amount of water is available; whether any other issues would preclude permit approval, and, in the case of groundwater application, whether the proposed use is located in a designated critical groundwater area and thus restricted" (Amos, 2009, p. 20). Third, after consulting with other state agencies, the Department issues a public notice that includes a request for comments (Amos, 2009). Following the public comment period, the Department completes its application review and, within sixty days of completing the initial review, issues a proposed final order approving or denying the application, or approving the application with modifications or conditions (Amos, 2009).

The Department also administers Oregon's Conserved Water Rights program. An early proponent of in-stream protections, Oregon started enacting a minimum perennial stream flow program in 1955 (Amos, 2009). In-stream water right means “a water right held in trust by the Oregon Water Resources Department for the benefit of the people of the State of Oregon to maintain water in-stream for public use" (ORS 537.332). 
In 1987, the Oregon legislature revamped instream protections by adopting the In-stream Water Rights Act that recognized the environmental value of leaving water in a water body (Amos, 2009). Under this Act, in-stream water rights were granted equal footing with all other water rights. Unlike agricultural, municipal, or industrial uses, which represent private out-of-stream applications of water, the Water Resources Department holds in-stream rights in trust, and the water remains in its natural stream for public use and benefit (Amos, 2009). The In-stream Water Rights Act fundamentally changed water use in Oregon by recognizing that in-stream water rights provide a public benefit and therefore satisfies the statutory beneficial use ${ }^{13}$ requirement (Amos, 2009). In particular, the Act recognized that public use includes, but is not limited to, the following: (1) recreation; (2) conservation, maintenance, and enhancement of aquatic and fish life, wildlife, fish and wildlife habitat and other ecological values; (3) pollution abatement; or (4) navigation (ORS 537.332).

Turning to water quality, pollution in Oregon's major river, the Willamette River, was one of the first environmental issues raised by Oregon's citizens. In 1938, Oregon's first agency focusing on the environment was established: the Oregon State Sanitary Authority (Department of Environmental Quality website). The Oregon Legislature directed it to address point source discharges from industrial and municipal facilities, and

\footnotetext{
${ }^{13}$ Beneficial use of water is defined in both Oregon statute and rule. In statute, beneficial use is defined as "municipal, domestic, irrigation, power development, industrial, fish and wildlife, recreation, and pollution abatement" uses (ORS 536.300). In rule, beneficial use is defined "as an instream public use or a use of water for the benefit of an appropriator for a purpose consistent with the laws and the economic and general welfare of the people of the state and includes, but is not limited to, domestic, fish life, industrial, irrigation, mining, municipal, pollution abatement, power development, recreation, stockwater and wildlife uses" (690-400-0010 (3)).
} 
clean up pollution in the Willamette River (Department of Environmental Quality

website). In 1969, the Oregon Legislature created a new, independent agency, the Oregon

Department of Environmental Quality (DEQ), charged with cleaning up and protecting

the state's water, land, and air (Department of Environmental Quality website)

The Federal Water Pollution Control Act of 1948 was the first major U.S. law to address water pollution. Growing public awareness and concern for controlling water pollution led to sweeping amendments by Congress in 1972 (U.S. Environmental Protection Agency website). Congress amended the law in 1972, when it became commonly known as the Clean Water Act (CWA), and goal of making waters of the United States swimmable and fishable by 1985 . These amendments established a water quality permit program focused on point sources, ${ }^{14}$ gave the U.S. EPA authority to implement pollution control program for industry, maintained existing requirements to set water quality standards for all contaminants in surface waters, and funded the construction of wastewater treatment plants (U.S. EPA) Under the CWA, U.S. EPA approves water quality standards for each state, and while Oregon has the ability to establish water quality standards, state standards must meet or exceed federal standards. Subsequently, in 1987, the CWA was amended to address non-point ${ }^{15}$ sources, and soon

\footnotetext{
${ }^{14}$ Point source refers to when water pollutant comes from a single location, such as discharges from the end of pipes or ditches. The term "point source" is defined as "any discernible confined and discrete conveyance, including but not limited to any pipe, ditch, channel, tunnel, conduit, well, discrete fissure, container, rolling stock, concentrated animal feeding operation, or vessel or other floating craft, from which pollutants are or may be discharged. This term does not include agricultural storm water discharges and return flows from irrigated agriculture (CWA §502(14))

${ }^{15}$ Non-point source refers to diffuse sources of water pollution. The term is defined to mean "any source of water pollution that does not meet the legal definition of "point source" in section 502(14) of the Clean Water Act (U.S. Environmental Protection Agency, n.d.).
} 
after, DEQ began issuing permits requiring cities, counties, and sewerage agencies to comply with best management practices to control pollutants in stormwater runoff that ends up in rivers and streams (Department of Environmental Quality website).

At the state level, in 1971, the Oregon Legislature passed the Forest Practices Act that sets standards for the commercial harvesting of trees on Oregon's forestlands, including a major focus on the protection of water resources (Oregon Department of Forestry). In 1993, the Oregon Legislature passed the Agricultural Water Quality Management Act, also known as Senate Bill 1010. This bill designated the Oregon Department of Agriculture to be the lead agency to address non-point source water pollution from agricultural sources. According to U.S. EPA, states report that non-point source pollution is one of the leading remaining causes of water pollution in the United States (U.S. EPA). The CWA was part of a set of federal environmental laws passed at the federal level with the goal of implementation at the state level.

Another important piece of national legislation that affects water resources management in Oregon is the federal Endangered Species Act (ESA). First passed by Congress in 1973, the ESA provides for "the conservation of species that are endangered or threatened throughout all or a significant portion of their range, and the conservation of the ecosystems on which they depend" (NOAA Fisheries, n.d.) It affects public and private lands, although differently. On federal lands or for significant federal actions, the federal agencies have a positive mandate to restore listed threatened and endangered species. Non-federal lands and non-federal actions have a lesser standard to not "take" listed species.

Two federal agencies implement the Act: the U.S. Fish and Wildlife Service and 
NOAA Fisheries under the National Oceanic and Atmospheric Administration. When species are listed as threatened and/or endangered, these agencies must designate habitat critical for species survival. Because Oregon's rivers, streams and lakes provide critical habitat ${ }^{16}$ for listed species, the ESA plays an important role in shaping aspects of Oregon water policy. For example, the ESA has the potential to affect Oregon water policy including limiting water rights, increasing stream flows, and removing fish passage barriers, which in some cases are major dams. Fish passage must be addressed in locations where fish are currently or were historically present, and fish screens ${ }^{17}$ are encouraged on all water right diversions. In these instances, ESA requirements influenced state water policies, resulting in stronger management practices that addressed fisheries requirements.

Now that I have provided an overview and chronological history of federal and state laws affecting water governance, I will review Oregon's institutional water framework along with the key state actors involved in managing the state's water resources.

\subsection{Oregon's Institutional Water Framework}

Oregon's institutional water framework includes a complex web of federal, state and local agencies involved in managing some aspects of Oregon's water resources. (See Figure 5.2 Oregon Institutional Water Framework.) In addition, all but one of Oregon's

\footnotetext{
${ }^{16}$ Essential fish habitat describes "all waters and substrate necessary for fish spawning, breeding, feeding or growing to maturity (U.S. Fish and Wildlife Service, n.d.).

${ }^{17}$ Fish screens are designed to physically prevent fish from swimming or being drawn into a pipes, canals, hydropower turbines or other features that divert water.
} 
water-related state natural resource agencies work with citizen boards and commissions that participate in developing water policy. In this section, I review the principal state agencies that are involved in managing Oregon's water resources. In particular, two state agencies, the OWRD and DEQ, serve as the primary regulatory actors for water quantity and quality. The OWRD regulates water quantity, while the DEQ maintains primary jurisdiction over water quality.

The OWRD, like most institutions, has adapted its mission over time to reflect the changing landscape. Their current mission is to "serve the public by practicing and promoting responsible water management through two key goals: (1) to directly address Oregon's water supply needs; and (2) restore and protect streamflows and watersheds in order to ensure the long-term sustainability of Oregon's ecosystems, economy, and quality of life" (Oregon Water Resources Department, 2013, p. 3). The Oregon Water Resources Commission, a citizen board appointed by the Oregon Legislature, uses its rule-making powers to set state water policy. OWRD implements the Commission's rules and issues orders in the form of water right permits, transfers, adjudications, and other actions.

The DEQ is responsible for protecting and enhancing Oregon's water and air quality, managing the proper disposal of solid and hazardous wastes, and providing assistance in cleaning up contaminated properties and enforcing Oregon's environmental laws (Oregon Blue Book online, 2016). Their mission is "to be a leader in restoring, maintaining and enhancing the quality of Oregon's air, land, and water" (Department of Environmental Quality website, 2016). The citizen-based and legislatively appointed Environmental Quality Commission has rule-making authority and provides guidance for 


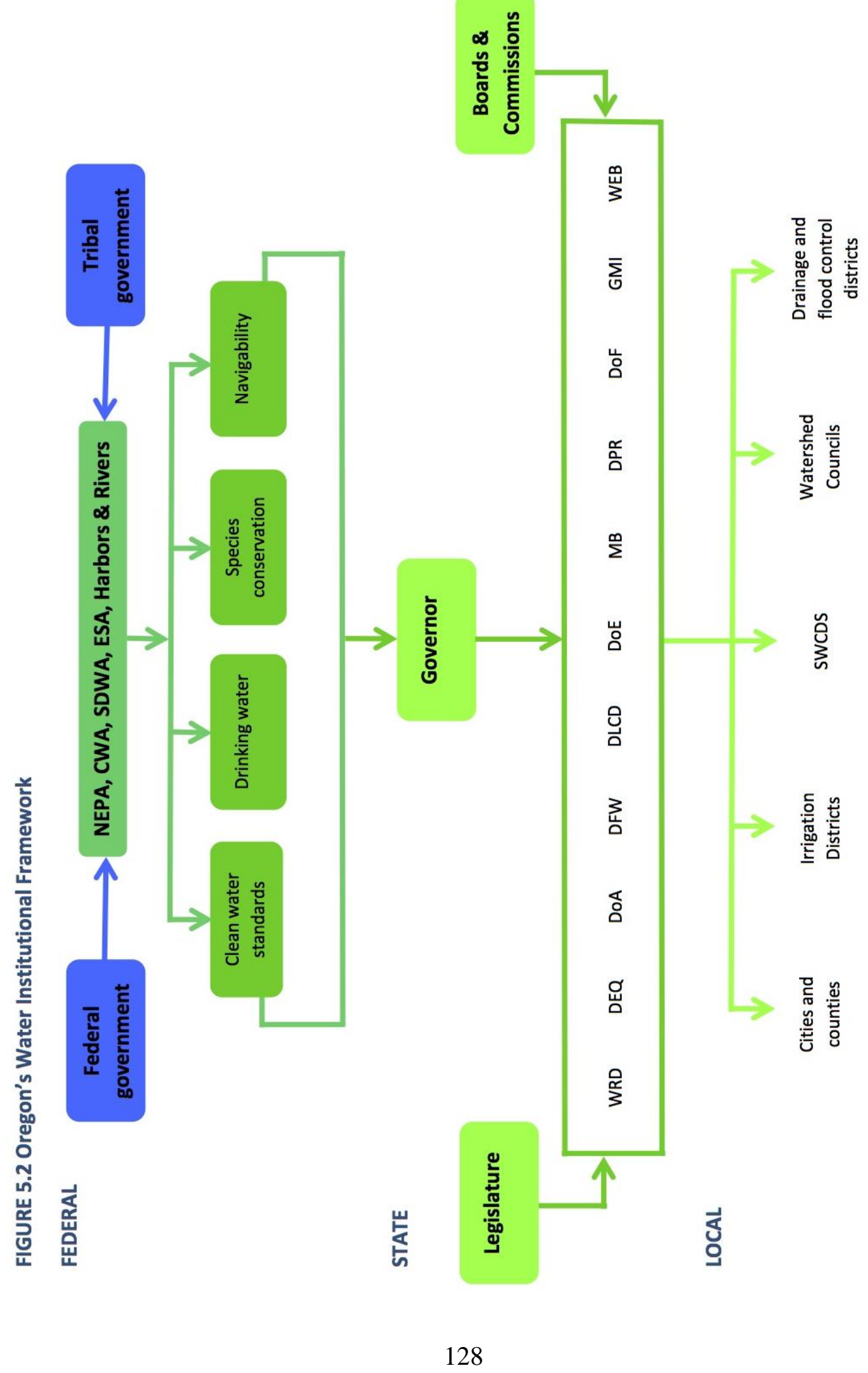


DEQ's day-to-day work. As described in the section above, the DEQ implements the federal Clean Water Act; however, the Oregon Legislature delegated responsibility for water quality protection on agricultural lands to the Oregon Department of Agriculture and to the Oregon Department of Forestry for regulating water quality on non-federal forests. At the local level, cities, and counties are responsible for protecting water quality through comprehensive planning, stormwater management, and other programs (Oregon Water Resources Department, 2010).

In addition to the water quality and quantity programs described previously, Oregon's institutional framework encompasses many other facets of water management. The Public Health Division of the Oregon Health Authority administers the federal Safe Drinking Water Act, which regulates the quality of drinking water delivered through community water systems. The Department of Land Conservation and Development implements the Land Use Program that aims to ensure that land use policies take into account water availability prior to issuing new development permits. Department of State Lands administers the Wetland/fill Program, and the Parks and Recreation Department administers the state Wild and Scenic Rivers Act. Oregon's Department of Fish and Wildlife (ODFW) plays a significant role in the water quantity allocation process, particularly as a commenter on water permits and transfer applications when the permits have an impact on fish and wildlife.

ODFW, the Parks and Recreation Department through the Oregon Scenic Waterway Act, and DEQ may request in-stream water rights to protect in-stream flows for fish and wildlife habitat, recreation or scenic values, or water quality purposes. However, the reality is that most of Oregon's streams and rivers are over allocated, and 
therefore limited water is available for in-stream purposes. When and if these in-stream water rights are issued, they are typically junior water rights, meaning senior out-ofstream water rights must be met first before water can be allocated for in-stream uses.

Oregon's land use planning policies also influence water management in Oregon. Oregon's land use planning law, SB 100, enacted primarily to preclude unrestricted development of forest and farmland, established clear statewide goals (Oregon Department of Land Conservation and Development). Oregon's planning laws define the "land" in "land use plan" to include "water, both surface and subsurface" (ORS 197.015(5)). Although 15 of the 19 statewide land use planning goals specifically reference water resources, very little practical direction is provided to local planners to assist them as they develop their comprehensive plans as they are required to do under Oregon land use planning goals (Bastasch, 2006, p. 288). Consequently, most comprehensive plans are not well coordinated with local or regional water supplies or water management realities (Bastasch, 2006, p. 288).

In response to growing concerns about federal listings of threatened and endangered fish species, the Legislature created the Governor's Watershed Enhancement Board (GWEB) in 1987 to offer lottery-funded state grants for fish habitat-improvement projects. GWEB was formed to foster locally-based approaches to improving watershed conditions and promoting better coordination and collaboration among state water agencies. In 1995, the Oregon Legislature unanimously passed House Bill 3441, which provided guidance for establishing these voluntary, non-regulatory watershed councils. In the following legislative session, Governor John Kitzhaber proposed the Oregon Plan for Salmon and Watersheds (the Oregon Plan), spawning an entire network of watershed 
councils to restore watersheds by improving water quality and habitat for native fish. The Oregon Plan was endorsed and funded by the Oregon Legislature in 1997 through Oregon Senate Bill 924 (1997 Or. Laws, ch.7) and House Bill 3700 (1997 Or. Laws, ch. 8). It represents a long-term, ongoing effort that began as a focused set of actions by state, local, tribal and private organizations and individuals in October of 1995 (Executive Order No. EO 99-01). The Oregon Plan first addressed coho salmon on the Oregon coast, but was then broadened to include steelhead trout on the coast and in the Lower Columbia River, and later expanded to all watersheds supporting wild salmon populations throughout the state (Executive Order No. EO 99-01).

Implementation of the Oregon Plan created an entire new community-based, integrated approach to watershed management. Under the Oregon Plan, Governor Kitzhaber called for greater levels of collaboration and communication across waterrelated state agencies. In 1999, the Legislature established the Oregon Watershed Enhancement Board (OWEB was the successor to GWEB) to administer grants and provide technical support to watershed councils. OWEB ${ }^{18}$ is led by a $17-$ member an interagency and citizen group that oversees watershed restoration efforts. Although OWEB is not directly involved in regulating or managing water resources, it plays a coordination role among federal and state natural resources agencies, and represents an

\footnotetext{
${ }^{18}$ Of OWEB's seventeen members, eleven are voting members. Voting members include: At least 1 tribal representative, 5 citizen representatives, 1 member each from the following Oregon boards and commissions: Board of Forestry, Board of Agriculture, Environmental Quality Commission, Fish and Wildlife Commission, Water Resources Commission. Six are non-voting Board members. Five represent federal natural resource agencies with expertise in forest and agricultural land management, water quality, and salmon recovery, and one represents the Oregon State University Extension Service (Oregon Watershed Enhancement Board, n.d.).
} 
institutional step forward towards integrating watershed management efforts. OWEB also provides significant funding for watershed restoration projects, and thus has played a role in influencing the water planning process (Amos, 2009). In particular, OWEB has adopted goals and priorities, both statewide and at the regional level, that form the basis of its funding decisions.

Next, as part of Oregon's water governance framework, I will briefly touch upon the legal foundations of Indian water rights. Indian reserved water rights play an important role in Western water law, thus tribal involvement in integrated water management is included in this discussion of Oregon's legal and institutional framework. It is also important to include the role of reserved rights given the importance of indigenous water management in the New Zealand case.

\subsection{Indian Reserved Water Rights in Oregon}

Although allocation of water resources is generally a matter of state law, the federal government also has the authority to allocate water rights (Congressional Research Service, 2011). In the United States, discussion around Indian water rights began with treaty negotiations carried out between the United States and Indian tribes in the Pacific Northwest (Mecham, 2016). In 1854 and 1855, a number of Pacific Northwest Indian Tribes entered into treaties with the U.S. Government (Mecham, 2016). A common feature of these treaties is the "express reservation of tribal hunting, fishing, and gathering rights on-and off-reservations" (Mecham, 2016, p. 9). In most of these treaties, tribes reserved the "exclusive rights of taking fish in all streams running through and bordering" the Reservation (Mecham, 2016, p. 9). The treaties also expressly reserved the right to fish at usual and accustomed fishing sites off the Reservation "in common" with 
non-Indian settlers (Mecham, 2016, p. 9). Access to fishing and water rights, which does not necessarily mean exclusive use, is a contentious issue that has played out mainly in the courts.

In 1905, a major legal test of Indian reserved fishing rights played out in the U.S. Supreme Court in the case United States v. Winans (198 U.S. 371). The case attempted to resolve a conflict between members of the Yakama Nation who had been blocked from a traditional Columbia River fishing site by landowners who had obtained a patent for the land from the U.S. government. The Supreme Court held that "the treaty was not a grant of rights to the Indians, but a grant of rights from them, a reservation of those [rights] not granted" (198 U.S. 381). Soon after, in 1908, the Supreme Court issued a landmark decision addressing tribal reserved water rights in United States v. Winters (207 U.S. 564). Justice Joseph McKenna, in writing for the Court, opined that when a reservation of land for the Indians was established, adequate water to meet the needs of the reservation was also implied in that reservation (Mecham, 2016). The Court found, as in the previous Winans decision, that water was reserved for the tribes as part of the federal trust responsibility (Mecham, 2016). The federal Indian trust responsibility, one of the most important principles in federal Indian law, is a legal obligation under which the United States "has charged itself with moral obligations of the highest responsibility and trust" toward Indian tribes as described in Seminole Indians v. United States (316 U.S. 286). It is also a "legally enforceable fiduciary obligation on the part of the United States to protect tribal treaty rights, lands, assets, and resources" (U.S. Department of Interior, Indian Affairs, n.d.).

The Winters and Winans Supreme Court decisions provide the legal framework 
for Indian reserved water rights in Oregon. Although Indian tribes are entitled to water under the reserved rights doctrine as determined by the courts, Congress provided states with authority to adjudicate ${ }^{19}$ federal water rights under the McCarran Amendment (43 U.S.C. 666), which waived the United States immunity from lawsuits (Anderson, 2006). States, including Oregon, are at the center of efforts to decide Indian reserved water rights (Anderson, 2006). These rights are determined on a case by case basis, usually through lengthy water right litigation or adjudication processes.

In all water right adjudications, the United States government, as part of their federal trust responsibility towards the Tribes, participates as trustee on behalf of any Tribe with reserved water right claims in the basin being adjudicated. In many cases, Tribes also participate in the adjudication on their own behalf. In addition, the United States Supreme Court has made it clear that if tribal reserved water rights are adjudicated in state courts under the McCarran Amendment, "[s]tate courts, as much as federal courts, have a solemn obligation to follow federal law" that applies to the Tribe's water rights (43 U.S.C. 666). In addition, should the state court not follow federal law, "any state court decision alleged to abridge Indian water rights protected by federal law," if appealed to the Supreme Court, "can expect to receive a particularized and exacting scrutiny" (Arizona v. San Carlos Apache Tribe of Arizona, 463 U.S. 545, 571 (1983)).

Tribal water right claims frequently conflict with state law-based rights held by

\footnotetext{
${ }^{19}$ Water right adjudication is the legal process to determine who has a valid water right. In Oregon, this entails a process by which pre-1909 vested water rights are quantified and documented through an adjudication procedure in circuit court (Oregon Legislatures, September 2012).
} 
non-Indians, and, in many river basins, there is insufficient water to satisfy both Indian and non-Indian water rights claims. For example, in 2013 the state of Oregon completed a lengthy adjudication process, culminating 38 years of work, to determine surface water rights in the Klamath River Basin (Oregon Water Resources Department, n.d.) The state determined that the most senior claims are held by the United States in trust for the Klamath Tribes as these claims carry a priority date of "time immemorial" (Oregon Water Resources Department, n.d.). The tribal claims were recognized for certain reaches of the major tributaries to Upper Klamath Lake, and for Upper Klamath Lake itself. Other tribal claims were denied for streams outside the boundaries of the former Klamath Indian Reservation (Water Resources Department). The exercise of the very senior water rights that were granted to the Klamath Tribes have required that junior non-tribal water right holders curtail or halt all water use such as irrigation or stock watering.

The uncertainties and complexities of both adjudication and legal processes have prompted many tribes to engage in settlement negotiations directly with the federal government to determine their reserved water rights (Anderson, 2006). In 1997, the water right claims of the Confederated Tribes of the Warm Springs Reservation in central Oregon were resolved through negotiations between the State of Oregon, the Tribes, and the federal government. The settlement made certain that the Tribes would have adequate water resources for current and future needs, clarified the sovereignty of the Tribes over the administration of their water rights and provided legal protections for non-tribal water right holders in the Deschutes River basin (American Indian Law Center, 2013). This settlement avoided the lengthy and contentious water right adjudication process described above. Also, at the request of the Oregon Governor and the Confederated Tribes of the 
Umatilla Indian Reservation Chairman, the Department of the Interior established a federal negotiation team in 2012 to work with the State and the Tribes toward a negotiated settlement of unresolved claims for in-stream flows and consumptives uses such as irrigation; these negotiations are ongoing. (Personal communications with D. Mecham, U.S. Department of Interior, March 2, 2017.)

What this means is that as Sovereign governments, Indian Tribes play an important role in integrated water governance and management policies in Oregon. The recognition of this special relationship between the Tribes and the state was outlined in state legislation creating Oregon's integrated water strategy. The next section provides a detailed account of the history and factors leading to formation of Oregon's Integrated Water Resource Strategy.

\subsection{Oregon's Integrated Water Resources Strategy}

As the need for water grows in Oregon, tension around the allocation and regulation of scarce water has increased. Oregon faces growing challenges in managing its water resources with fully or over allocated surface water (during summer months), declining groundwater levels, impaired water quality, and threatened and endangered fish species. Changing conditions, including climate variability, population growth, land use, and other factors have heightened concerns around the future of Oregon's water resources. The Oregon Progress Board's State of the Environment Report 2000 identified a concern about the adequacy of Oregon's water supply. Oregon Water Resource Commissioners and state lawmakers shared apprehensions about unresolved water resource management issues and the lack of strategic direction and vision. Starting in 2007, the Water Resources Commission recognized the need for more adequate resources 
for the Oregon Department of Water Resources. This included additional staff to implement existing programs and funding for additional water availability studies and monitoring data. At the time, Oregon was one of only two western United States without an integrated water plan.

It is important to note that this interest in integrated water planning was not new to Oregon. In 1955, the Oregon Legislature mandated a coordinated, integrated state water resources policy (ORS 536.220) and the Oregon Water Resources Department developed a basin program to implement this effort. Basin plans were developed for each basin and these plans acted as state administrative rules to establish "future allowable water uses in, and other water regulations specific to, Oregon's eighteen major river basins" (Bastasch, 2006, p. 78). These basin plans were focused on future allocations and did not affect previously issued water rights or permits. The intent of the basin program was to balance existing and future water needs with the public interest for each basin. However, the plans became mired in bureaucratic requirements and were not widely supported by the local users. They focused on basin-by-basin classification and lacked an over-arching state water policy or strategic direction (Bastach, 2006). The state experimented with different forms of basin programs throughout the 1990s, but results and legislative acceptance were mixed (Bastasch, 2006). Given the challenges of implementing the basin plans and shifting budget priorities, OWRD abandoned basin programming in the late 1990s.

Being mindful of past efforts, the Water Resources Commission and Department began laying the groundwork for another water planning effort in 2007. Concerned about growing conflicts around limited water supplies, the Oregon Water Resources 
Commission encouraged the OWRD to initiate a strategic planning process utilizing an integrated water management approach. At the same time, several legislators (including the author) expressed an interest in developing a comprehensive and integrated water strategy for Oregon. The Legislature provided funding for a data-gathering exercise to improve the state's ability to forecast water demands, as well as to identify opportunities for conservation, water reuse, and water storage. In early 2008 , the Oregon Legislature passed SB 1069 directing the Oregon Water Resources Department (WRD) to establish a statewide Water Conservation, Reuse, and Storage Investment Fund to provide grants for the planning and feasibility studies necessary to develop community water supply projects. The Legislature also provided cost-share funding for communities engaged in long-term water planning.

Researcher Involvement in the Oregon Case Study

Before continuing, I wish to point out that, starting in 2007, the author served as an Oregon State Representative and later Senator, and in these roles, was involved in the policy making process as chair of the Environment Committee. The author, along with several other legislators, was concerned about Oregon's siloed regulatory framework and the inability to manage Oregon's water resources in an effective and efficient manner. In Oregon, water quality and quantity is managed separately and the complexity of water issues demanded a more coordinated approach. Also, Oregon did not have a long-term plan or vision for future water use and management. ${ }^{20}$

${ }^{20}$ In 2008, Oregon was one of two western states without an official, long-term water management strategy. 
As committee chair, the author approached the Institute for Water and Watersheds (IWW) at Oregon State University and the Oregon University System Institute for Natural Resources (INR) to lead workshops to gain input from Oregonians about waterrelated challenges and their vision for water in the 21st Century. Oregon Sea Grant Extension (OSGE) joined the team to plan a series of water roundtables, as they came to be called, that were open to all interested Oregonians. Sponsors from government, private industry, nonprofits, and individuals interested in Oregon's water future provided funding. In September-October 2008, the OSU team held five roundtables in Bend, Newport, Ontario, Medford, and Salem "to receive input and advice from Oregonians and develop information to inform efforts to identify and communicate a vision for water management" (OSU Institute for Water and Watershed, Oregon Sea Grant Extension, OUS Institute for Natural Resources, \& Oregon House Committee on Energy and Environment, 2008, p. 5). Roundtable attendees were asked to respond to eight questions designed to identify their interests and the source of their water. They were also asked which of the following five factors - quantity, quality, economic, ecological, and social they valued most about Oregon and its water (OSU Institute for Water and Watershed, Oregon Sea Grant Extension, OUS Institute for Natural Resources, \& Oregon House Committee on Energy and Environment, 2008, p. 5). A final summary report synthesizing the roundtable results was issued in December 2008. These roundtables set the stage for subsequent discussions about integrated water management. Key themes that emerged from the water roundtables were: 
One size does not fit all; regions vary greatly and regional differences need to be recognized;

Public information and education about water use and management are needed;

and

Oregon needs integrated water management and implementation. (OSU Institute for Water and Watersheds et al., 2008, p. 12).

The data from the Oregon Water Supply and Conservation Initiative, along with feedback from the statewide roundtables, helped inform policy discussions at both the legislature and the Water Resources Commission regarding Oregon's future water needs. The author co-led these discussions at the legislature along with two members of the House, Representatives Bob Jenson, and Jefferson Smith. This convergence of interests by both elected and appointed policy makers helped propel discussions about the need for a statewide integrated water strategy. During the 2009 Legislature session, legislative work groups were convened and ultimately, public hearings were held in the House of Representative and at the Joint Committee on Ways and Means. ${ }^{21}$ During these deliberations, Oregon's Legislature posed two questions essential to Oregon's water future: what is the current state of Oregon's water supply relative to its needs; and what must Oregon do to ensure that sustainable supplies of clean and abundant water are available to meet future in-stream and out-of-stream needs? The result was a bi-partisan bill, HB 3369, intended to address Oregon's water resource management challenges and

21 The Joint Committee on Ways and Means is the legislative appropriations committee that determines Oregon's budget policy. Both Senate and House members serve on the committee to facilitate adoption of a biennial budget (Oregon State Legislature, n.d.). 
account for coming pressures by developing an Integrated Water Resources Strategy (Strategy).

HB 3369 directed the Water Resources Department to develop a state-wide integrated water strategy to help Oregon meet its future water needs in terms of water quantity, water quality, and ecosystem functions. It also established a Water Investment Grant Fund for water-related infrastructure needs. The Oregon Water Resources Department was to work in close cooperation with DEQ and ODFW to develop an integrated water Strategy in consultation with other state, local, and federal agencies, other states, Indian tribes, stakeholders, and the public, with updates every five years. HB 3369 passed both chambers of the Oregon Legislature with a 43-16 vote (one excused) in the House and a 20-9 (one excused) vote in the Senate (Oregon State Legislature). The bill was signed by the Governor Kulongoski and became effective on August 4, 2009 (Oregon State Legislature).

At the same time that legislators were discussing and debating integrated water management at the Capital, Water Resources Commissioners conveyed the urgency and need for planning Oregon's water future (Oregon Water Resources Department, 2010). To set the stage for discussion about Oregon's Integrated Water Resources Strategy, four Water Resources Commissioners took the lead researching and writing seven "issue papers," The issue papers provided background information for development of the Strategy and covered the following topics: a needs statement, water quantity, water quality, economic development, ecology and ecosystems, the implications of climate change, and culture, community, and water and were made available for public review and discussion as part of public outreach for the Strategy (Oregon Water Resources 
Department, 2010).

The Commission laid out the purpose of a strategic, integrated water plan including:

Encourage planning ahead

Balance competing needs

Promote wise use of water

Promote participation

Foster public health, safety \& good will

(Oregon Water Resources Commission Minutes, July 9, 2009)

In addition, they crafted a vision for the Strategy: "A statewide integrated water resources strategy will bring various sectors and interests together to work toward the common purpose of maintaining healthy water resources to meet the needs of Oregonians and Oregon's environment for future generations" (Oregon Water Resources Commission Minutes, 2009), and established a working group to guide the Commission through the Strategy development process. The Commission strongly recommended that the Strategy be developed through a collaborative process and stated that "a participatory approach is an effective means for achieving consensus and long-lasting agreement. Real collaboration takes place only when stakeholders and the interested public are part of the decision-making process" (Oregon Water Resources Department, 2010, p. 7). They also recognized that "incorporating the views of a wide variety of governmental agencies, stakeholders, and the public will be a challenge, but is a key component to the success of such a Strategy" (Oregon Water Resources Department, 2010, p. 7). 
HB 3369 directed the Oregon Water Resources Department to work in close cooperation with the Oregon Department of Environmental Quality, Oregon Department of Fish and Wildlife, and Oregon Department of Agriculture to develop the Integrated Water Strategy. Staff from these four agencies formed the project team who led the Strategy development process through the following five phases which are described in more detail below:

$>$ Phase 1 (2009): Drafted issue papers and key principles, developed workplan and public involvement strategy, and appointed three advisory groups including the Policy Advisory Group;

Phase 2 (2010): Identified statewide water needs through 11 open houses, a survey, stakeholder workshops, and briefings;

Phase 3 (2011): Developed a recommended actions progress report with a public comment period held on a 2011 discussion draft;

> Phase 4 (2012): Released Oregon's first Integrated Water Resource Strategy. Additional public comment held, boards/commissions briefings, final draft adopted June 2012;

Phase 5 (2012): Water Resources Commission adopted final Strategy in August 2012 (Bateman and Rancier, 2012);

Post-adoption phase (2012-2017): OWRD staff transitioned to implementation and evaluation of Strategy that laid the foundation for budget and policy packages in 2013, 2015, and 2017 legislative sessions. Implementation also included rule making, launch of various new programs, and scientific analysis. (Personal discussions with OWRD staff). 
In the first phase, a set of strategy guiding principles were developed that mirrored Integrated Water Resource Management concepts of sustainability, accountability, integration, and collaboration (Bateman and Rancier, 2012). The Strategy guiding principles (see Table 5.1), vision, goals, and objectives were developed in consultation with advisory groups consisting of Water Resources Commission members, stakeholders, and members of the public (Bateman \& Rancier, 2012). The issue papers were distributed for public comment along with the Strategy work plan.

Also during Phase 1, OWRD convened a Policy Advisory Group (PAG) to assist with identifying priorities and developing recommendations for inclusion in the Strategy. The PAG included 18 stakeholders and partners representing an Indian Tribe, irrigated agriculture, industry, local government, recreational users, and conservation organizations. (See Appendix F for details on PAG advisory group members.) They developed a group vision that guided the PAG's work (see Table 5.2). The collaborative group process was facilitated by an independent contractor and operated under a consensus decision-making basis, meaning that the Strategy included only recommended actions where agreement could be reached, or there was no objection raised against inclusion of an action. PAG discussions and recommendations were instrumental to the successful development of the Strategy. The Water Resources Commission appointed one of its members as the PAG liaison, providing full reports on the PAG's work at each Commission meeting. 
Table 5.1 Guiding Principles of Oregon's Integrated Water Resources Strategy

The Strategy's guiding principles emphasized the following:

- Accountability

- Balance

- Collaboration

- Conflict Resolution

- Facilitation by the State

- Incentives

- Implementation

- Interconnection/Integration

- Public Process

- Reasonable Cost

- Science-Based, Flexible Approaches

- Streamlining

- Sustainability

(Source: Oregon Water Resources Department, 2012)

Table 5.2: Policy Advisory Group's Vision for the Strategy

Everywhere in our State, we see healthy waters able to sustain a healthy economy, environment, cultures, and communities.

Healthy waters...are abundant and clean. A healthy economy...is a diverse and balanced economy, nurturing and employing the State's natural resources and human capital to meet evolving local and global needs, including a desirable quality of life in urban and rural areas. A healthy environment...included fully functioning ecosystems, including headwaters, river systems, wetlands, forests, floodplains, estuaries, and aquifers. Healthy cultures and communities...depend on adequate and reliable water supplies to sustain public health, safety, nourishment, recreation, sport, and other quality of life needs.

(Source: Oregon Water Resources Department, 2012) 
Two additional groups were formed to facilitate communication and coordination among state actors involved in water resource management: (1) An Oregon Agency Advisory Group consisting of 18 state natural resources, economic development and public health agencies, and the Governor's office; and (2) a Federal Liaison Group, comprising 10 federal agencies that manage water, land, and fish and wildlife (Oregon Water Resources Department, 2012). Both of these groups met quarterly and provided technical information, guidance, and peer review throughout the Strategy development process.

During Phase 2 in 2009 and 2010, the PAG met quarterly to discuss, deliberate, and develop policy guidance and recommendations for addressing integrated water issues. In the spring of 2010, eleven open houses were held across Oregon to solicit public input on integrated water strategies. Participants were asked to identify the key water issues facing their communities and suggest solutions (Bateman and Rancier, 2012). OWRD also facilitated multiple government-to-government meetings, dozens of stakeholder workshops, seven rounds of public comment, and continual opportunities for online, written, and verbal input (Oregon Water Resources Department, 2012). Based on input from the before-mentioned sources, the Department released a Strategy discussion draft for public comment in December 2011 under Phase 3, with a revised draft in June 2012, Phase 4. Ultimately, the Oregon Water Resources Commission adopted the final version of the Strategy on August 2, 2012 under Phase 5 (Bateman and Rancier, 2012). Governor John Kitzhaber shared his vision about the importance of the strategy in the preface. He stated that "Benjamin Franklin once said that when the well runs dry, we realize the value of water. The Integrated Water Resources Strategy is a long-overdue 
assessment that reflects how we value water here in the state of Oregon. Fortunately, our well hasn't run dry, and with this kind of strategic planning, it won't" (Oregon Water Resources Department, 2012, p. v). The Strategy focused on the following four objectives:

1) Understanding Oregon's existing water resources (i.e., water availability, quantity, management (point and non-point sources)

2) Assessing in-stream and out-of-stream needs

3) Identifying future pressures that affect needs and supplies

4) Meeting Oregon's in-stream and out-of-stream needs. (Oregon Water Resources Department, 2012).

Evaluating the state of existing water resources management and the impact of present and future demands on those resources, the Strategy recognized that many factors influence the future availability and use of Oregon's water resources. These include, but are not limited to, climate change, expanding population, land-use changes, and rising energy costs (Oregon Water Resources Department, 2012). Accordingly, the Strategy attempted to address pressures that affect both water quality and quantity needs, and determine how to increase supplies to meet actual in-stream and out-of-stream demands given the over appropriation of existing supplies. Recommendations focused on "new" water supplies that can be realized through aggressive water conservation and reuse, along with the more traditional approach of developing water supply storage and development projects. Watershed restoration and fish protection were also recognized as an integral component of Oregon's water Strategy. 
The final 2012 Strategy recommended over 40 actions to achieve integrated water management. A number of these actions focused on filling data gaps to achieve a better understanding of Oregon's water resources and institutions (Bateman and Rancier, 2012). Others focused on targeted efforts such as funding for infrastructure development, improving water efficiency and conservation, promoting water re-use, protecting and restoring in-stream flows and habitat for fish and wildlife, and dedicated funding for implementation.

\section{Place-based Planning}

Recognizing the importance of local communities engaging in integrated, placebased water planning efforts, the Strategy accentuated the following (Recommendation 9A):

Place-based planning allows these conversations to take place at a scale that a statewide strategy may not be able to achieve. Voluntary placebased plans can "roll up" and inform the statewide Strategy. Placebased plans can leverage technical and funding resources available through the Strategy to make more meaningful local impacts. This approach is meant to empower communities to conduct voluntary, place-based integrated water resources planning in consultation with the State. (Oregon Water Resources Department, 2012, p. 79)

Place-based planning was recommended because water problems are perceived as being local in nature and best handled at the basin level. This approach was of particular importance to the Water Resources Commission as it responded to citizen and local community concerns about the need to recognize regional differences. The Strategy recommended that, at a minimum, the State should create a planning template to ensure recognition of the public interest in water, robust public involvement, and a "balanced 
representation of all interests" (Oregon Water Resources Department, 2012, p. 80). This recommendation was developed in response to concerns by some stakeholders that a community-led planning process could be dominated by local interests, thus underrepresenting public interests.

After adoption of the Strategy, the Oregon Legislature enacted additional bills targeted towards implementation. In the 2013 session, the Legislature passed SB 839 to provide funding, through grant and loan programs for water conservation, reuse, and storage projects. SB 839 passed both chambers of the Oregon Legislature with a 60-0 vote in the House, and a 19-1 Senate vote (Oregon State Legislature). In 2015, the Oregon Legislature passed SB 266 authorizing the Oregon Water Resources Department to issue grants and outlining specific requirements for place-based water resources planning efforts including: "(a) be developed in collaboration with a balanced representation of interests; (b) balance current and future in-stream and out-of-stream needs; (c) include the development of actions that are consistent with the existing state laws concerning the water resources of this state and state water resources policy; (d) facilitate implementation of local solutions; (e) be developed utilizing an open and transparent process that fosters public participation; and (f) be developed in consultation with the department"(Oregon State Legislature, 2016). SB 266 passed both chambers of the Legislature with a 55-4 vote (one excused) in the House, and a 19-7 (four excused) vote in the Senate (Oregon State Legislature, n.d.).

OWRD issued draft guidelines describing five steps and key planning principles central to the place-based planning efforts:

$>$ Step 1: Build a collaborative and inclusive process; 
Step 2: Gather information to understand current water resources and identify gaps;

$>$ Step 3: Examine current and future water needs for people, the economy, and the environment;

> Step 4: Develop and prioritize strategic, integrated solutions to meet water needs; and

$>$ Step 5: Create and approve a local integrated water resources plan.

These guidelines were developed by the Department through a series of stakeholder workshops, public input, and assistance from several natural resource agencies (Oregon Water Resources Department, 2016). After soliciting and evaluating 16 letters of interest from around the state, the Oregon Water Resources Commission awarded grants to organizations in four areas: (1) Malheur Lake Basin; (2) Lower John Day Sub-Basin; (3) Upper Grande Ronde Sub-Basin; and (4) Mid-Coast Region (Oregon Water Resources Department, 2016). As of the writing of this dissertation in spring 2017, these local planning efforts were underway, with agreements in place with the Portland State University National Policy Consensus Center and the Association of Oregon Counties to provide collaborative training and technical assistance to the four pilot planning groups (Oregon Water Resources Department, 2016).

In 2016, the Strategy reached its four-year anniversary. OWRD initiated a review and update process in March 2016, which included hosting public meetings and convening another 18-member Policy Advisory Group to advise OWRD during this update process. During June 2016, seven open houses were held around the state 
(Pendleton, Ontario, Salem, Newport, Medford, Bend, and Beaverton) to provide citizens with an update of progress made under the 2012 Strategy, and to solicit public input about priorities for the Strategy update. Approximately 200 people attended the open houses (OWRD Staff Report, August 18, 2016). OWRD also posted an online survey from mid-June to mid-July 2016 to solicit public input from those unable to attend the open houses. The Department received 66 survey responses (OWRD Staff Report, August 18, 2016). Themes that emerged from the 2016 public and stakeholder input process were as follows:

$>\quad$ Groundwater: concerns were raised regarding declining aquifers in northeast Oregon.

$>\quad$ Place-based Planning: interests were expressed in several locations about fostering place-based approaches to integrated water resource planning. Monitoring: agencies were encouraged to improve water measurement and collaborate with local partners on monitoring priorities.

$>\quad$ Education: participants felt there was a general lack of understanding of water issues in Oregon. The state government should conduct more outreach and partner with local communities on water education.

Conservation: these efforts have helped buffer impacts of drought; however, more disincentives for use of conservation methods need to be addressed. In-stream demands: this area was identified as a key data gap that were not been accurately accounted for in the Strategy (Oregon Water Resources Staff Report to Water Resources Commission, August 2016) 
The second version of the Policy Advisory Group met four times throughout 2016. This group was convened by OWRD to develop new recommended actions that were absent from the 2012 IWRS, and provide additional guidance to the Department. Only two of the original PAG members also served on the second version of the PAG. Under the second PAG, members were asked to serve as individual citizens rather than representing a specific stakeholder group or special interest. The effort was facilitated by OWRD staff, and operated under a consensus-based decision-making process. The PAG completed its work in January 2017, offering 23 overarching statements, new recommended actions, and confirming and supporting statements. These were intended to enhance the already-existing recommended actions from the 2012 Strategy. OWRD released a draft of the 2017 Integrated Water Resources Strategy on April 19, 2017 with a two-month period for public review and comment period. The updated Strategy introduces five new areas of focus along with supporting recommendations: planning and preparation for "extreme events" including droughts, floods, and the Cascadia earthquake; ensuring public safety/dam safety; providing an adequate presence in the field; strengthening permitting programs for water quantity and water quality; and, developing additional groundwater protections (Oregon Water Resources Department, 2017).

To review, this section provided a history and overview of the legal and institutional arrangements around water governance in Oregon. This background helps build an understanding of the factors that lead to development of Oregon's Integrated Water Resources Strategy. It also sets the stage for a discussion about the role of state and non-state actors in a collaborative network governance approach to developing 
integrated water policies. Next, I present an in-depth discussion and analysis of the Oregon case based on in-depth interviews and other data sources.

\section{6 Discussion and Analysis of Oregon Case Study Findings}

A key focus of this case study research was to gain a better understanding of factors for success in collaborative networks focused on developing integrated water policies. In order to learn more about Oregon's collaborative network process and augment my personal knowledge and experience of the case, I utilized several methods for gathering research evidence. This included extensive document and archival research, and review and categorizing of the following sources:

legislative information including legislative bills and amendments, legislative committee briefs, hearing summaries, and audio tapes, and House and Senate debates;

Water Resource Commission meeting agendas and minute, staff reports, and briefing documents;

Strategy-related public meetings and open house materials (agendas, staff reports and summaries);

media reports (newspaper and radio);

Policy Advisory Group meeting information (agendas, staff reports, presentation materials);

25 semi-structured interviews of state and non-state actors.

The semi-structured interviews helped provide a more in-depth understanding about the Integrated Water Resources Strategy policy development process, as I was able to triangulate information gleaned from the interview data with information gathered 
from other sources such as personal knowledge and experience, document reviews, and participant observations. As described in Chapter 3, Research Design and Methods, a purposive sample of 25 state and non-state actors who had been involved in the development of Oregon’s Integrated Water Resources Strategy were interviewed. In order to ensure representation of a broad spectrum of interests and ideological perspectives, a cross-section of individuals and organizations involved in the Strategy development process were interviewed. These included participants in both versions of the Policy Advisory Groups (non-state actors), observers (those attending the meetings but not directly on the PAG), and state actors (state government agency directors and officials, state agency commission members, and Governor's office staff). The interview respondents represented a range of interest areas including irrigated agriculture, ranching, non-irrigated agriculture, forest management, Tribes, environmental and conservation, recreation, fisheries, state and municipal government, policymakers, and special districts.

To develop my interview protocol, I relied upon information I had gained through direct experience and background knowledge, extensive document reviews, observations from attending Strategy meetings, and input from my academic advisors. The interviews were typically 45 minutes to an hour in length and recorded for later transcription and coding. The semi-structured interviews provided rich data about the collaborative network approach to integrated water policy development in Oregon. Each participant told a story, from his/her perspective that created a more comprehensive picture of the strategy policy framing and development process. Some of the themes that emerged from the research data were consistent with themes from the literature; however, new themes arose, in situ, from the research data. 
Presented below are the areas of convergence and insights derived from the Oregon case study including key findings that emerged from the interview data:

$>$ Collaborative network processes create interdependencies between non-state actors through knowledge transfer and shared learnings, foster relationships, and generate some levels of trust;

Fragmented institutional arrangements constrain Oregon's ability to deliver integrated water governance;

Limited and unstable funding and resources constrain network processes;

$>$ Resolving value conflicts remains challenging despite collaborative networks;

Place-based approaches to integrated water management offer promise;

Climate change and water scarcity are key policy drivers.

The following is a detailed description of each of these key themes, including theoretical application and findings.

\section{$\underline{\text { Benefits and Challenges of Collaborative Network Processes }}$}

As described earlier in this chapter, the Integrated Water Resources Strategy was developed through a collaborative network approach involving a diverse set of state and non-state actors. Over half of the interview participants (out of 25) spoke at length about the benefits of the collaborative process, including fostering mutual learning and information sharing, knowledge transfer, relationship and trust building, identification of shared interests, and perceiving issues/problems through a similar lens. These findings were consistent with themes from the literature on collaborative and network governance.

All but two (out of 25) interviewees expressed support for the IWRS collaborative 
policy process in that it fostered mutual understanding, a shared knowledge of issues and problems, and a greater level of trust among network actors. One respondent observed:

There is recognition by all the stakeholders that we're all in this together and need to find answers. Even though there are still fights around the edges, there is recognition of the value of the collaborative process.

Another interviewee shared:

A lot of this is learning what is important to other people, why it's important to them, educating why our issues are important to us so we can all understand each other. I think once you understand each other then it is a lot easier to work towards common goals.

What emerged from the interview data is a general recognition that the collaborative network process helped move beyond stalemates that occur in the legislative and rulemaking process. From reading through the PAG meeting minutes, direct observation, and analyzing the interview data, there appeared to be general agreement on framing water problems, and identifying some solutions for future action. All but three interview participants shared that the IWRS process provided opportunities for relationship building and created greater levels of trust between stakeholders. Previously, many of the non-state actors around the table operated in the legislative or legal arena where it is a zero-sum game with minimal incentive for collaboration. A collaborative network created space for listening and mutual understanding that was lacking prior to the Strategy development. One respondent stated that:

I feel my best work on this group has been meeting with people between meetings to find common ground and try to find solutions I hadn't thought of, those sorts of things. So, I think the more people that are involved in these discussions, the better. If we're actually trying to 
carve a path forward and not put our gloves on and go our separate corner, that's the way to do these things. Those are long, hard conversations but that's how decent stuff happens.

A couple of participants were more critical of the process. They pointed out that even though two years of deliberation produced a Strategy with general buy-in and support, they expressed disappointment that trust and relationships developed during the collaborative process were undone during legislative battles over prioritizing policies and funding. One participant observed:

The Policy Advisory Group brought different perspectives together but it struggled to reach consensus on tough issues. With so many diverse interests, it's a challenge to overcome entrenched interests.

Four interviewees shared that although they appreciated serving on the Policy Advisory Group, the process needed consistent membership over a longer time period to build stronger ties and more durable relationships. The PAG process was helpful for developing framing and formulating policies but could have been extended to assist with the Strategy implementation.

Planning documents, meeting minutes, and interview data revealed that the collaborative network process focused attention on the need for more integrated and robust data about Oregon's water resources. This included the need for additional water quality and quantity monitoring studies, improved water measurement, water availability studies (both surface water and groundwater), and better integration of data between state agencies. Overall, there was recognition that additional data is necessary to make informed decisions. One interviewee captured the need for better and more coordinated data as follows: 
So the data piece, data and research, really became a focus that everyone had some agreement on. Although there's always the issue of what do you do before you have all the data you think you need? And how do you pay for the data?

In summary, the Integrated Water Resource Strategy collaborative policy development process represented a major shift from how water policies have been developed in the past in Oregon. Historically, water policies have developed through very contentious legislative and rule-making processes, top-down agency driven approaches (often created in silos), or through legal battles in the courts. Water issues are extremely complex, and having the right people around the table engaging in listening, knowledge transfer, and collaborative learning emerged as an important factor for a successful policy framing and formulation process. With a focus on trust, reciprocity and mutual understanding, this process represented a shift from conventional hierarchical command and control authority to processes that are more horizontal and relational in nature (Keast et al., 2014). However, the need for consistent engagement emerged as an area for improvement in Oregon's collaborative process.

\section{Fragmented Governance Arrangements and Institutional Barriers}

The Strategy seeks, among other key objectives, to integrate water quality and quantity, account for climate change impacts, and improve integration of land use planning and water resource management. Case study research gleaned through key informant discussions, interview data, and personal experience and observations revealed that although the Strategy has provided a framework for greater integration and collaboration among water-related natural resource agencies, Oregon's siloed governance framework still poses a barrier to effective long-term integrated water outcomes. For 
example, although OWRD is tasked as the central convener and implementer of the Strategy, it is unclear who is ultimately responsible for ensuring integrated outcomes. It appears that OWRD served as the primary motivator, yet the agency is dependent on other state actors to assist in program delivery. As one interviewee observed:

OWRD has the responsibility to develop an integrated water strategy without the full set of tools or authority to implement it.

The need for more coordinated water management was a recurring theme that emerged from the interview data. Fragmented and overlapping governance arrangements constrain Oregon's ability to deliver integrated water governance. Integrated water resource management is challenging to deliver successfully if the underlying governance structures are not in alignment. One respondent noted:

I think the way that in Oregon our natural resource agencies are these separate agencies from each other, so those silos definitely create institutional barriers to creating the integrated approach and understanding to how these issues impact each other.

Another interviewee expressed frustration about the challenges of Oregon's fragmented water management system:

There is such a plethora of state agencies, and there is no coordinating natural resource body whose job it is to coordinate all of these agencies. So therefore, the agencies tend to feel their portfolio is their first and foremost thing. So to the degree that they are encouraged to work collaboratively to make certain things happen, including a lot that is in the Strategy, it may depend on many things including buy-in, agency resources, commission priorities, user groups...so it is a daunting process.

Finally, one respondent summed up the need for changing Oregon's underlying natural resource governance structure as follows: 
I think this integrated water strategy is so important to get the right outcome. That the silo approach to getting there is not the right approach. Now, whether or not the agencies can exist and still get there or not is the question. I'm not sure it can without insuring that there's some sort of integrated structure in place to show that the coordination is occurring with defined outcomes, targets to get to certain places, measuring our results, and making changes if we're not getting there. But really, we need to change the way we are doing business.

As stated earlier in the chapter, water quality and quantity programs have developed with very different regulatory drivers, stakeholders, and political actors. The Governor's office, through the Natural Resources Office, acts to coordinate these water programs through the Natural Resources Cabinet. The Cabinet is comprised of natural resource agency directors; however, there is no effort to institutionalize a formal coordinated water governing body. Research for this study revealed several other efforts led by the Governor's Natural Resources Office. One was the Clean Water Partnership that focuses on improving water quality and watershed health by 2025 , and includes state and federal agencies. Another is the Oregon Stream Team, created in 2013, and comprised of multiple state natural resource agencies working on coordinating water quality and quantity monitoring data. The Stream Team supports the intent of the Integrated Water Resources Strategy, and the work of the Stream Team does show promise for improving inter-agency data collection and coordination. One respondent commented on the Strategy's efforts to help facilitate greater levels of interagency coordination and communication:

I think some of the fundamental barriers or structures are still there. All the agencies have their statutory authorities and responsibilities. Sometimes those are in conflict. The budgets are all handled separately 
by legislative committees. However, with the Strategy, the agencies are more apt to work together than prior to adoption.

Having shown that Oregon's fragmented water governance system poses challenges to integrated water management, case study research revealed that development of the Strategy did make progress towards better coordination among Oregon's natural resources agencies in the budgeting process. Key informants shared that agency officials viewed the Strategy as the "go to" document for developing their budget packages and funding requests. Although OWRD was tasked as the lead agency, three other state agencies (DEQ, ODA, and ODFW) played a significant role in policy input and development. Agency directors and staff attended the policy advisory and agency coordination meetings on a regular basis. In addition, agency liaisons were designated to attend board and commission meetings at other agencies to keep tabs on Strategy discussions. One respondent commented:

In terms of successes, it did make some progress taking steps in overtaking silos between the different agencies that are involved in different aspects of water. I think they generated a more collaborative approach to monitoring, for example, between water quality and other aspects. This is sort of more coordination and communication between the agencies.

Another respondent observed that the Strategy has produced a more coordinated state agency funding process around water resources programs:

Its biggest success has been a clear and consistent and coordinated message to the legislature about the funding needs for the variety of agencies in order to implement the Strategy. I think that has been a really big success. 
An additional challenge lies with coordination of appointed natural resource agency boards and commissions; these citizen-led boards exhibit both oversight and policy-making functions that effect water management. Oregon's natural resource agency boards and commissions set water-related policies, adopt rules, and influence the budgeting process. Again, there is no formal avenue for coordinating water policies among the different natural resource agency boards and commissions except through the Governor's Natural Resources Office. Oregon's boards and commissions tend to be dominated by organizations that have a vested interest in agency operations, regulations, and outcomes creating a dynamic where collaboration with other agencies is not necessarily rewarded.

Historically, OWRD staff controlled the water planning and implementation process where the emphasis was on meeting water supply needs and other water-related objectives were secondary. It is important to note that OWRD, which is in charge of managing water allocation, led the Strategy's development process and is tasked with overseeing implementation. The interview data suggests that through the development of the Integrated Water Strategy, authority was more diffuse and other water management goals were introduced. Instead of one agency directing water resource planning functions, a variety of state actors and stakeholders were involved, requiring coordination of multiple agency missions, legislative mandates, regulatory and judicial requirements, plans, and actions for horizontal alignment.

As a key informant noted, one organization cannot effectively steer the Strategy, especially given the goal of fully integrating water quality and water quantity. Top-level leadership and political will is an essential part of the process to ensure successful 
integrated water management. The issue of adequate leadership also arose from the interview data as an important factor of success in future implementation. As one interview participant stressed:

You need to have leadership. Whether it comes from a particular subbasin, whether its strong leadership to solve some issue in a collaborative manner, or whether that's at the legislature or at the governor's office. To me, those things are really important.

The presence of this siloed approach to water management remains a key constraint in delivering integrated water management in Oregon. Based on personal knowledge and observations, along with interviews with key informants, special interest groups and constituencies still exert powerful control over agency agendas, budget processes and funding, and program priorities. As explained in this section, Oregon lacks a formal overarching department of natural resources and relies on the Governor's Natural Resource office to serve this coordination function. Without an overhaul of Oregon's natural resource agency management system, delivering integrated water management on a statewide level will remain challenging.

In addition, overcoming tensions between the top-down vertical controls of bureaucratic hierarchies with a horizontal, polycentric management system poses service delivery constraints. Under a horizontal governance model, cooperation is based on collaborative management where empowerment is grounded through knowledge and information sharing, rather than authority based on a legal paradigm (Agranoff and McGuire, 2003). Navigating the complexity of this intersection paradox remains a challenge. 


\section{Consistent Funding, Data Needs, and Staff Resourcing}

Not unexpectedly, the need for adequate funding and staff resources for natural resource agencies was raised as a cause for concern by all participants interviewed for this case study. Oregon's natural resource budgets represent a small fraction of state expenditures, with combined agency budgets constituting about one percent of the state's general fund budget. Over the years, Oregon's natural resource agency budgets have become more reliant on federal funds and lottery dollars, which tend to support specific projects rather than core agency budgets (Oregon Water Resources Department, 2017). In addition, most natural resource agencies rely on permit fees and fees for service that do not cover the full cost of agency services (Oregon Water Resources Department, 2017). Although the Strategy has created a new sense of urgency for funding water-related data needs and staffing, stable funding and resourcing was cited as a consistent barrier to effective implementation of integrated water management programs and policies during the interviews.

Since the adoption of the Strategy, the legislature has set aside funds for capital projects, place-based planning projects, and several water studies, including groundwater analyses. One respondent argued that more funding needs to be set aside for monitoring, data collection, and data coordination between the agencies.

But if you look at the state budgeting process, there is a fair amount of money going to grants and loans for actual projects, but there is far less money going to collection of the actual data we need to make sound decisions about things like groundwater management or demand for water. You could prioritize the goals of the plan along some rational spectrum as well. 
Investing in adequate resourcing and capacity building for state and non-state actors involved in integrated water management was a recurring theme. Personal experience and observation, along with a review of historical budget planning documents, and key informant discussions highlighted an ongoing problem of inadequate and unstable funding, staff resources, and investments in Oregon's water programs. Planning documents show that there is room for improvement around measuring and monitoring both water quantity and quality and greater coordination of water data among natural resource agencies. Interview data and discussions with key informants revealed concerns about inadequate state funding to support the necessary staffing or data to make informed decisions, especially around water allocation. Effective and efficient management of water resources is dependent on up-to-date information about existing conditions, and for projecting future use. In sum, the lack of solid data and staffing to track and manage water in an integrated manner were sentiments echoed throughout the interview process. $\underline{\text { Resolving Value Conflicts }}$

Resolving value conflicts among actors to achieve workable solutions is challenging. Not surprisingly, Western water law (the doctrine of prior appropriation) and the constraint of balancing economic and environmental values emerged from the research as significant barriers to resolving water issues. Key informants acknowledged that discussions around changes to the Western water law were too politically challenging and therefore, a non-starter in the collaborative process. Meeting minutes show that the Policy Advisory Group (PAG) brainstormed discussion topics early in the process but this topic was not directly included. Thus, discussions around Western water law were deemed off the table. 
Although the collaborative network process did create a forum for conducting a broad comprehensive analysis of the integrated water domain, overcoming long-standing value conflicts remained challenging. Interview data revealed frustrations around the inability to resolve long-standing value conflicts. One interviewee summed up the situation as follows:

The challenge is always the diverse set of stakeholders with highly diverse points of views and their perceived water needs. How can we address providing abundant, clean water for all while still respecting a variety of views? How do we balance regulatory versus voluntary actions to address those issues? How to move beyond the status quo of prior appropriation?

Balancing environmental and economic (in-stream versus out-of-stream consumptive) uses was also a significant point of tension that emerged in the PAG meeting minutes and from the interview data. Concerns were raised by environmental and conservation participants that the strategy development process was driven by economic interests with unequal attention given to ecological perspectives. Conversely, representatives from rural interests expressed frustration that in-stream and ecological flows dominated the conversation when livelihoods were at stake. These perspectives underscore the tension between urban and rural interests, and consumptive and in-stream water uses in Oregon. One interviewee characterized the challenge of resolving these conflicts through the collaborative process as follows:

It's [water] a finite resource and everybody wants it in one way or another. I'm not saying that there are winners and losers but there are a lot of conflicts that are hard to resolve. And that was the challenge in the Integrated Water Resource Strategy development; that's just part of the process.... 
Another respondent described the situation in terms of prioritization of limited resources:

There is the continual push-pull in terms of investment of state resources. How much should go towards improving protections for instream resources versus how much should go towards more sustainable consumptive use of water?

Yet, one respondent expressed optimism that the Integrated Water Resources Strategy was a positive step towards overcoming entrenched interests:

...what I am trying to contribute to the effort is a recognition that this isn't necessarily a zero sum game. By that I am meaning, I think there are multiple opportunities, that there can be coordinated work and efforts put forward that compliment not only the environmental concerns but also the economic concerns.

\section{Bottom-up Versus Top-down Approaches}

Another policy area discussed by the PAG members and the Water Resources Commissioners during development of Oregon's Integrated Water Resources Strategy was appropriate geographical scale for implementing integrated water management policies. From discussions with key informants, review of PAG and Water Resource Commission meeting minutes, and interview data it appears that there was widespread concern that implementing integrated policies on a statewide, one-size-fits-all manner was not an effective approach in Oregon. Discussions with key informant interviews revealed that local communities were concerned that a top-down state-led plan might endanger private water rights. This was not surprising, given Oregon's strong populist history regarding water as a private property right, and the researcher's personal experience dealing with water right ownership issues in the Oregon Legislature.

Rural-based interview respondents raised concerns about the urban/rural divide 
and a general distrust of government, especially related to managing water rights. Placebased water planning was identified by these respondents during the interview process as a beneficial way to recognize local needs and regional differences. They cited bottom-up initiatives as an opportunity for local communities to build capacity and work collaboratively with the state in order to understand their water resource challenges and needs, and to identify and implement potential solutions.

Place-based planning emerged as a crucial implementation piece of the Strategy. Under Recommendation 9A, the Strategy specifically lists undertaking place-based integrated water resource planning (Oregon Water Resources Department, 2012, p. 80). A key informant cited the 1980s state-led basin planning effort as an example of a failed attempt to deliver integrated planning in a top-down manner. Basin programs were Oregon's first attempt at formulating a coordinated, integrated state water resources policy (see ORS 536.220) (Bastasch, 2006). These basin plans were prescriptive in nature, complex, and hard to understand (Bastasch, 2006). Key informants explained that the previous basin planning efforts also lacked local buy-in and support. In contrast to the previous state-led efforts, the PAG and Water Resources Commission encouraged adoption of bottom-up, place-based planning efforts. One interview participant shared that:

As long as we have a good process for place-based planning where those things really get worked out around a particular geography and hydrology, I think that can work well. But it needs to be fundamentally ground-up around what is appropriate for a particular basin.

Another respondent discussed how these place-based planning efforts work within the context of the statewide Strategy while empowering local communities: 
Place-based planning allows these conversations to take place at a scale that a statewide strategy may not be able to achieve. Voluntary placebased plans can "roll up" and inform the statewide Strategy. Placebased plans can leverage technical and funding resources available through the Strategy to make more meaningful local impacts. This approach is meant to empower communities to conduct voluntary, place-based integrated water resources planning in consultation with the State.

Place-based planning has received widespread support from both state and nonstate actors; however, all the PAG members interviewed acknowledged that state guidance and oversight are essential. PAG meeting minutes and interview data revealed that initially, there appeared to be apprehension by some PAG members about the purpose and makeup of local collaborative efforts. These concerns centered on reaching a common understanding of what place-based planning efforts were intended to achieve. There was general support of local flexibility for solving water management issues, but unease about divesting state authority to manage water resources. Consequently, the Strategy incorporated a recommendation to "develop a template for place-based integrated water resources strategies." The Strategy specifically recognizes that "a placebased planning effort will need to comply with existing state laws and requirements" (Oregon Water Resources Department, 2012, p. 80). Since release of the Strategy, OWRD has issued agency guidelines to support implementation of place-based planning efforts. According to OWRD, these guidelines are a tool to support voluntary planning efforts aimed at meeting instream and out- of-stream needs, including water quantity, water quality, and ecosystem needs.

One interviewee summed up the benefits of place-based planning as thus: 
In many ways, place-based planning makes sense, in terms of actually developing a plan for Oregon's water resources and thinking about even the types of supply and development projects we were talking about funding. Those needs should come out of a more local or regional plan for water resources. I see the value in doing that kind of planning. Some of the folks in the conservation community have concerns about place-based planning because it could become a vehicle for more local control; there's always the fear that there will be some effort not to follow state laws and regulations.

The scholarship around water governance and watershed-scale collaborative processes also highlights the importance of implementing integrated water management at the appropriate spatial scale. Pahl-Wostl (2015) asserts that "governance and management at the watershed scale leads to a more holistic and integrated approach in terms of management goals and objectives, distribution of benefits, and decision making that results in balanced management" (p. 99). "Spatial scales for water governance have implications for both the biophysical boundaries and the actors involved in a governance system” (Pahl-Wostl, 2015, p. 99).

\section{Climate Change and Water Scarcity as Key Policy Drivers}

Addressing climate change and water scarcity emerged as key policy drivers underlying the Strategy development process. Recognizing that impacts of climate change are very local, almost every respondent described how climate change is affecting water resources. All interview participants discussed the impacts of the 2016 drought and how that galvanized parties to work together to develop short-term solutions. One interviewee shared that climate change has created a greater level of awareness among the general public including an increased focus on conservation: 
We have broad recognition that we have a finite amount of water and that climate change is happening, and that affects our water availability, so we are now seeing an increased focus on conservation by all the parties, all the users.

One respondent highlighted more specific impacts they have observed around climate change:

Overall, Oregon is experiencing warmer temperatures and more precipitation in the form of rain instead of snow. This raises concerns especially in the agricultural community that relies on snowpack as "natural storage" to deliver water over a longer period of time.

Another respondent reflected on how climate change has elevated the need for a more sophisticated and resilient water management system with greater attention to the instream needs:

The main value is recognizing that our water resources is rapidly coming under more and more stress from several different sides. And a need to really start to modernize our management systems so that it's more resilient in dealing with climate change and drought. Also, it has generated a greater awareness of the in-stream needs for water, a more refined understanding of in-stream needs than we have had previously.

Concerns were raised that the state's response to climate change and drought management focused on infrastructure investments, such as piping irrigation ditches and building water supply storage impoundments, rather than innovative and less costly alternatives such as water demand management or conservation. Not surprisingly, interview responses varied widely around preferred strategies for addressing climate change impacts. With that said, a clear consensus around the appropriate responses to climate change was not achieved through the collaborative network process. 


\section{Discussion Summary}

The case study findings show that in regards to shaping Oregon's integrated water policy, a collaborative network approach created a more conducive environment for meaningful dialogue among vested interests, built some levels of interdependency and trust, thus generating a wider array of policy options than through previous legislative and bureaucratic efforts. However, long-standing political, legal, and institutional challenges continue to constrain effective integrated water management and the delivery of integrated outcomes in Oregon. Table 5.3 summarizes the strengths and weaknesses of Oregon's collaborative network process around integrated water management. 
Table 5.3 Strengths and Weaknesses of Oregon's IWRS Process

$\begin{aligned} & \text { Strengths of Collaborative Network } \\ & \text { Governance Process }\end{aligned}$
- Engaged a broad range of stakeholder
groups

Weaknesses of Collaborative Network Governance Process

- Process created a forum for building relationships, and some trust and social capital

- Fragmented institutions and water governance structure

- PAG was not a permanent body

- Did not create interdependencies across stakeholder groups

- Greater transparency and opportunity for stakeholder participation

- Consensus decision making process

- Collaborative process created shared learnings and greater understanding of different viewpoints

- Not strong incentives for special interests to stay at table; weak organizational learning

- Challenging to reach consensus on balancing in-stream vs. out-of-stream flows

- Lack of strong leadership due to tensions between horizontal and vertical governance structure

- Promoted inter-agency coordination and communication

- Difficult to reconcile competing values (i.e., economic vs. ecological)

- Greater emphasis on addressing water quantity needs vs. water quality or in-stream needs 


\subsection{Comparison of Oregon Case Study to Network Governance Literature}

In this section, I revisit collaborative and network governance literature and compare my case study research results with the theoretical framework underpinning network governance. For this analysis, I focused on the collaborative policy network tradition which emphasizes pluralistic process models of public policy decision-making and focuses on the relation between the state and interest groups and the influence on policy making (Keast et al., 2014; Klijn \& Koopernjan, 2012). The Oregon case study represented a collaborative network that was formed "to deal with very complex problems that no one organization or group is able to deal with on their own" (Keast et al., 2014, p. 34). In this case, a network of state and non-state actors convened to develop policies around integrated water management. The following section includes a discussion of how network governance theoretical constructs performed in the Oregon case. For each topic area, I present a brief review of the applicable theory, an application of the theory in the Oregon case, and the resulting lessons learned.

Strength of network ties has a bearing on how the policy network is governed. Social network exchange theory emphasizes that actors enter into a social network for a reason, usually some goal attainment or resource exchange (Koliba et al., 2011). The rules governing these resource exchanges "are shaped by the formality of the relations and the depth of coordination between two or more network actors" Koliba et al., 2011, p. 101). When two actors enter into horizontal relationships, they break the traditional principal-agent dynamic of vertically arranged relationships and facilitate new ways of thinking (Koliba et al., 2011). Strong ties between interdependent actors helps enable the policy framing and formation process (Koliba et al., 2011; Klijn \& Koopernjan, 2012). 
The case study research findings illustrate that a collaborative, network approach to water policy development adds value by developing ties between network actors thus enabling new ways of problem framing and policy development. As the theory predicted, building interpersonal relationships and horizontal ties among non-state actors did result in higher levels of cooperative behaviors than what is generated through other policymaking arenas (i.e., legislative or bureaucratic rule making). This was accomplished by fostering shared learning, knowledge transfer, and a greater understanding of different perspectives and viewpoints around water during Oregon's collaborative process.

Having illustrated that, I posit that the ties between network actors in the Oregon case were still relatively weak due to the limited duration of the network, the opportunity for non-state actors to engage outside the collaborative process to shape policy, legal barriers, and Oregon's fragmented institutional framework. Despite the weak network ties, the collaborative process did generate agreement on a number of important areas where previous efforts had stalled. Interview findings revealed that the network helped elevate the need for more robust water-related data collection and monitoring to inform decision makers. It also galvanized support for greater funding of water programs identified in the Strategy. Furthermore, the recognition of place-based integrated water planning efforts as an important tool for achieving integrated water management at the local level emerged from this process. Not surprisingly, however, network actors failed to reach consensus around how to fund or prioritize the many recommendations included in the Strategy or around highly contentious policy issues as balancing in-stream and out-ofstream uses, water measurement requirements, and methods for resolving over-allocation of existing water rights. 
Trust between network actors is cited often in the literature as a vital component of successful governance networks (Klijn \& Koopernjan, 2012; Keast et al., 2014; Provan \& Kenis, 2007; Ansell \& Gash, 2008). Trust is an important asset to achieve in networks as it "reduces uncertainty and facilitates investments in collaborative processes among interdependent actors with diverging and sometimes conflicting interests" (Klijn \& Koopernjan, 2012, p. 8). The literature also stresses that trust enhances the possibility that network actors will share information and develop innovative solutions (Klijn \& Koppenjan, 2012).

Regarding building trust between actors in the Oregon case, interview findings revealed another key component of the story. It appears that Oregon's collaborative network approach created a new forum for information exchange and mutual learning. This dynamic helped foster collaboration and trust necessary to develop consensus around water policies for the Integrated Water Strategy. Prior to this effort, non-state actors were frequently focused on protecting their own self-interests through the contentious legislative or regulatory process. Under these circumstances, there is little incentive to understand where other actors are coming from or to reach consensus on water issues. It also appeared that non-state actors on either end of the ideological spectrum were skeptical of state actors' motives. Unfortunately, relationships and ties that formed among members of the Policy Advisory Group did not necessarily translate into reciprocity in the political or regulatory arena, especially once the policy formulation process convened.

Democratic anchorage and accountability play a key role in the success of networks. Sorensen and Torfing (2005) posit that "governance networks are 
democratically anchored to the extent that they are properly linked to different political constituencies and to a relevant set of democratic norms that are part of the democratic ethos of society" (2005, p. 201). Oregon's case did lend legitimacy to the policy network both formally (via elected officials) and informally (via bureaucrats) representing citizens as well as particular interest groups.

Oregon's network formed in response to legislation passed by democraticallyelected politicians. HB 3369 directed that a wide range of interests be included in the Integrated Water Resources Strategy development process. The policy network created to develop integrated water policies included non-state actors (organizations and interest groups) that were accountable to their constituencies, along with state actors (federal and state agencies) that were accountable to the public and the interest groups they serve. Government agencies represent state power and legitimacy, but also provided sources of information that helped inform network policy decisions and ensure that public values are represented. Furthermore, the network process followed democratic rules and norms by adopting a transparent decision-making process defining how decisions were made within the network (through a consensus-based process).

Social capital is formed in the bonds between actors and linked to organizational learning and knowledge transfer (Keast et al., 2014). Social capital, as defined by Putnam (1993) "refers to features of social organization, such as trust norms, and networks, that can improve the efficiency of society by facilitating coordinated actions" (p. 167). The case study research revealed that Oregon's collaborative network process developed horizontal ties between actors and in turn did generate some level of social capital during the initial two-year process. This dynamic created opportunities to frame 
recommendations around integrated water policies in a collaborative rather than adversarial manner.

It is important to recognize that since the PAG had not been institutionalized, the group disbanded once the Strategy development process was complete. The network policy process was short-lived, and thus preserving social capital outside of the PAG was challenging due to deep-rooted philosophical and value divides among non-state actors. It may be that in order to build upon the social capital created through the collaborative process, a more durable network institution was needed. Similarly, this holds true for interactions among state actors given the fragmented nature of Oregon's natural resource agencies. Case study research findings revealed that development of the Strategy provided a new forum for regular communication and coordination among the key state agencies involved in water management. Specifically, this was reflected in a more coordinated budgeting process tied to policy recommendations outlined in the Strategy. Although the Strategy added capacity for inter-agency coordination and collaboration, it did not result in a formalized institutional arrangement.

\subsection{Summary}

This chapter provided an in-depth account of Oregon's water history, key water governance frameworks and institutions, and the legal underpinnings shaping and constraining Oregon's integrated water management efforts. In 2009, a statewide integrated water resources strategic planning process was launched to bring together various sectors and special interests to work towards a common purpose of meeting future water needs for economic and environmental purposes. This effort resulted in development of a widely supported strategic plan for Oregon's water future. 
Through the case study, I reflected on my own experiences, researched archival data, observed collaborative processes, interviewed network participants to glean a diverse range of perspectives, and tested theoretical constructs to arrive at my research findings. Key informant and interview data served to illuminate important points about the benefits and challenges of collaborative policy networks that played a key role in informing the research.

In conclusion, viewing this case through a collaborative network theoretical lens facilitated a greater understanding of the integrated water policy processes in Oregon. What I observed and gleaned through my research is generally consistent with key themes that emerged in the literature; however, a few new themes arose that build upon existing theoretical frameworks. The Oregon case revealed a hybrid governance network depicting both vertical ties (within bureaucracies) and horizontal ties (through the collaborative network process). In the next chapter, I will address my original research questions, provide a comparative analysis of the two case studies, and present additional theoretical findings. 


\section{CHAPTER 6. COMPARATIVE ANALYSIS OF CASES}

In the previous two chapters, I examined two case studies using the analytical lens of collaborative and network governance theory to unpack the complexities of collaborative water governance. As part of this comparative case study analysis, the aim was to gain a better understanding of the role of networks in developing integrated water policies that successfully guide implementation and ongoing governance. This research examined the role of state and non-state policy actors, conditions for collaboration, strength of actor ties, opportunities for collective learning, democratic anchorage, development of trust and social capital, and barriers to success in two. In this chapter, I revisit my original research questions by conducting a comparative analysis of findings

for the two cases. Also included is a section comparing the treatment of tribal water rights in each case study. Lastly, a summary of comparative points is provided along with a review of each network model.

\subsection{Comparative Analsysis of Research Findings}

To review, integrated water management is a wicked problem facing elected officials, policy makers, public adminstrators, and water managers today. In order to gain a better understanding of how collaborative networks perform in the context of integrated water management, this study considered the following seven research questions:

1. How are the different governance networks structured and how are their boundaries determined?

2. How do the collaborative processes work, and what role do state and non-state actors play in setting water policies in New Zealand and Oregon? 
3. What functions do they carry out? How are the networks governed, and how are policies developed in the collaborative?

4. How are these networks held accountable? To what extent are the networks democratically anchored?

5. How fully are surface water and groundwater, water quality and quantity, and land use integrated in management systems under New Zealand and Oregon governance structures?

6. What are the legal, political, and institutional barriers affecting water governance in New Zealand and Oregon?

7. How did issues such as climate change and water scarcity influence approaches to water management?

What follows is a comparative analysis of case study findings in response to each research question. A cross-case comparison table outlining characteristics found in response to each research question is presented in Table 6.1. 
Table 6.1 Comparative Analysis on Research Guide Question Responses

\begin{tabular}{|c|c|c|}
\hline Research Question & New Zealand Case & Oregon Case \\
\hline $\begin{array}{l}\text { Q1: Network structures and } \\
\text { boundaries? }\end{array}$ & $\begin{array}{l}\text { Long-term collaborative } \\
\text { network through LAWF. } \\
\text { Central and regional policy } \\
\text { focus. Plenary and small } \\
\text { groups. }\end{array}$ & $\begin{array}{l}\text { Limited duration PAGs to assist } \\
\text { with Strategy design and } \\
\text { update. State policy focus with } \\
\text { input from federal and technical } \\
\text { advisors. }\end{array}$ \\
\hline $\begin{array}{l}\text { Q2: Collaborative process; role } \\
\text { of state and non-state actors }\end{array}$ & $\begin{array}{l}\text { Collaborative, consensus-based } \\
\text { process. Non-state actors in } \\
\text { LAWF with 'active observer' } \\
\text { state actors. Blurred lines of } \\
\text { power and authority. }\end{array}$ & $\begin{array}{l}\text { Collaborative, consensus-based } \\
\text { process. State and non-state } \\
\text { actors both actively } \\
\text { participated. Clear lines of } \\
\text { power and authority. }\end{array}$ \\
\hline $\begin{array}{l}\text { Q3: Network functions, } \\
\text { governance, and policy } \\
\text { development }\end{array}$ & $\begin{array}{l}\text { Autonomous process. Define } \\
\text { and frame water problems and } \\
\text { design policy solutions. } \\
\text { Mutually acceptable principles, } \\
\text { rules, and norms. Strong } \\
\text { internal social capital. }\end{array}$ & $\begin{array}{l}\text { State-led process. Define and } \\
\text { frame water problems and } \\
\text { recommend policy solutions. } \\
\text { Mutually acceptable principles, } \\
\text { rules, and norms. Weak internal } \\
\text { social capital. }\end{array}$ \\
\hline $\begin{array}{l}\text { Q4: Network } \\
\text { accountability/democratic } \\
\text { anchorage }\end{array}$ & $\begin{array}{l}\text { Government granted political } \\
\text { legitimacy. Democratic } \\
\text { anchorage through Ministers } \\
\text { and government officials, and } \\
\text { connection to LAWF } \\
\text { constituencies. Weak public } \\
\text { process. }\end{array}$ & $\begin{array}{l}\text { Government granted political } \\
\text { legitimacy. Democratic } \\
\text { anchorage through Governor, } \\
\text { elected officials, government } \\
\text { officials and PAG } \\
\text { constituencies. Stronger public } \\
\text { process. }\end{array}$ \\
\hline $\begin{array}{l}\text { Q5: Integrated water } \\
\text { management and governance } \\
\text { structures }\end{array}$ & $\begin{array}{l}\text { Water quality, water quantity } \\
\text { and land use managed by } \\
\text { regional government. Historic } \\
\text { lack of central oversight created } \\
\text { patchwork of water policies. }\end{array}$ & $\begin{array}{l}\text { Water quality, water quantity } \\
\text { and land use managed by } \\
\text { separate agencies and at } \\
\text { different spatial scales. } \\
\text { Conjunctive management } \\
\text { between surface \& } \\
\text { groundwater. Multi-level } \\
\text { implementation. }\end{array}$ \\
\hline Q6: Constraints & $\begin{array}{l}\text { Weak scope of network } \\
\text { authority. Bureaucratic inertia. } \\
\text { Insufficient social and political } \\
\text { capital between LAWF and } \\
\text { state actors. }\end{array}$ & $\begin{array}{l}\text { Legal (prior appropriation } \\
\text { doctrine); fragmented } \\
\text { governance structure; deep- } \\
\text { seated value divides; inadequate } \\
\text { resources; data gaps. }\end{array}$ \\
\hline Q7: Climate change & $\begin{array}{l}\text { Not a key policy driver in } \\
\text { freshwater reforms but listed in } \\
\text { LAWF report. }\end{array}$ & $\begin{array}{l}\text { Key policy driver in } \\
\text { development of Strategy. }\end{array}$ \\
\hline
\end{tabular}




\section{Research Question \#1, Governance Network Structures and Boundaries: How are the different governance networks structured and how are their boundaries determined?}

New Zealand's government asked LAWF to recommend potential reform of New Zealand's fresh water management - to identify shared outcomes and goals, and options to achieve them (Land and Water Forum, 2010). LAWF represents a multi-actor, horizontal governance network that provides an avenue for framing and developing integrated water policies. Over 60 non-governmental interest groups participate in the Land and Water Forum and it meets regularly (monthly in most instances) to discuss water policies. The smaller group, consisting of 30 major stakeholders from primary industry, electricity generation, tourism, environmental and recreational interest groups, and $i w i$, serves as the core group to deliberate policy details and present recommendations back to the large group. Scientists and other experts provide technical and policy advice throughout the LAWF process. Representatives from local and central government are non-voting members (called active observers), and participate in the small group discussions. LAWF operates as an autonomous organization rather than part of a specific government entity, and is led by an independent chair. Although staffing is provided through an independent secretariat, the central government provides some of LAWF's funding.

LAWF was charged by government ministers with charting a new course for freshwater management. Through a collaborative process, the Forum developed specific terms of reference (operating principles), protocols for participation, and policy goals for their work. Forum participants have discussed, deliberated, and formulated policy 
recommendations around a wide range of issues including, but not limited to, improving water quality, addressing water over-allocation, improving surface and groundwater management, addressing $i w i$ water rights, protecting and improving drinking water quality, protecting recreational and ecological values, and improving regional water governance. Regarding spatial boundaries, the Forum develops policy recommendations aimed at both the central and regional levels, as New Zealand water governance system includes top-down policy guidance from central government with bottom-up implementation happening at the regional level. LAWF's operating time frame changed during the course of the freshwater reform process. Document reviews showed that the Forum was originally scheduled to convene for one year; however, government ministers extended LAWF's timeframe to continue its progress. As of 2017, LAWF had been meeting continuously for over nine years.

In the Oregon case, the collaborative network policy process similarly brought together a variety of actors (public sector, private sector, and NGOs) to develop Oregon's first Integrated Water Resource Strategy. In contrast to New Zealand, Oregon's collaborative network process was nested in state government, and thus did not operate autonomously. OWRD served as the lead government agency in developing the strategy, working in conjunction with other state and federal agencies. OWRD hired a professional facilitator and convened a stakeholder policy advisory group that met regularly for two years (its intended duration) to help frame and develop integrated water policy recommendations. It was reconvened in 2016 to assist with policy updates, although this iteration was comprised of mostly different representatives than the first PAG (only two members overlapped with the first PAG). Ultimate authority for adopting the Strategy 
resided with the Oregon Water Resources Commission, whereas funding for implementation was approved by the Oregon legislature.

The Strategy provided a blueprint to better understand and meet Oregon's instream and out-of-stream needs taking into account water quantity, water quality, and ecosystem needs (Oregon Water Resources Department, 2012). Oregon's Water Strategy was intended to help address water management challenges created by boundary problems by developing recommendations that transcend fragmented governance arrangements. Oregon's network process attempted to work against this silo effect by providing a forum for state and non-state actors to coordinate and collaborate around integrated water policies.

In sum, both network cases represent a shift from top-down command and control water policy development to a horizontal, collaborative effort engaging a broader set of interests. These collaborative networks helped move beyond the status quo by bringing together actors representing a variety of interests and areas of expertise to deliberate about a broad range of policy alternatives. However, challenges emerged during the transition to implementation phases in both cases. More detail about how the collaborative policy process worked, including barriers to success, is provided later in this chapter.

\author{
Research Question \#2, Role of State and Non-state Actors in Collaborative \\ Governance: How do these collaborative processes work, and what role do state \\ and non-state actors play in setting water policies in New Zealand and Oregon?
}


The New Zealand case represents a collaborative network of predominantly nonstate actors focused on framing and designing freshwater policies. Elected and appointed government leaders provided legitimacy to LAWF by endorsing creation of the Forum, providing partial funding and other resources, and encouraging stakeholders to engage in freshwater reforms through this process. The collaborative network created a new opportunity for direct dialogue among disparate interests, development of a shared commitment and mutual understanding around water problems, and building trust and social capital, primarily among non-state actors.

Over 60 interest groups representing non-state actors have been involved in LAWF, capturing a wide range of viewpoints and perspectives. Although LAWF was created as an autonomous trust, state actors participated regularly throughout the policy design process. LAWF met monthly and reported to cabinet ministers on a regular basis. On occasion, cabinet ministers would attend and address the plenary group. In addition, agency staff attended LAWF meetings regularly as "active observers."

Case study interviews and researcher observations suggest that high levels of trust, commitment, and social capital were generated among non-state actors. This was due to a number of factors including robust social ties among network actors, the length of the collaborative process, stable staff resourcing, and strong leadership by a wellrespected and influential chair. As a result, LAWF produced four freshwater reform reports detailing approximately 250 consensus-based water policy recommendations from 2009 through 2015. The findings from this research suggest that in the New Zealand case, the collaborative network process helped create new interdependencies among non-state actors with a strong commitment to LAWF as an institution. However, the collaborative 
process did not appear to engender the same level of interdependency between LAWF and state actors. Key informant and participant interview data revealed tensions around government adoption of LAWF's recommendations. The government did accept and enact many of LAWF's key recommendations; however, they also rejected or modified others.

The LAWF network did not displace or eclipse the power of elected or appointed government officials, thus ultimate decision-making power still resides with democratically-elected government ministers (Keast et al., 2014). However, discussions with key informants and interview data revealed that some LAWF members were under the impression that once the collaborative network had reached consensus on water policies, then the government would adopt these recommendations. Document reviews and key informants confirmed that government ministers did not commit to ceding decision-making authority. LAWF's Terms of Reference document underscores that the government would continue to make policy decision affecting water management and the design of policy instruments, legislation, and regulations was excluded from LAWF's scope. Nonetheless, tension about lines around authority (vertical control versus horizontal ties) caused erosion of trust and social capital between LAWF and the government. Ministers were accused by some network actors of 'cherry picking' policies it favored rather than supporting LAWF's collectively-formulated recommendations causing some actors to leave the network. These factors suggest that LAWF's real political power was limited in that government ministers and bureaucrats maintained ultimate decision-making authority around adoption and implementation of integrated water policies. 
In contrast, under the Oregon case, state actors led the collaborative network process to frame and develop the Integrated Water Strategy. OWRD served as the lead agency working closely with DEQ, ODFW, and ODA. The Oregon Water Resources Commission played an important guidance and oversight role, along with the Governor's natural resources office. Non-state actors played a framing and policy guidance role through sharing perspectives and knowledge, lending political credibility to the process, and helping foster stakeholder buy-in and support for the strategy. Interview data suggest that the collaborative network process's greatest assets were to develop and enhance new and existing actor relationships, foster shared learning, and create a strategy for advancing integrated water management in Oregon.

From the onset, the lines of power and authority in the Oregon case were clear; the collaborative network served to inform and guide development of integrated water policies for inclusion in the Strategy. Decision-making authority and power remained with state actors (i.e., legislators, the governor, agencies, boards and commissions); however, as described in more detail in research question \#6 below, Oregon's fragmented legal and institutional arrangements create barriers that hinder the state's ability to manage water in an integrated manner. The Oregon case study research implies that the collaborative network process served an important role by promoting levels of coordination and collaboration across state agencies. While recognizing that, tension between horizontal ties and vertical ties continue to constrain the state's ability to deliver effective integrated water management. 


\section{Research Question \#3, Network Governance and Functions: What functions do the networks carry out? How are the networks governed, and how are policies developed in the collaborative?}

In the New Zealand case, LAWF was designed to bring together non-state actors to define and frame water problems and design policy solutions. State actors, primarily government policy analysts, had served this function previously. Under the LAWF process, state actors serve solely in an advisory role to the collaborative. Research findings show that LAWF brought together a wide range of interests with divergent viewpoints to reach consensus on freshwater policy reforms, whereas previous government-led efforts had failed. Through the collaborative process of dialogue, mutual learning, and problem framing, LAWF built a significant amount of trust and social capital among its membership. Ultimately, the results of this collaborative process were transformed into a series of policy recommendations that had high levels of support among water users, stakeholders, and the general public. The LAWF process, however, faced challenges when it came to government acceptance and implementation of a number of recommendations.

As an autonomous, unelected organization, LAWF is self-governed through a set of mutually acceptable principles, rules, and norms. Specific terms of reference and protocols for participation were fashioned to guide the collaborative network process. Policy development, led primarily by the small group (consisting of 30 stakeholders), is brought to the plenary (large) group for final consideration and approval. Members are guided through agendas set by chair and the LAWF trustees (three members of the small group). Researcher observations and interview data revealed that the independent chair 
served an important role as 'broker' of the collaborative. The chair's persuasive influence fostered collaboration among network actors helping to facilitate consensus on a wide range of policy recommendations.

With respect to incentives for ongoing stakeholder engagement, interview findings suggest that the Ministers' imprimatur for LAWF acted as an incentive for nonstate actors to participate and remain at the table. Specifically, the ministers at the time emphasized that LAWF was the "go to" forum for developing consensus-based freshwater policies. This commitment by government ministers helped lend legitimacy to the LAWF process and discourage stakeholders from meeting separately with government officials to forward their own agendas.

Shaped through continuous interactions, collaborative learning, and strong leadership, the LAWF network process helped create strong horizontal connections or ties among non-state actors and deepen trust, commitment, and shared narrative in the freshwater space. Generation of social capital allowed network actors to interact with each other in new ways to achieve collective ends. Hence, through these collaborative arrangements, LAWF was able to move beyond the bureaucratic and political inertia that had plagued previous efforts to formulate new water policies.

To compare, the collaborative process that formed around Oregon's Integrated Water Resources Strategy convened state and non-state actors to define water problems, frame solutions, and provide policy recommendations to decision makers and bureaucrats. One major distinction between the two cases was the role of state actors in the policy network. In Oregon, the collaborative PAG process was led by the primary state actor, the Water Resources Department. This was in contrast to the New Zealand 
case where LAWF worked alongside state actors; however, it operated as an autonomous organization with independent staff. OWRD provided dedicated staff to manage the Strategy development process with assistance from other state and federal agencies. In contrast to the New Zealand case, Oregon utilized an independent facilitator hired on contract, rather than appointing a chairperson to lead and facilitate the meetings. During the second round of the Policy advisory group meetings held in 2016, OWRD staff facilitated the meetings to update the Strategy.

Similar to New Zealand, Oregon's collaborative network operated under a set of mutually acceptable principles, rules, and norms. The terms for consensus-based decision making, information sharing among network members, project team and facilitator roles, along with agency and commission roles were discussed and adopted by the PAG. The advisory group met regularly for two years to share information, transfer knowledge, promote mutual understanding, and build relationships. During the two-year process, non-state actors developed horizontal ties that allowed for development of some consensus-based policies around water issues. Ultimately, this process was transformed into a series of policy recommendations that formed the basis of the Integrated Water Resources Strategy.

Two important points of distinction between the cases are also worth noting. First, in the New Zealand case, LAWF was an ongoing process that enabled development of long-term relationships, trust, and social capital among network actors that might not have occurred outside of the network process. Although there was no formal agreement preventing actors from leaving the network, direct lobbying outside the LAWF process was discouraged by government ministers, serving to limit points of policy access. In 
contrast, Oregon's policy advisory group was chartered by the government and disbanded after the Strategy document was adopted. It did not transition into an ongoing, independent deliberative body as was the case in New Zealand. Another policy advisory group was formed in 2016 to advise state actors on Strategy policy updates; however, this effort was short-lived and engaged different actors from the previous incarnation. Lack of continuity and consistency among non-state policy actors were raised during the case study interview process. Second, stakeholders who participated in Oregon's collaborative policy process continued interactions with legislators and agency staff throughout the collaborative process, thus affording non-state actors multiple points of access to the policy process. This utilization of multiple points of access to the policy process was discouraged in New Zealand case.

The research findings highlight that the New Zealand case exhibited the ability to reach consensus on a wider range of water policies than the Oregon case. This may be attributed to a number of factors, including the durability of the network, strong leadership, incentives for stakeholders to participate, or legal and institutional constraints that are discussed in more detail in question 5 below.Figure 6.1 presents a diagram depicting comparative water policy drivers in the two case studies. Both countries utilize national legislation and policies for freshwater management; however, there is much less room for sub-national interpretation and standard setting in the United States compared to New Zealand. The color shows the range of flexibility with red signifying strict implementation. In contrast to the United States, the nature of the Resources Management Act in New Zealand is to provide a national template but allow regional governments a fair amount of flexibility in setting water quality standards and allocation schemes. 
Figure 6.1 Comparative Water Policy Drivers in New Zealand and Oregon, U.S.

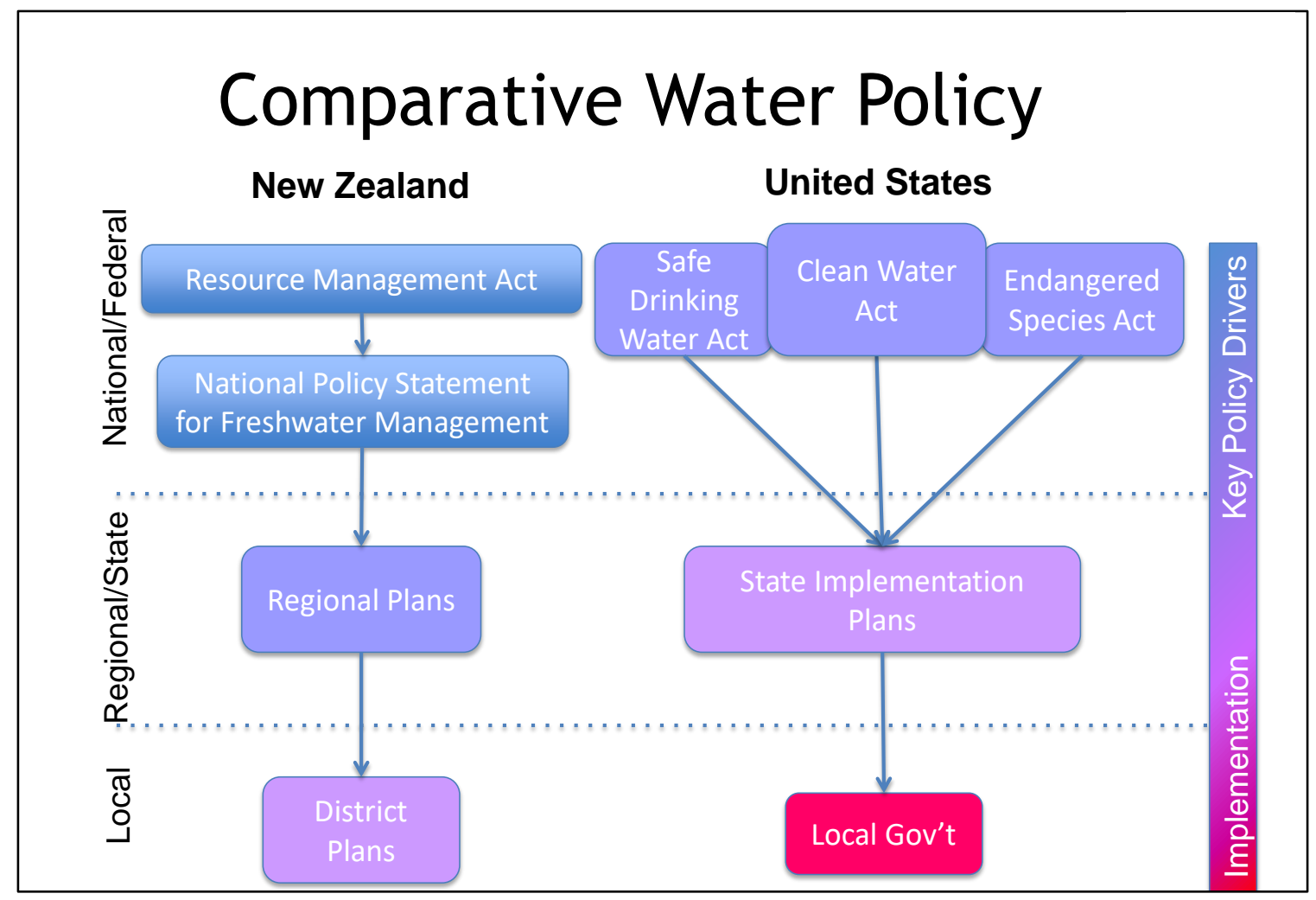

Research Question \#4, Democratic Anchorage: How are these networks held accountable to the public? To what extent are the networks democratical anchored?

To review the concept of democratic anchorage, Sorensen and Torfing posit that "governance networks are democratically anchored to the extent that they are properly linked to different political constituencies and to a relevant set of democratic norms that are part of the democratic ethos of society" (p. 201). The authors (Sorensen and Torfing, 2005, p. 201) define democratic anchorage as comprising a combination of: 
control by democratically elected politicians;

accountable to the territorially defined citizenry;

representative of the membership base of the participating groups and organizations; and

following the democratic rules specified by a particular grammar of conduct.

Applying these criteria, the research illustrates that both case studies were democratically anchored; however, the New Zealand case demonstrated lower levels of transparency and public accountability.

New Zealand's collaborative network process was endorsed and supported by democratically-elected politicians (cabinet ministers who also serve as members of parliament). The network was accountable to New Zealand citizens mainly through linkages with elected ministers; however, LAWF members are unelected representatives of $i w i$, stakeholders, and special interest groups. One could arguably point out that even though LAWF members are not directly answerable to the public, they are accountable to their own constituencies and members of their participating organizations. Finally, LAWF developed and followed specific rules of conduct that were endorsed by the entire group. These guidelines serve as the formal rules of conduct for network decision making. It is important to note that the network members were self-selecting, and it is unclear how actors gained access to these positions. Some scholars have characterized LAWF as a group of policy elites (Eppel, 2014), which might suggest the potential for power imbalances due to varying degrees of access to knowledge and resources among the members. 
Oregon's collaborative process was similarly supported by democraticallyelected politicians (legislators and the governor). In contrast to the New Zealand case where LAWF participation occurred through a self-selecting process, OWRD identified participating groups and individuals for inclusion in the collaborative process. In both versions of the PAG (2012 and 2016), the Oregon Water Resource Department Director's Office contacted special interest and stakeholder groups to solicit names for the PAG. The Director also conferred with counterparts at the three other state agencies (Oregon Department of Agriculture, Oregon Department of Environmental Quality, Oregon Department of Fish and Wildlife) and the Governor's Office. The intent was to find perspectives from all types of water quantity and water quality categories -- conservation, tribes, public interest groups, municipalities, special districts, irrigated agriculture, nurseries, cattlemen, dairy industry, counties, etc. The other consideration, however, was geographical diversity. The Water Resources Director's office then contacted individuals asking whether they would be willing to serve as individuals, not industry representatives. The final step was a letter of appointment from the Director to the prospective PAG member (personal communication with OWRD staff, March 12, 2017).

It is important to note that the effort to select individuals who did not represent a constituency was particularly strong in the 2016 PAG reconvening. Advocacy groups were only afforded a seat at the table through a volunteer representative rather than a staff person to serve on the PAG. OWRD sought participants that would not be representing a particular stakeholder group, but rather individual viewpoints. It appears that the agency's aim was to reduce political posturing in the PAG; however, this discounts the fact that policy recommendations may eventually be delivered through legislative bills 
and budget packages that must be shepherded through the political system.

The Oregon collaborative process was accountable to citizens through linkages with elected politicians, government staff, and gubernatorial-appointed Water Resources Commission members who ultimately adopted the Strategy. The Strategy project staff hosted workshops, open houses, and public surveys, and consulted with additional stakeholder groups not directly involved in the PAG to solicit feedback on the Strategy. Reports and updates were delivered to elected officials at legislative public hearings and information sessions, and through interaction with the Governor's office. In addition, the process was accountable to the membership of the participating groups and organizations. Prior to reaching consensus on policy recommendations, network actors communicated and consulted with their members and constituencies. Finally, the Oregon collaborative process developed and followed specific rules of conduct endorsed by the entire group.

Both cases afforded a greater diversity of voices in the water policy framing process than through either parliamentary or legislative processes (Sorensen and Torfing, 2007). However, a key distinction was public access to information appeared to be a more opaque process in New Zealand than in Oregon. As a researcher who had become familiar with the LAWF process, I found it challenging to access information about future meetings or discussion documents. Although the meetings were not closed to the public, they were not widely advertised. This may be due to the fact that LAWF was not considered a government agency, although their efforts were supported, in part, by government funding. In contrast, information about Oregon's process was easy to access, and all meeting agendas and materials were posted on the agency's website. Opportunities for public comment were included at each Policy advisory group meeting, 
and several rounds of open houses and surveys were conducted to solicit public input during Oregon's Strategy development process.

\section{Research Question \#5, Water Governance Institutions: How fully are surface water and groundwater, water quality and quantity, and land use integrated in management systems under New Zealand and Oregon governance structures?}

Reflecting on the issue of water governance, New Zealand's underlying water governance and institutional framework created a greater opportunity for integration between water quality, quantity, and land use. New Zealand's Parliament and Ministries establish the policy framework for water management, whereas the Resource Management Act (1991) serves as the primary legislation for water governance (Eppel, 2014). Responsibility for achieving policy outcomes and implementing integrated water management lies with New Zealand's regional governments (Eppel, 2014). These regional governments, known as regional councils, are organized by catchment (or watershed), and are responsible for planning and managing water quality, quantity, and land use decisions through development of regional freshwater plans and issuance of resource consents. Regional freshwater plans contain policies that make direct connections between land use changes and impacts to water resources.

New Zealand's regional governance framework sets clear authority for sustainable management of water quantity, quality, and land use, and lends itself to integrated water management. Accordingly, the regional elected body is responsible for developing and adopting freshwater plans that provide policy directives for managing water quality and quantity, mitigating soil erosion, flood control, harbor navigation, 
pollution control, and surrounding coastal areas. Territorial authorities (local districts and city councils) provide the actual delivery of infrastructure around water, wastewater, and stormwater, along with controlling the effects of land use on local water bodies. These local authorities must operate within the legal context of the regional freshwater plans.

In sum, New Zealand offers a nested water governance framework involving central, regional, and local governments that aims to avoid duplication or overlapping jurisdictions. As discussed earlier, a key limiting factor of New Zealand's water governance framework has been a lack of strong central directives resulting in a patchwork of regional water policies rather than a fragmented governance system. The LAWF collaborative process was convened to develop and promote central policies to overcome this shortcoming.

In contrast to New Zealand, Oregon's water management system is much more fragmented, with compartmentalized agencies that exhibit individual policy authority. Oregon's water governance regime represents a paradox of horizontal governance intersecting with vertical authority. To illustrate, water quality is guided by the Clean Water Act, a top-down federal policy, and managed by three separate state agencies, the Department of Environmental Quality, Department of Agriculture, and Department of Forestry. All three state agencies receive direction from distinct citizen and stakeholderled boards and commissions, and operate under a patchwork of legal and policy directives. Drinking water quality is overseen by the Oregon Health Authority under yet a different federal law, the Safe Drinking Water Act, and with a distinct state regulatory framework. Additionally, the management and delivery of water and wastewater services occurs through city and county governments, private and public utilities, and thousands 
of special districts, many with overlapping jurisdictions.

Regarding water quantity, surface water and groundwater are regulated and managed by the same agency, the Oregon Department of Water Resources. Yet, the legal framework was developed sequentially without integration in mind. Oregon has been regulating surface water since 1909 , whereas groundwater did not fall under state jurisdiction until 1955 . When surface water availability began to wane, water users began turning to groundwater for their water source, motivating lawmakers to adopt groundwater regulations (Bastasch, 2006.) The Department is supposed to manage groundwater and surface waters conjunctively ${ }^{22}$ if it determines that the two are hydraulically connected (Amos, 2009). Although Oregon is ahead of many Western states in recognizing connections between surface and ground water, the existing groundwater management system tends to be reactive rather than predictive (Amos, 2009). Lack of sufficient scientific data about groundwater availability is cause for concern about the state's ability to manage surface water and groundwater in an effective and integrated manner. The need for more robust data to ensure proper management of the state's water resources was raised repeatedly during the Oregon participant interviews.

Finally, under Oregon law, the availability of water and potential impacts to water quality are supposed to be considered as part of Oregon's land use planning program. Under state regulations, the Water Resources Department and the Department of Land

${ }^{22}$ Conjunctive management refers to where surface water and groundwater are considered a connected system and managed as such. 
Conservation and Development are tasked with ensuring land use compatibility and water availability. However, local land use planners often lack sufficient information about availability of water resources to make long-term decisions. In Oregon, better coordination is still needed to ensure conjunctive management of groundwater and surface water, integrated management between water quality and quantity, and greater connection between land use and impacts to water resources.

\section{Research Question \#6, Barriers to Success: What are the legal, political, and institutional barriers ${ }^{23}$ affecting water governance in New Zealand and Oregon?}

Research revealed that both case studies faced barriers to success in delivering integrated water management. In the New Zealand case, overlapping authority and jurisdiction among national-level government agencies was identified by key informants as a barrier to consistent policy setting. To address this concern, the New Zealand government formed an inter-agency water directorate in 2012 in an attempt to overcome fragmentation and provide coordinated advice to Ministers on freshwater reforms. The directorate includes representatives from Ministry for the Environment, the Ministries of Primary Industries and Business, Innovation and Employment, and the Departments of Conservation and Internal Affairs, Treasury, the Department of Prime Minister and Cabinet, and the Office of Treaty Settlements. Discussions with key informants suggest that communication and coordination around freshwater policies has improved with

\footnotetext{
${ }^{23}$ In this report, use of the term institutional barriers refers to governance arrangements, regulatory
} frameworks, resources, and culture that may serve as barriers to integrated approach to water management. 
adoption of this formalized interagency coordinating group.

Another barrier identified in the New Zealand case study was weak scope of network authority. Although LAWF played a leading role in policy development, its authority around policy prioritization and implementation is limited. Ultimately, New Zealand's elected politicians and government institutions are responsible for adopting and implementing LAWF's policy recommendations and as described previously. Decisions around which LAWF policies to adopt and implement forward reside with central government ministers and ministry staff. Even though LAWF viewed itself as an autonomous network governance institution supported with independent staff, ultimate authority and power reside with state actors as they maintain legal controls and functions (McGuire and Agranoff, 2010).

The manifestation of this tension played out recently when government Ministers rejected LAWF's recommendations on water quality standards and proposed an alternative policy path. After the government released its Clean Water package in late February 2017, a major stakeholder representing conservation and environmental interests pulled out of the collaborative process citing that “...we have considerable good will towards the intent of the collaborative governance process, and towards fellow Forum members who we have worked alongside over the last nine years. But good faith from the Government is an essential component that is required for this process to work, and without that we are left with no choice but to withdraw" (Royal Forest and Bird Protection Society of New Zealand letter to Minister Nick Smith, March 6, 2017). About a year prior, another key conservation stakeholder group had pulled out for similar reasons. Tensions between LAWF and the government remain high and it appears that 
government actions have eroded trust between LAWF and the central government.

In reflecting on this recent turn of events, several factors may have led to this tension. Possible causalities include unrealistic expectations by network actors around their ability to affect government decisions, unclear lines of communication between LAWF and government officials, and a lack of social capital between LAWF and the government. In regards to this latter causal factor, even though government ministers vested LAWF with authority for freshwater reform policy guidance (a role traditionally held by the ministries), turf battles ensued with ministry officials. Discussions with key informants and direct observations indicate that there were tensions around who had the policy lead on some issues. Perhaps another key factor to consider is whether LAWF's collaborative process can be sustained with cyclical changes in stakeholder organizational representatives, elected ministers, chief ministerial policy staff, and senior executives, including LAWF personnel. Although LAWF has made substantial progress in forming consensus around integrated water policies, this recent turn of events highlights the effect of political constraints in the New Zealand's case.

With respect to the Oregon case, document reviews, personal observations, and key informant interviews exposed several challenges to achieving integrated water policies and management through the collaborative process. First and foremost, Western water law (the legal doctrine of prior appropriation) poses a significant legal barrier to developing innovative solutions to managing water quantity. In the West, water rights are closely associated with property rights. The interview data revealed that some interest groups initially were wary of the collaborative Strategy development process. These interests were concerned that Integrated Water Resources Strategy would facilitate 
changes to Western water law and threaten their water rights. Thus, up front in the collaborative policy making process, participants discussed keeping changes to Western water law 'off the table.' Once stakeholders received assurances that the collaborative process would not undermine existing water rights, there was greater opportunity for engagement from all parties.

With that said, the intransigent nature of Western water law remains a major limitation to water policy innovation in Oregon. For example, even though Oregon has one of the most advanced water conservation programs in the West, conserving water for in-stream flows remains challenging because prior consumptive claims have precedence over newer in-stream claim supporting conservation and wildlife purposes. To provide for in-stream flows, OWRD must make a determination that a new conserved water right will not injure (or diminish) an existing water right (Amos, 2009). Then, even if the conserved water right is granted, the priority date will be junior to other water rights in the basin, thus posing a constraint to reserving water in-stream for non-consumptive uses.

Second, interview findings highlighted concerns that managing water quality and quantity in a fragmented governance framework still hinders the ability to achieve integrated water management in Oregon. Although the collaborative Strategy process improved coordination and collaboration between the core state agencies dealing with water, institutional barriers to integration persist. In other words, the Strategy document provided policy guidance but failed to address the underlying fragmented governance structure. It did not set up a formal system for ongoing coordination among public agencies or reorganize the structure.

Oregon's water governance framework is highly complex as shown previously in 
Figure 5.2. At the state level, this includes ten state agencies with administrative and regulatory functions to manage water in Oregon. As early as 1955, the Legislature recognized the need for coordinated basin plans to address resource management challenges on a watershed basis. However, as mentioned in the Oregon case study, responsibility for natural resource interagency and intergovernmental coordination resides with the Governor's Natural Resource Policy Advisor. In addition to receiving guidance from the Governor's office, all of these state agencies receive direction from gubernatorial-appointed citizen governing boards, except for the Office of Energy, the Division of State Lands (governed by the State Land Board) and the Watershed Enhancement Board (which is comprised largely of the chairs of the other boards and commissions). These boards and commissions can be influenced by special interests, creating tension between vertical lines of authority (from the governor and legislature) and horizontal (clients and special interests).

Although it is still early in the Strategy implementation process, the case study research findings suggest that the fragmented nature of Oregon's water governance structure poses significant constraints to implementation. Although a collaborative network approach created stronger bonds among both state and non-state actors, sustaining these ties remains a challenge. While addressing these organizational barriers was outside the scope of the collaborative network process, overcoming these silos is necessary to deliver integrated water management in Oregon.

Third, another key constraint to integrated water management is inadequate funding and resources. A consistent theme that emerged throughout the research data was the need for stable funding for state agency personnel, data collection and management, 
and consistent implementation of water programs. Oregon's budget for natural resource programs has not kept up with growing demands and increasing population. Escalating pressures on Oregon's water resources require stable staffing and program oversight, more sophisticated and coordinated data, and greater investments in coordinated management systems. Oregon's collaborative network process did provide greater cohesion among the state natural resource agencies for water-related legislative budget requests. Since the Strategy was adopted in 2012, many of the agency water-related budget requests are linked to specific Strategy recommendations. Case study research revealed that the collaborative network process fostered greater legitimacy for legislative budget requests, and stronger ties among state agencies involved in water programs.

Fourth, Oregon maintains a long history of conflict around water. Deep- rooted value divides among vested water interests proved challenging to overcome through the collaborative process. Even though the collaborative network helped build greater levels of mutual understanding and trust, resolving intractable water issues requires sustained levels of leadership, political will, and social capital. Similar to the New Zealand case, Oregon faces ongoing tension between economic and ecological uses of water that are difficult to resolve through the collaborative process. This theme emerged strongly through the interview data as respondents cited high levels of frustration around the inability to resolve these long-standing value conflicts. Constraining factors to resolution include fragmented water governance, entrenched interests, power imbalances, and lack of political will and leadership.

In closing, both cases exhibited some constraints that hinder the ability to deliver integrated water management effectively. Policy and governance constraints identified 
through the case study research include deep seated histories of conflict, intractable legal and institutional arrangements that create barriers, political uncertainty, bureaucratic inertia, imbalances of power and resources, and unstable and inadequate funding. In addition, lack of shared expectations about how policy recommendations from the collaborative process will affect governmental decisions around implementation downstream emerged as a barrier.

\section{Research Question \#7, Climate Change and Scarcity: How did issues such as climate change and water scarcity influence approaches to water management?}

In both New Zealand and Oregon, change in climate is already occurring. Warming temperatures, changes in precipitation and runoff, and sea level rise have affected and will likely continue to affect water supply and quality. Changes to our water resources affect many sectors including agriculture, infrastructure, human health, energy production, and ecosystems (U.S. Environmental Protection Agency, n.d.). During the key informant and LAWF participant interviews for the New Zealand case, I probed the climate change issue and found that it did not feature prominently as a policy driver in the freshwater reform process. Water scarcity, however, emerged an issue of concern due to over-allocation of water consents in some areas of the country. Although climate change did not emerge as a predominant theme from the interview data, it was identified as a concern in several Land and Water Forum reports. For example, the third report of the Land and Water Forum (2012) cited needing to manage the likely effects of climate change with this targeted recommendation: "catchment-based limits should be set as plan rules that define the quantity and reliability of water that is available for 
allocation (the allocable quantum) and that take into account any flow and water level fluctuations caused by seasonal or other climate variations" (Land and Water Forum, 2012, p. 42). Their fourth report referenced climate change effects and water scarcity, mainly in the context of addressing over-allocation and meeting future supplies.

Alternatively, in the Oregon case, climate change and water scarcity emerged via document reviews and interview data as a prominent influencing factor in development of Oregon's integrated water policies. In addition, research on the strategy's enabling legislation, HB 3369, revealed that concern about climate change and scarcity served as a major driver for seeking ways to integrate water management. The bill language specifically identifies climate change in both the preamble and substantive sections of the bill (section 44(3)(D)(I)). HB 3369 calls for "continuous monitoring of climate change effects on Oregon's water supply and for recommendations regarding the water user actions that are necessary to address climate change" (ORS 536.220). The strategy identifies climate change as one of four cross-cutting issues of "vital importance" to Oregon's water future along with groundwater, funding, and institutional coordination (Oregon Water Resources Department, 2012, p. 4). Highlighting climate change as a key concern, the Strategy calls for several recommendations including supporting continued basin-scale climate change research efforts, and assisting with climate change adaptation and resiliency strategies (Oregon Water Resources Department, 2012, p. 76). Drought preparation also became a larger focus in the 2016 PAG process due to the hot, dry summer of 2016 that heightened awareness about water scarcity issues. This comparison reveals that climate change played a more prominent role as a policy driver in the Oregon case than in the New Zealand case. 
In sum, I have provided an in-depth comparative analysis of collaborative network governance processes in New Zealand and Oregon. One surprising aspect of this research study is that neither collaborative network model resulted in true power-sharing arrangements as found under a New Public Governance framework. While recognizing that these two case studies showed a shift from vertical structures of policy framing to horizontal structures, the transition to policy implementation proved challenging under a network governance approach for a variety of reasons described above.

\subsection{Additional Observations from the Case Study Analysis}

One of the benefits that can result from case study research, or any research that is deeply imbedded in context and based on inductive logic, is the possibility that findings related to topics beyond the original research questions may arise. In this instance, the role of indigenous water rights and tribal treaty obligations in integrated water management emerged as an issue that needs further attention. In particular, tribal perspectives in water management have not yet been well institutionalized in either case and warrant more attention than provided here. Based on the research and personal observations, I will briefly touch on tribal water governance issues germane to network governance approaches to integrated water management.

\section{Comparison of Native Community Role in Integrated Water Management}

With respect to involvement of native communities in integrated water management, there are stark differences between the underlying legal and institutional frameworks in the two cases. In New Zealand, the government entered into a formal relationship with Māori under the Treaty of Waitangi signed in 1840. The Treaty provides the legal foundation for the Crown-Māori relationship in New Zealand, 
including use of land and natural resources. Many years later, the government set up the Waitangi Tribunal as a permanent commission of inquiry that makes recommendations on claims brought by Māori relating to Crown actions which breach promises made in the Treaty of Waitangi (Te Ara: New Zealand Encyclopedia). In New Zealand, similar to tribal relations in the United States, iwi deal directly with the central government for resolving water issues, although each $i w i$ negotiates independently with the government based on their ancestral history, lands, and grievances.

The Land and Water Forum took on addressing iwi rights and interests as part of their policy charge and released a series of supportive recommendations in their reports. In addition, $i w i$ as network partners were well represented on the Forum. Throughout their deliberations, LAWF emphasized that $i w i$ rights and interests in fresh water need to be resolved between $i w i$ and the Crown, thus recognizing the special role that $i w i$ play in New Zealand's legal framework. LAWF's recommendations underscore that as Treaty partners, the Crown and iwi should reflect on the Forum's statement on $i w i$ rights and interests in fresh water and seek a resolution that strengthens water quality limits, and ensures that any water rights provided to $i w i$ comport with rights of other users (Land and Water Forum Third Report, 2012). This recommendation reflects the underlying tensions about making an across the board allocation of water rights to $i w i$ (e.g., 10 percent allocation for each catchment). As of spring 2017, the New Zealand government had yet to develop an overarching policy for resolving $i w i$ water rights.

Interestingly, while the Crown and the Iwi Leaders Group are still in discussions about a national policy for addressing iwi rights and interests, regional councils are moving ahead and developing individually tailored approaches for addressing this issue in their 
catchment areas. I observed that both central and regional governments are making greater efforts to include $i w i$ in meaningful engagement and collaboration in the freshwater space. Some regions have implemented co-governance arrangements established as part of Treaty settlements, whereas other regions are experimenting with different power-sharing approaches on a voluntary basis. However, it is important to note that Treaty settlements at the central government level (or the anticipation of them) are very important drivers in these voluntary arrangements.

As explained earlier in this paper, federally recognized Indian tribes in the United States are sovereign nations in that they possess the ability to govern themselves within the United States. Tribes engage on a government-to-government basis with the federal government. The federal Native American trust responsibility resides with the United States government to protect tribal treaty rights, lands, assets, and resources. With that said, tribal reserved water rights are adjudicated in state courts under the McCarran Amendment, and thereby water issues are resolved on a case-by-case basis. This poses challenges to institutionalizing the role of tribal governments around integrated water policies as there are no overarching state-wide policies for address tribal water issues.

In the Oregon network process, a tribal representative served on the Policy Advisory Group to ensure a tribal perspective in development of the Strategy. It is uncertain if the PAG reached out to all of Oregon's federally recognized tribes to solicit input. On the administrative side, there are ongoing relationships between Oregon's natural resource agencies and tribal governments. These relationships were specifically recognized in the Strategy document along with the following issues of tribal interest regarding integrated water management: environmental justice, water needs and water 
rights, water quality monitoring and watershed restoration and management (Oregon Water Resources Department, 2012). Moving forward, it will be important to ensure integration of tribal interests across boundaries, especially around the issue of addressing unresolved tribal water rights.

In sum, New Zealand's unique model has an opportunity to serve as a leader in reconciling management of freshwater resources with indigenous rights. The government has demonstrated some policy leadership and support of this bi-cultural approach to integrated water management. A partnership-based decision-making approach could result in more efficient and ultimately, more effective freshwater outcomes. In both cases, enhancing tribal voices in these freshwater discussions brings unique and important perspectives, as waterways are not just resources to be managed and developed, but places full of meaning for past, current, and future generations.

\subsection{Building on Network Governance Theory}

The proposition at risk posited that collaborative networks involving public, private, and non-profit actors are better equipped than government-driven efforts to develop effective and durable outcomes. This involves a shift from a top-down, vertical command and control governance approaches to a shared governance network that employs horizontal ties with partner organizations and interest groups. Testing this proposition, what can we learn from these two case studies? Did these collaborative network structures make a difference? Developing a holistic theory would be imprudent based on two case studies; however, I offer observations for refining and improving existing network governance theoretical constructs.

The findings from this comparative case study research suggest that collaborative 
network governance works well for framing and designing new integrated water policies through the process of information sharing, creating mutual understanding, building trust, and creating social capital. With respect to transitioning these policies into action through government-sponsored programs, the network governance framework proved challenging, albeit for different reasons in each case study. Both efforts relied on factors outlined in network governance theory such as transfer of knowledge and relationship building, building of trust and social capital, and democratic anchorage. Institutional arrangements and the lack of sufficient social and political capital posed challenges to implementing integrated water policies in these case studies and were not well documented in the literature. The New Zealand case was unable to institutionalize network authority, resulting in selective implementation by government while Oregon failed to address institutional fragmentation and lacked solid political leadership despite developing consensus around a statewide integrated water resources strategy. More detailed observations are presented below.

Research findings in the New Zealand case study showed that an ongoing collaborative network offers benefits to creating consensus on complex water issues. LAWF provided an opportunity to build long-term relationships among non-state actors and succeeded in moving policy conversations forward where previous government-led efforts had failed. By creating a shared history and collaborative experience, LAWF enabled non-state actors to form strong ties, build trust, and high levels of internal social capital. Consistent, long-term relationships and influential leadership within the collaborative contributed to this success. However, relationships with government exhibited weaker ties that translated into a lack of sufficient political capital and goodwill 
to implement a number of consensus-based water policies. Figure 6.2 depicts these arrangements under the New Zealand network governance policy framework.

Some LAWF members had high expectations that the collaborative, consensusbased policy recommendations would translate into implementation, and it appears that the government support for this happening weakened over time. Other weak links included revolving government actors, weakening political legitimacy with government, and reliance on goodwill of government decision makers. This case study illustrates that since LAWF lacked authority for policy implementation, it needed to build stronger social and political capital with government institutions to ensure successful implementation.

In contrast, the Oregon case developed a collaborative network that was specifically set up to develop policies; it was time-limited and never intended to deliver or oversee implementation. When it reconvened to look at targeted implementation issues several years later, institutional knowledge about the prior collaboration and its outputs were lost because the actors changed. This resulted in weaker ties, and lower levels of trust and social capital among stakeholders. In addition, Oregon lacked strong leadership within the collaborative to broker challenging policy issues. Finally, one state agency was tasked with responsibility for stewarding the integrated water management process, but lacked broad authority for implementation or coordination with other agencies. Figure 6.3 depicts these dynamics under the Oregon network governance policy framework.

Despite receiving strong political support from both the legislature and governor in the Oregon case, translating these recommendations into action proved challenging given the underlying legal and institutional constraints. Dealing with the hurdle of the 
prior appropriation doctrine, fragmented water governance structures, and overlapping spatial jurisdictions with weak coordination necessitates strong political leadership to move integrated water management policies forward. 


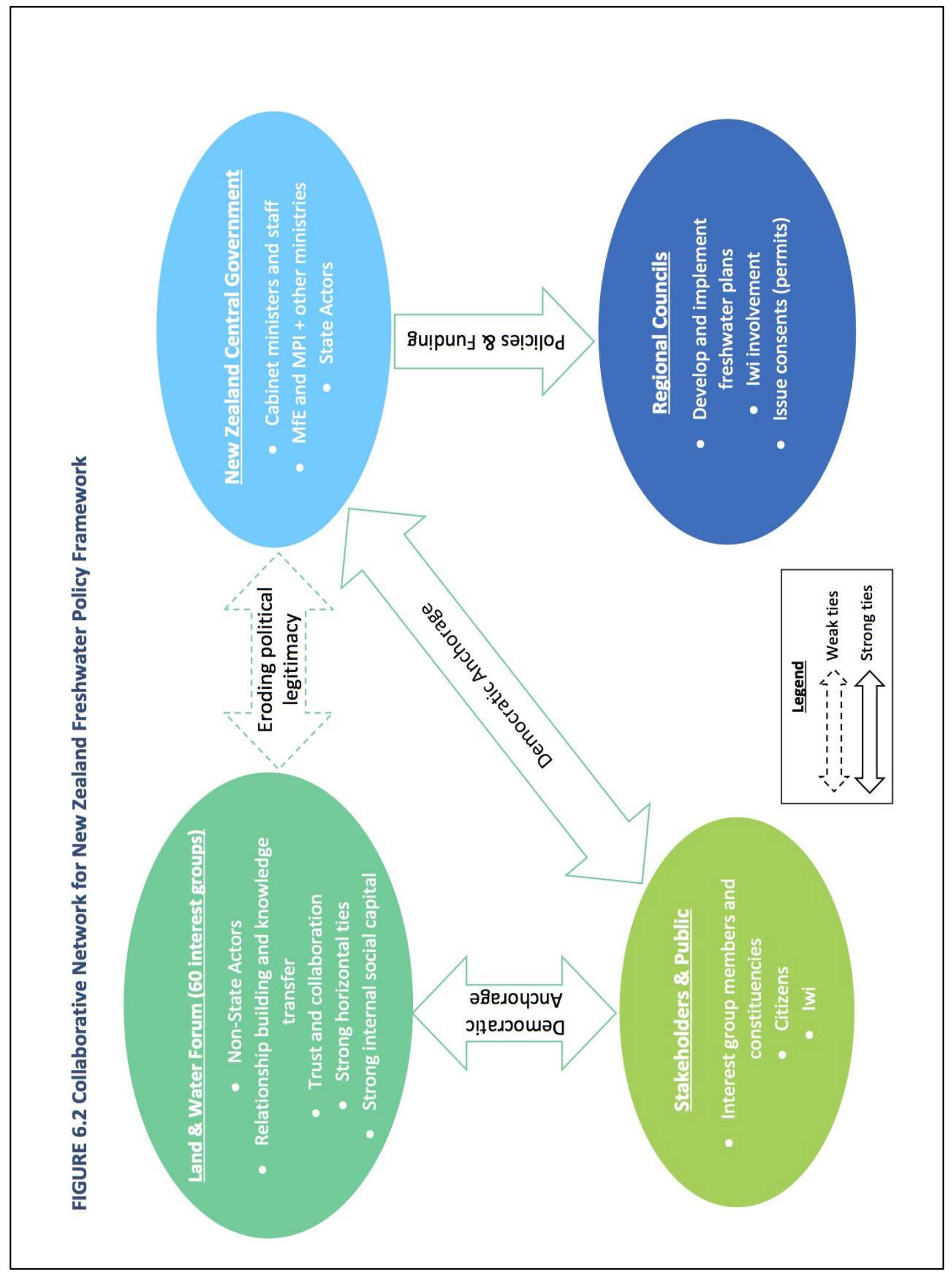




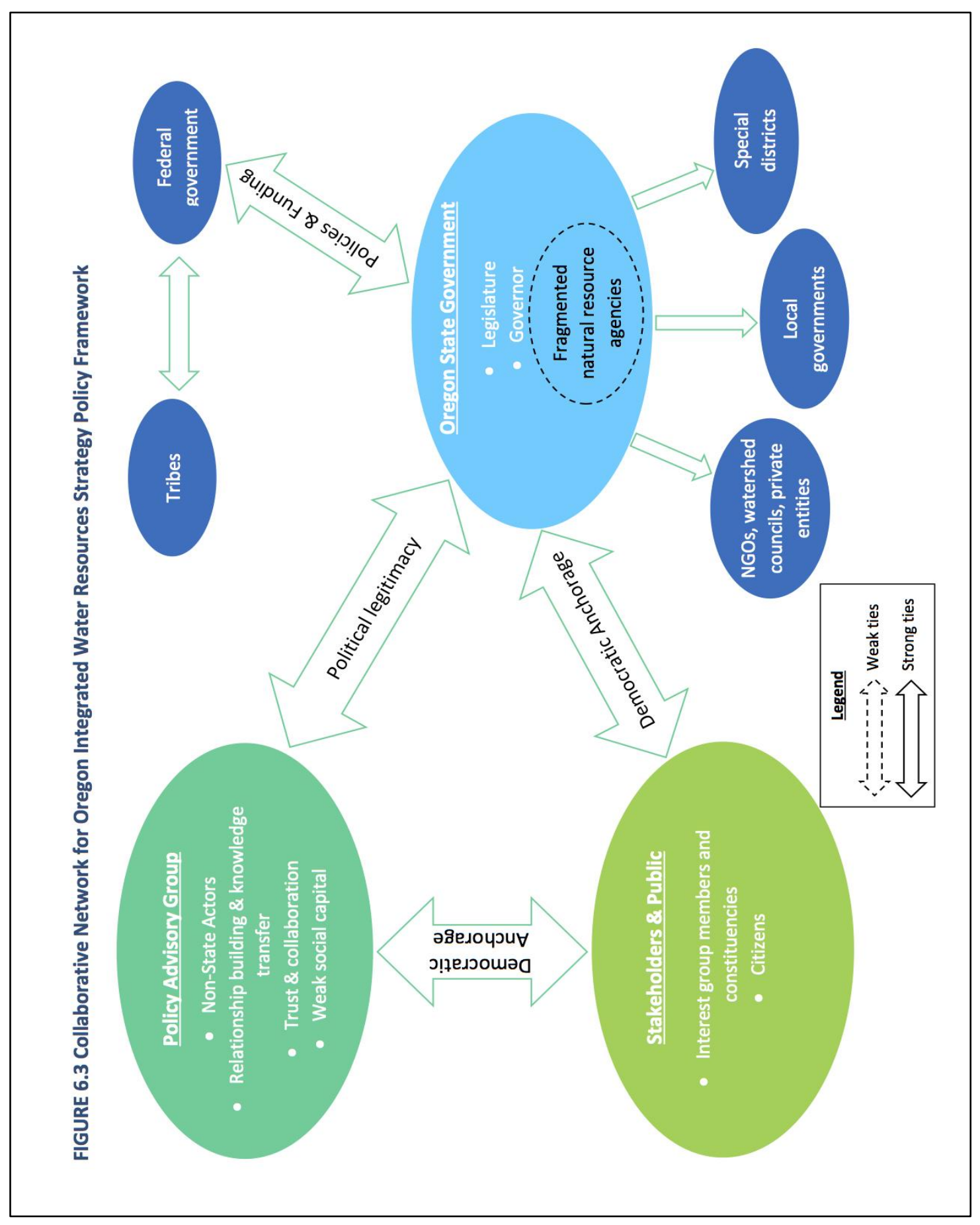




\subsection{Summary}

By conducting in-depth analysis on these two network governance cases, I have provided new insights on the efficacy of collaborative networks in developing and delivering integrated water management. Both cases feature promising aspects, along with limitations, for generating new water policies and promoting integrated water management. This comparison revealed a similar dynamic in both cases in that the network processes fostered a shared understanding of complex water problems, and enabled a collective and collaborative process to develop new water policies. However, implementation constraints posed challenges for delivering integrated water management on the ground.

In conclusion, both collaborative network cases exhibited areas of tension created by the intersection of horizontal and vertical governance structures. While network governance can facilitate state and non-state actors working together to address intractable water problems, the lines of authority and power need to be clearly defined and articulated up front. In the case of New Zealand, actors within the LAWF network exhibited strong internal bonds, but weak ties with government constrained the effective delivery of water policy outcomes. In the Oregon case, the collaborative network between state and non-state actors exhibited stronger ties, however, the ability to make innovative changes was hindered by a shorter operational time frame, a fragmented water governance framework, intractable legal constraints, deep-seated value conflicts, and limited leadership. In the next chapter, I will share final conclusions and insights regarding the role of networks in integrated water management, and areas for future research exploration. 


\section{CHAPTER 7. CONCLUSIONS AND IMPLICATIONS FOR FURTHER POLICY RESEARCH}

Integrated water management is a wicked public policy problem with no clear path to resolution. In this dissertation, I have studied and comparatively analyzed two collaborative governance processes created to tackle complex water problems in New Zealand and Oregon, U.S.A. Both cases convened a wide range of state and non-state actors in efforts to find common ground, build consensus for change, and develop innovative water policy solutions to guide subsequent implementation.

The goal of this comparative case study analysis was to gain a better understanding of network governance frameworks as applied to integrated water management, including the key defining elements, necessary conditions for collaboration, and primary factors for success. The research questions probed the role of state and nonstate policy actors, conditions for collaboration, strength of actor ties, opportunities for collective learning, democratic anchorage, development of trust and social capital, barriers to success, and the role of climate change. Several fascinating differences and similarities between these two cases emerged that add complexity to existing literature and theory.

Recognizing institutional differences in the two case studies, the comparative analysis revealed interesting similarities and differences between the two case studies as outlined in Table 6.3. In both cases, factors outlined in network governance literature, such as transfer of knowledge and relationship building, creating trust and social capital, and democratic anchorage were exhibited; however, new themes emerged that augment network governance scholarship. On the basis of these two case studies, key research 
findings are summarized below.

First, one of the most striking similarities revealed by this case study research is that collaborative network governance worked well for framing and designing new integrated water policies, but encountered challenges with transitioning these policies into action, albeit for different reasons in each case study. Research findings revealed that policy making and reaching agreement around integrated water policies proved easier than transitioning these policies to implementation. The challenge exhibited in the New Zealand case was the inability to institutionalize network authority, resulting in selective implementation by government. This eroded trust and social capital built up over years of collective and collaborative engagement by state and non-state actors. In Oregon, the collaborative process developed new levels of trust and social capital; however, this did not necessarily transition through the implementation phase. In both cases, state actors retained decision-making authority for delivering integrated water policies and programs. Therefore, institutionalizing these collaborative network arrangements to help deliver effective integrated water outcomes may be beneficial.

Second, managing the complexities around the intersection of top-down, vertical command and control governance with horizontal collaborative approaches remains an on-going challenge of New Public Governance. Both cases exhibited challenges regarding the capacity of the governing bodies and institutions to develop power sharing arrangements with collaborative networks. Fragmented governance arrangements, underlying legal constraints, and the lack of sufficient social and political capital pose challenges to delivering integrated water policies in these two cases. This research highlights the need for additional capacity to develop clear lines of communication, 
coordinated governance structures, integrated systems thinking, and political leadership to successfully deliver results around integrated water management.

Finally, the two cases represented examples of the use of formal and informal processes for policy development. New Zealand's on-going collaborative network represented a formal arrangement that supported mutual learning and built capacity among non-state actors for developing innovative freshwater reform proposals. The process enabled important progress on previously intractable freshwater problems that might not have occurred otherwise. Oregon's process was less formal and showed promise in creating a new space for dialogue, mutual learning, and knowledge transfer. However, the short duration of this process limited Oregon's opportunity to build higher levels of trust and social capital between non-state and state actors. New Zealand's ongoing collaborative forum could serve as a model for building long-term civic capacity and social capital, especially among non-state actors, in the integrated water management arena.

\section{Areas for Future Research}

Conducting research for this dissertation generated several ideas about areas for future examination. Both cases studied highlighted the importance of implementing integrated water management at the watershed scale. The rationale is that bottom-up approaches create local buy in, a sense of ownership, and locally-derived solutions that can address the complexity of each basin. Place-based, bottom-up collaborative approaches offer promise and perhaps can avoid limitations and constraints identified by this comparative analysis. These efforts also have the potential to deliver effective integrated water management outcomes by building a collaborative and inclusive process, 
gathering information and data needs to identify knowledge gaps, examining current and future water needs that balance economic and environmental demands, and creating local integrated water resource plans. A more in-depth study of place-based planning could provide valuable information for policy makers about the effectiveness of these efforts in delivering integrated water management at the watershed scale.

Overcoming the complexities and challenges of managing a hybrid system of horizontal policy development with vertical implementation warrants additional investigation. During this research, moving from policy to implementation proved to be a constraint, and understanding the underlying causal factors were beyond the scope of this comparative analysis. The question remains, can a broad-based collaborative horizontal structure deliver when it comes to implementation of integrated water policies? If so, when, where and why might there be advantages or disadvantages to employing these networks? This is a fruitful area for future research that could provide additional insights. Another area ripe for further examination is specific to the Oregon case. Given Oregon's fragmented natural resource governance and regulatory framework, what is the best mechanism for delivering integrated water outcomes? Given the multitude of state agencies, organizations, and commissions involved in water management, and the lack of an institutionalized joint coordination body, who guides implementation of the Integrated Water Resources Strategy? Even with adoption of an overarching statewide vision and plan, the underlying fragmented governance and regulatory system poses challenges for delivering water outcomes holistically. Further research in New Public Governance theory could help foster more effective water governance frameworks for delivering integrated water outcomes in Oregon. 
Another area for future research is how culture influences collaborative governance approaches as this issue was not explicitly explored as part of this research. Finally, a more in-depth analysis of the role of indigenous perspectives in integrated water management warrants further exploration. New Zealand approaches indigenous water planning in a comprehensive manner that can serve as a model for offers for other governments working to incorporate tribal perspectives into natural resource planning. However, New Zealand is struggling to develop an overarching policy addressing $i w i$ rights and interests in water. In Oregon, tribal treaty rights are dealt with on tribe by tribe basis, creating challenges for developing a comprehensive statewide policy. This research briefly touched upon tribal involvement in water policies, but given the complexities of this issue, a standalone study would be valuable.

Despite the limitations of Oregon and New Zealand's collaborative network governance structures, this research supports the thesis that collaborative governance structures can be effective in developing policies to address wicked, multi-dimensional, multi-sectoral problems. Understanding the challenges and constraints associated with these collaborative efforts can assist other jurisdictions as they assess best policy practices for ensuring integrated water management. The benefits of collaborative governance for policy development are substantial, and the limitations appear to be obstacles to overcome and not fatal flaws. The main challenge lies in transitioning from policy and planning to applying changes on the ground affecting the way we manage water today and in the future. 


\section{REFERENCES}

Agranoff, R., \& McGuire, M. (2003). Collaborative public management: New strategies of local government. Washington DC: Georgetown University Press.

Ajar, K. F., \& Collier, C. R. (2011). Integrated water resources management: Bringing it all together. Water Resources IMPACT, 13 (3): 3-8.

American Indian Law Center, Inc. (2013). Retrieved March 17, 2017 from http://www.ailc-inc.org/PhotoGallery-Transitions-2013.html.

American Water Resources Association. (2011a). AWRA Position Statement: Integrated water resources management in the US. Retrieved March 5, 2017 from http://www.awra.org/policy/policy-statements- IWRM.html.

American Water Resources Association. (2012, November). AWRA Position Statement: Case studies in integrated water resources management: From local stewardship to national vision. Retrieved March 29, 2017 from http://www.awra.org/committees/AWRA-Case-Studies-IWRM.pdf.

Amos, A. (2009). Freshwater conservation: Oregon water law and policy - Phase 1 Report. Portland, Oregon: The Nature Conservancy.

Anderson, R. T. (2006). Indian water rights and the federal trust responsibility, National Resources Journal 46(2), 399-437. Retrieved March 23, 2017 from https://papers.ssrn.com/sol3/papers.cfm?abstract_id=1138864.

Ansell, C., \& Gash, A. (2008). Collaborative governance in theory and practice. Journal of Public Administration Research and Theory, 18(4), 543-571.

Bastasch, Rick (2006). Oregon water handbook: A guide to water and water management. Corvallis OR: Oregon State University Press.

Bateman, B., \& Rancier, R. (2012). Case studies in integrated water resources management: From local stewardship to national vision. Retrieved February 16, 2017 from http://www.awra.org/committees/AWRA-Case-Studies-IWRM.pdf

Benham, C., Hussey, K. \& Beavis, S. (2014). Planning for success in a climate change future: Collaborative water governance in the Upper Murrumbidgee Catchment, Southeastern Australia. Australian Journal of Water Resources, 18(1): 1-14.

Benington, J. \& Moore, M. (2010). Public value: Theory and practice. Melbourne, Australia: Palgrave.

Bisely, A. (2016, May 23). Op ed: A once-in-a-generation opportunity to safeguard New Zealand's fresh water. Retrieved March 17, 2017 from stuff.co.nz http://www.stuff.co.nz/environment/74587607/a-onceinageneration-opportunityto-safeguard-New-Zealand's-fresh-water.

Biswas, A.K. (2004). Integrated water resources management: a reassessment, Water International, 29(2), 248-256. Retrieved February 28, 2017 from DOI: $10.1080 / 02508060408691775$.

Biswas, A.K. (2008). Integrated water resources management: is it working? Water Resources Development, 24(1): 5-22. Retrieved February 14, 2017 from doi: 10.1080/07900620701871718. 
Borgatti, S. P., \& Foster, P. C. (2003). The network paradigm in organizational research: a review and typology. Journal of Management, 29(6), 991-1013.

Bosselmann, K., \& Vernon, T. (2011). Water rights and sustainability. Auckland: New Zealand Centre for Environmental Law.

Bourget, P. G. 2006. Integrated water resources management curriculum in the United States: Results of a recent survey. Journal of Contemporary Water Research \& Education (135): 107-114.

Bulkeley, H., \& Newell, P. (2010). Governing climate change. Routledge Global Institution. CUNY Graduate Center, New York, NY.

Cartwritght, D. \& Harary, F. (1956) Structural balance: a generalization of Heider's theory. Psychology Review, 63, 277-293.

Charmaz, Kathy. (2006). Constructing Grounded Theory. London, UK: Sage.

Cooper, P. J. (2003). Governing by contract: Challenges and opportunities for public managers. Washington D.C.: CQ Press.

Cortner, H. J. \& Moote, M. A. (1999). The politics of ecosystem management. Washington D.C.: Island Press.

Davis, M. D., \& Threlfall, J. (2006). Integrated water resource management in New Zealand: legislative framework and implementation. Journal of Contemporary Water Research and Education, 135(1), 86-99.

Department of the Interior, U.S. Fish and Wildlife Service. (2003). Endangered Species Act of 1973 as Amended through the 108th Congress. Retrieved from http://www.nmfs.noaa.gov/pr/laws/esa/

Dingfelder, J. (2016). New Zealand's approach to integrated freshwater management with a focus on indigenous interests. Retrieved March 21, 2017 from http://fulbright.org.nz/publications/new-zealands-approach-to-integratedfreshwater-management-with-a-focus-on-indigenous-interests/.

Durette, M., \& Barcham, M. (2009). Indigenous water governance: An integrated approach to resource management. Prepared for Nga Pae o te Maramatanga.

Environment Foundation. (2016). Resource consents and processes. Environment Guide. Retrieved March 14, 2014 from http://www.environmentguide.org.nz/rma/resource-consents-andprocesses/existing-activities/

Eppel, E. (2013). Collaborative governance case studies: The land and water forum. Working Paper No: 13/05, Victoria University, Institute for Governance and Policy Studies, Wellington.

Eppel, E. (2016). Towards better understanding of the mechanisms which create sustainable public services and public service organisations: Insights from New Zealand's freshwater management. Paper presented at the 20th Conference of the International Research Society for Public Management: Collaborative, globalised, interdisciplinary, 13-15 April, 2016. Hong Kong: Hong Kong Polytechnic University.

Evans, J.P. (2012) Environmental governance. Abingdon, Oxon: Routledge.

Fenemore, A., Neiland, D., Allen, W., \& Shona, R. (2011). Improving water governance in New Zealand. Policy Quarterly, 7(4), 10-19.

Flick, U. (2014). The sage handbook of qualitative data analysis. London, UK: Sage. 
Glaser, Barney G. (1998). Doing grounded theory: Issues and discussions. Mill Valley, CA: Sociology Press.

Gleick, P. (2003). Global freshwater resources: Soft-path solutions for the $21^{\text {st }}$ Century. Science, 302(5650), 1524-1538.

Global Water Partnership (GWP) (2000). Towards Water Security: A framework for action. Stockholm: Global Water Partnership

Global Water Partnership Technical Committee. (2004). Catalyzing change: A handbook for developing integrated water resources management (IWRM) and water efficiency strategies. Stockholm: Global Water Partnership

Global Water Partnership Technical Committee. (2004). Unlocking the door to social development and economic growth: How a more integrated approach to water can help. Stockholm: Global Water Partnership. Retrieved February 21, 2017 from http://www.gwptoolbox.org/images/stories/gwplibrary/policy/pb_1_english.pdf.

Global Water Partnership Technical Committee. 2005. Catalyzing change: A handbook for developing integrated water resources management (IWRM ) and water efficiency strategies. Retrieved February 21, 2017 http://www.unwater.org/downloads/ Catalyzing_change-.

Global Water Partnership IWRM. (n.d.). Global water partnership. Retrieved May 3, 2016 from http://www.gwp.org/en/The-Challenge/What-is-IWRM/.

Goldsmith, S. and Eggers,W. (2004). Governing by network: The new shape of the public Sector. Washington D.C.: Brookings Institute Press.

Gray, B. (1989). Collaborating: Finding common ground for multiparty problems. San Francisco: Jossey-Bass.

Hardin, G. (1968). The tragedy of the commons. Science, 162(3859), 1243-1248. Retrieved May 31, 2016, from http://www.environnement.ens.fr/IMG/pdf/hardin_1968.pdf

Harmsworth, G., Awatere, S., \& Robb, M. (2015, December). Māori values and perspectives to inform collaborative processes and planning for freshwater management. Landcare Research Policy Brief No. 14. Palmerston North, New Zealand: Landcare Research.

Healey, P. (1997). Collaborative planning: Shaping places in fragmented societies. London, UK: MacMillan.

Healthy Rivers: Plan for Change. (2016). Restoring and protecting our water/Te whakapaipai me te tiaki i o tatou wai. Hamilton: Collaborative Stakeholder Group.

Heclo, H. (1978). Issue networks and the executive establishment. Public Administration Concepts and Cases, 413, 46-57.

Howard-Williams, C., Bisley, A., \& Taylor, K. (2013). Free flow: Researching water security through cooperation, pp. 174-177 Retrieved March 19, 2017 from http://unesdoc.unesco.org/images/0022/002228/222893e.pdf.

Innes, J. E., \& Booher, D. E. (1999). Consensus building and complex adaptive systems: a framework for evaluating collaborative planning. Journal of the American Planning Association, 65(4), 412-423.

Intergovermental Panel on Climate Change. Retrieved March 2, 2017 from http://www.ipcc.ch/ 
Keast, R., Brown, K., \& Mandell, M. (2007). Getting the right mix: unpacking integration meanings and strategies. International Public Management Journal, 10(1), 9-33.

Keast, R. (2011). Joined-up governance in Australia: How the past can inform the future. International Journal of Public Administration, 34(4), 221-231.Keast, R., Mandell, M. \& Agranoff, R. (2014). Network Theory in the Public Sector: Building New Theoretical Frameworks. Routledge: New York.

Kemmis, Daniel. (1992). Community and the politics of place. Norman, OK: University of Oklahoma Press.

Kickert, W. J., Klijn, E. H., \& Koppenjan, J. F. M. (Eds.). (1997). Managing complex networks: Strategies for the public sector. Sage.

Kilduff, M., \& Tsai, W. (2003). Social networks and organizations. Sage.

$\mathrm{Ki}$-moon, Ban (2008). Ban Ki-moon warns that water shortages are increasingly driving conflicts. Retrieved February 2, 2017 from http://www.un.org/apps/news/story.asp?NewsID=25527\#.WRdrdWjyvIV .

King, M. (2003). The Penguin history of New Zealand. Auckland, NZ: Penguin Group.

Klijn, E. H., \& Koppenjan, J. F. (2000). Public management and policy networks: foundations of a network approach to governance. Public Management an International Journal of Research and Theory, 2(2), 135-158.

Klijn, E. H., \& Koppenjan, J. (2012). Governance network theory: past, present and future. Policy \& Politics, 40(4), 587-606.

Koliba, C., Meek, J. W., \& Zia, A.. (2011). Governance networks in Public Administration and Public Policy. Boca Raton, FL: Taylor and Francis Group.

Koliba, C., DeMenno, M., Brune, N., \& Zia, A. (2014). The salience and complexity of building, regulating, and governing the smart grid: lessons from a statewide public-private partnership. Energy Policy, 74, 243-252.

Koppenjan, J. F. M., \& Klijn, E. H. (2000). Public management and policy networks: foundations of a network approach to governance. Public Management an International Journal of Research and Theory, 2(2), 135-158.

Koppenjan, J. F. M., \& Klijn, E. H. (2004). Managing uncertainties in networks: A network approach to problem solving and decision making. New York, NY: Routledge.

Koudstaal, R., R. R. Rijsberman, and H. Savenije. (1992). Water and sustainable development. Natural Resources Forum (November): 277-290.

Land Air and Water Aotearoa (LAWA). (2016, May 28). Land Air and Water Aotearoa (LAWA): Wellington Region. Land Air and Water Aotearoa (LAWA): Retrieved March 14, 2017 from http://www.lawa.org.nz/explore-data/wellington-region/

Land Air and Water Aotearoa (LAWA). (2016, June 20). Gisborne Regional Profile. Land Air and Water Aotearoa (LAWA): Retrieved February 7, 2017 from http://www.lawa.org.nz/explore-data/gisborne-region/

Land and Water Forum. (2010). Report of the Land and Water Forum: A Fresh Start for Freshwater. Wellington: The Land and Water Forum.Retrieved March 20, 2017 from http://www.landandwater.org.nz/Site/Resources.aspx 
Land and Water Forum. (2012a). Second Report of the Land and Water Forum: Setting Limits for Water Quality and Quantity, and Freshwater Policy-and Plan-Making through Collaboation. Wellington: The Land and Water Forum.

Land and Water Forum. (2012b). Third Report of the Land and Water Forum: Managing Water Quality and Allocating Water. Wellington: The Land and Water Forum.

Land and Water Forum. (2015). The Fourth Report of the Land and Water Forum. Wellington: The Land and Water Forum.

Land and Water Forum. (2016, May 10). Land and Water Forum. Retrieved March 3, 2017 from http://www.landandwater.org.nz/Site/Resources.aspx.

Lennox, J., Proctor, W., \& Russell, S. (2011). Structuring stakeholder participation in New Zealand's water resource governance. Ecological Economics, 70(7), 1381-1394.

Logan, H. (2013). Inside the black box: The influence of government executive Forces on environmental policy effectiveness in New Zealand (Thesis Lincoln University).

Lubell, M., Fulton, A. (2008). Local policy networks and agricultural watershed management. Journal of Public Administration Research Theory; 18(4): 673-696. Retreived on March 5, 2017 from doi:10.1093/jopart/mum031.

Ludwig, F. Van Slobbe, E.; \& Cofino, W. (2014). Climate change adaptation and integrated water resources management in the water sector. Journal of Hydrology, $518,235-242$.

Mandell, M. P. (1994). Managing interdependencies through program structures: a revised paradigm. The American Review of Public Administration, 24(1), 99-121.

Māori Dictionary - Online. (2016, May/June). Retrieved March 29, 2017 from http://Māoridictionary.co.nz/.

Maori Law Review. (2012). Māori rights in water - the Waitangi Tribunal's interim report. Retrieved February 6, 2017 from http://maorilawreview.co.nz/2012/09/maori-rights-in-water-the-waitangitribunals-interim-report/.

Marsh, L. (2002). Watershed solutions: Collaborative problem solving for states and communities. National Policy Consensus Center, Portland.

Maxwell, S. E., \& Delaney, H. D. (1990). Designing experiments and analyzing data: A model comparison approach. Belmont, CA: Wadsworth.

Maxwell, Joseph. (2013). Qualitative Research Design: An Interactive Process. Thousand Oaks, CA: Sage Publications.

McGuire, M. (2002). Managing networks: Propositions on what managers do and why they do it. Public administration review, 62(5), 599-609.

McGuire, M., \& Agranoff, R. (2010). Networking in the Shadow of Bureaucracy in Durant, F. (Ed), Oxford handbook of American bureaucracy. Oxford, UK: Oxford University press.

McLauchlan, G. (1989). The Illustrated Encyclopedia of New Zealand. D. Bateman.

Mecham, D. (2016). Indian Reserved Rights in the $21^{\text {st }}$ Century. The Water Report Issue 154. Evirotech Publications. Retrieved March 17, 2017 from http://www.thewaterreport.com/Issues\%20153\%20to\%20156.html 
Medema, W., McIntosh, B., \& Jeffrey, P. (2008). From premise to practice: a critical assessment of integrated water resources management and adaptive management approaches in the water sector. Ecology and Society, 13(2), 29.

Meier, K. J., \& O'Toole, L. J. (2001). Managerial strategies and behavior in networks: A model with evidence from US public education. Journal of Public Administration Research and Theory, 11(3), 271-294.

Meier, K. J., \& O'Toole Jr, L. J. (2005). Managerial networking: Issues of measurement and research design. Administration \& Society, 37(5), 523-541.

Memon, P., \& Kirk, N. (2011). Role of Indigenous Māori people in collaborative water governance in Aotearoa/New Zealand. Journal of Environmental Planning and Management, 941-959.

Meulman, L. (2008). Theoretical framework, Public management and the metagovernance of hierarchies, networks, and markets. Heidelberg: PhysicaVerlag.

Mills, Jane M., Stern, Phyllis N., Corbin, Juliet, Bowers, Barbara, Charmaz, Kathy \& Clark, Adele E. (2009). Developing grounded theory: The second generation. Walnute Creek, CA: Left Coast Press.

Milward, H., and Provan, K.(2006). A manager's guide to choosing and using collaborative networks. Washington D.C.: IBM Center for Business of Government.

Ministry for the Environment. (2007, December). Environment New Zealand 2007. Wellington: Ministry for the Environment.

Ministry for the Environment. (2009). An everyday guide to the RMA. Wellington: Ministry for the Environment. ISBN: 978-0-478-33205-6

Ministry for the Environment. (2013a). Proposed amendments to the National Policy Statement for Freshwater Managent 2011: A discussion document. Wellington: Ministry for the Environment.

Minstry for the Environment. (2013b). Freshwater reform 2013 and beyond. Wellington: Ministry for the Environment.

Ministry for the Environment. (30 June 2014). Report of the Ministry for the Environment. Wellington: Ministry for the Environment.

Ministry for the Environment. (2014a). Cabinet paper. Retrieved April 28, 2016, from Ministry for the Environment: http://www.mfe.govt.nz/more/cabinet-papers-andrelated-material-search/cabinet-paper.

Ministry for the Environment; Ministry for Primary Industries. (2014b). Freshwater programme: Managing within limits, pressures and opportunities. BN-14-01655

Ministry for the Environment. (2016, April 20). Climate change. Retrieved March 17 , 2017 from http://www.mfe.govt.nz/climate-change/how-climate-change-affectsnz/climate-change-impacts.

Ministry for the Environment. (2016, May 19). Te Mana o Te Wai Fund. Retrieved March 17, 2017 from http://www.mfe.govt.nz/more/funding/te-mana-o-te-waifund/about-fund.

Ministry for the Environment. (2016, May 23). Ministry for the Environment/publications/environmental reporting. Retrieved March 17, 2017 
from http://www.mfe.govt.nz/publications/environmental-reporting/environmentaotearoa-2015-fresh-water/overview.

Ministry for the Environment Briefing Document. (TePuna Doc\# 7349399) Wellington. Ministry for the Environment Briefing Document. (TePuna Doc\# 7388026) Wellington.

Ministry for the Environment (n.d.). Cabinet Paper: Economic Growth and Infrastructure Committee. Wellington.

Ministry of Justice. (2016, May 17). Watitanti Tribunal. Retrieved March 30, 2017 from http://www.justice.govt.nz/tribunals/waitangi-tribunal/about/who-are-we

Mitchell, Bruce. (2005). Integrated water resources management, institutional arrangements and land use planning. Environment and Planning, 37, 13351352.

Morgan, D. \& Cook, B. (2014). New Public Governance. New York. M.E. Sharpe Press. National Oceanic and Atmospheric Administration. (2016). Endangered Species Act (ESA). Retrieved May 3, 2017 from: http://www.nmfs.noaa.gov/pr/laws/esa/

National Oceanic and Atmospheric Administration, National Marine Fisheries Service. (n.d.). Habitat Conservation | Habitat Protection; What is essential fish habitat? Retrieved April 14, 2017 from: http://www.habitat.noaa.gov/protection/efh/

National Public Radio. (May 03, 2016). National Public Radio programs. Retrieved February 16, 2017 from http://www.npr.org/programs/atc/features/2003/aug/water/part1.html

New Zealand Encyclopedia (n.d.) Retrieved February 14, 2017 from http://www.teara.govt.nz/en.

New Zealand Environment Guide. (2016, April 29). Retrieved April 29, 2016, from www.environmentguide.org.nz.

New Zealand Government. (2014). National Policy Statement for Freshwater Management 2014. Ministry for the Environment, Wellington, New Zealand. [online] URL: ttp://www.mfe.govt.nz/publications/fresh-water/national-policystatement-freshwatermanagement-2014.

New Zealand Local Goverment. (2016, June 28). Glossary of terms. Retrieved from New Zealand Local Goverment:

http://www.localcouncils.govt.nz/lgip.nsf/wpg_url/Resources-GlossaryIndex\#RegionalCouncil.

New Zealand Local Government. (2016, May 03). New Zealand Local Government. Retrieved from http://www.lgnz.co.nz/home/nzs-local-government.

New Zealand Ministry of Justice. (1840). Waitangi Treaty. Retrieved March 15, 2017 from https://www.justice.govt.nz/about/learn-about-the-justice-system/how-thejustice-system-works/the-basis-for-all-law/treaty-of-waitangi/.

New Zealand Office of Treaty Settlement. (2016, May 12). Treaty Settlements. Retrieved from New Zealand Office of Treaty Settlement:

https://www.govt.nz/browse/history-culture-and-heritage/treaty-of-waitangiclaims/settling-historical-treaty-of-waitangi-claims/

New Zealand Parliament.(2000). Retrieved February 8, 2017 from https://www.beehive.govt.nz/speech/water-2000-conference-carlton-hotelauckland. 
New Zealand Population Clock. (2017). Retrieved February 10, 2017 from http://countrymeters.info/en/New_Zealand

New Zealand Planning Association. (2016, July 16). Quality Planning meaning of 'give effect'. Retrieved from Quality Planning http://www.qualityplanning.org.nz/index.php/manual/imposing-penalties/10useful-links/515-give-effect

Odendaal, P. E. (2002). Integrated water resources management (IWRM), with special reference to sustainable urban water management. In CEMSA 2002 Conference, Johannesburg, South Africa.

Office of the Minister for the Environment.( 2009). New start for fresh water. Minister for the Environment, Wellington, New Zealand. Retrieved March 23, 2017 from http://www.mfe.govt.nz/more/cabinetpapers-and-related-material-search/cabinetpapers/freshwater/newstart-fresh-water.

Ohlson, D. W. (1999). Exploring the application of adaptive management and decision analysis to integrated watershed management (Doctoral dissertation, University of British Columbia).

Olmstead, S. M. (2014). Climate change adaptation and water resource management : a review of the literature. Energy Economics, 46, 500-509. http://doi.org/10.1016/j.eneco.2013.09.005

Olson, M. 1971. The logic of collective action: public goods and the theory of groups. Cambridge, UK: Harvard University Press.

Oregon Climate Change Research Institute, K. Dello and P. Mote (eds.), Oregon Climate Assessment Report. (2010). Retrieved March 14, 2017 from http://library.state.or.us/repository/2010/201012011104133/summaries.pdf.

Oregon Department of Environmental Quality. (2010). Retrieved March 5, 2017 from http://www.oregon.gov/deq/pages/index.aspx.

Oregon Department of Forestry (n.d.). Retrieved March 5, 2017 from http://www.oregon.gov/ODF/Pages/index.aspx/.

Oregon Progress Board. Oregon State of the Environment. (2000). Retrieved March 5, 2017 from http://oregonstate.edu/dept/eoarc/publication/2000/490.

Oregon State Legislature. Oregon Laws. (nd.). Retrieved March 5, 2017 from https://www.oregonlaws.org/.

Oregon State Legislature. (n.d.). Legislative Fiscal Office; Joint Committee on Ways and Means. Retrieved April 16, 2017 from: https://www.oregonlegislature.gov/lfo/Pages/JointWaysMeans.aspx

Oregon State Legislature. (n.d.). Oregon Legislative Information; 2009 Regular Season; Overview. Retrieved February 21, 2017 from: https://olis.leg.state.or.us/liz/2009R1/Measures/Overview/HB3369

Oregon State Archives. Oregon Blue Book.(n.d.). Retrieved March 5, 2017 from http://bluebook.state.or.us/.

Oregon State Executive Orders website. (n.d.). Retrieved March 23, 2017 from http://archivedwebsites.sos.state.or.us/Governor_Kitzhaber_2003/governor/legal/e xecords/eo99-01.pdf. 
Oregon State University (2008). Oregon Sea Grant Extension, OSU Institute for Natural Resources, \& Oregon House Committee on Energy and Environment. Retrieved March 7, 2017 from http://inr.oregonstate.edu/.

Oregon Utility Statistics. (n.d.) Retrieved March 23, 2017 from http://www.puc.state.or.us/Pages/Oregon_Utility_Statistics_Book.aspx.

Oregon Water Resources Department. (2010). Retrieved February 16, 2017 from http://www.oregon.gov/owrd.

Oregon Water Resources Department. Instream Water Rights. (n.d.). Retrieved March 16, 2017 from http://www.dfw.state.or.us/OARs/400.pdf.

Oregon Water Resources Department. (2010). Integrated Water Resources Strategy Issue Papers. Oregon, Salem.

Oregon Water Resources Department. (2012, August). Oregon's Integrated Water Resources Strategy. Oregon: Salem.

Oregon Water Resources Department. (2016, April 29). Oregon Water Resources Department. Retrieved March 23, 2017 from http://www.npr.org/programs/atc/features/2003/aug/water/part1.html.

Oregon Water Resources Department. (2017). Staff Report. Retrieved February 21, 2017 from http://www.oregon.gov/owrd/LAW/docs/IWRS/IWRS\%20Update\%20Staff\%20R eport\%20\%28Final\%29.pdf.

Oregon Watershed Enhancement Board. (n.d.). Board and Director's Office. Retrieved February 20, 2017 from: http://www.oregon.gov/OWEB/pages/board_main.aspx

O’Toole, Jr, L. J., Meier, K. J., \& Nicholson-Crotty, S. (2005). Managing upward, downward and outward: networks, hierarchical relationships and performance. Public Management Review, 7(1), 45-68.

Pahl-Wostl, C. (2007). Transitions towards adaptive management of water facing climate and global change. Water resources management, 21(1), 49-62.

Pahl-Wostl, C. (2009). A conceptual framework for analysing adaptive capacity and multi-level learning processes in resource governance regimes. Global Environmental Change, 19(3), 354-365.

Pahl-Wostl, C., Holtz, G., Kastens, B., \& Knieper, C. (2010). Analyzing complex water governance regimes: The management and transition framework. Environmental Science and Policy, 13(7), 571-581. Retrieved February 7, 2017 from http://doi.org/10.1016/j.envsci.2010.08.006

Pahl-Wostl, C., Jeffrey, P., Isendahl, N., \& Brugnach, M. (2011). Maturing the new water management paradigm: progressing from aspiration to practice. Water Resources Management, 25(3), 837-856. Retrieved February 8, 2017 fromhttp://doi.org/10.1007/s11269-010-9729-2

Pahl-Wostl, C., Lebel, L., Knieper, C., \& Nikitina, E. (2012). From applying panaceas to mastering complexity: toward adaptive water governance in river basins. Environmental Science \& Policy, 23, 24-34.

Pahl-Wostl, C. (2015). Water governance in the face of global change: from understanding to transformation. New York, NY: Springer. 
Parliamentary Commissioner for the Environment. (2013, November). Water quality in New Zealand: Land use and nutrient pollution. Wellington: Parliamentary Commissioner for the Environment.

Parliamentary Commissioner for the Environment. (2015a). Update report-water quality in New Zealand: land use and nutrient pollution. Parliamentary Commissioner for the Environment. New Zealand: Wellington.

Parliamentary Commissioner for the Environment. (2015b). Managing water quality: Examing the 2014 National Policy Statement. New Zealand: Wellington.

Pawson, E., \& Brooking, T. (2013). Making a New Land: Environmental Histories of New Zealand. Dunedin: Otago University Press.

Powell, J. W. (1878). Report on the lands of the arid region of the United States. 45th Cong., 2nd Sess. Ex. Doc, 73.

Powell, W.W., (1990). Neither market nor hierarchy: network forms of organization. In: Cummings, L.L., Staw, B.M. (Eds.), Research in Organizational Behavior, 12, 295-336.

Provan, K.G., and Kenis, P. (2007). Modes of network governance. Structure, management and effectiveness. Journal of Public Administration Research and Theory, 18, 229-252.

Putnam, R. D. (1993). Making democracy work: Civic traditions in modern Italy. Princeton, NJ: Princeton University Press.

Ragin, Charles C. (2014). The comparative method: Moving beyond qualitative and quantitative strategies (2nd Edition ed.), Oakland, CA: University of California Press.

Rahaman, M., and Varis, O. (2005). Integrated water resources management: evolution, prospects and future challenges. Science, Practice, and Policy, 1(1), 15-21.

Relationships for a sustainable water resources future. Washington, D.C. Retrieved February 12, 2017 from http://www.building-collaboration-for-water.org/ Documents/nationalreport_final.pdf.

Rhodes, R. A. (1997). Understanding governance: Policy networks, governance, reflexivity and accountability. Philadelphia, PA: Open University Press.

Rogers, P., \& Hall, A. W. (2003). Effective water governance (Vol. 7). Global water partnership.

Rose, G. (1997). Situating knowledges: positionality, reflexivities and other tactics. Progress in Human Geography, 21(3), 305-320. Retrieved March 1, 2017 from http://doi.org/10.1191/030913297673302122.

Ross, A., Pickering-Sherman, K., Snodgrass G, J., Delcore, H. D., \& Sherman, R. (2011). Indigenous peoples and the collaborative stewardship of nature: Knowledge binds and institutional conflicts. Walnut Creek, CA: Left Coast Press.

Royal Society of New Zealand. (2016). Climate change implications for New Zealand. New Zealand: Wellington.

Ruru, J. (2009). The legal voice of Māori in freshwater governance: a literature review. Waikato: Landcare Reserach New Zealand.

Ruru, J., Stephenson, J., \& Abbott, M. (2011). Making our pace: Exploring tensions in Aoteareoa New Zealand. Dunedin: Otago University Press. 
Russell, S., \& Frame, B. \& Lennox. (2011). Old problems to new solutions: Integrative research supporting natural resource governance. Landcare Reserch. Lincoln, NZ: Manaaki Whenua Press.

Sabatier, P. A., Focht, W., Lubell, M., Trachtenberg, Z., Vedlitz, A., \& Matlock, M. (2005). Swimming upstream: Collaborative approaches to watershed management. Boston, MA: MIT Press.

Schick, A. (1996). The spirit of reform: Managing the New Zealand state sector in a time of change. A report prepared for the State Services Commission and the Treasury, New Zealand. State Services Commission.

Schusler, T. M., Decker, D. J., \& Pfeffer, M. J. (2003). Social learning for collaborative natural resource management. Society and Natural Resources, 16(4), 309-326. http://doi.org/10.1080/08941920390178874.

Schusler, T. M., \& Krasny, M. E. (2008). Youth participation in local environmental action: developing political and scientific literacy. ReidA. JensenB. B. NikelJ. SimovskaV. (Eds.), Participation and learning: Perspectives on education and the environment, health and sustainability, 268-284.

Scott, W. Richard (1995). Institutions and organizations. Thousand Oaks, CA: Sage Publications.

Selby, R., Moore, P., \& Mulholland, M. (2010). Māori and the environment: Kaitiaki. Wellington: Huia.

Selin, S., \& Chavez, D. (1995). Developing an evolutionary tourism partnership model. Annals of Tourism Research, 22(4), 844-856.

Sinner, J. (2011). Implications of the national policy statement on freshwater management. Nelson: Cawthron Institute.

Sinner, J., \& Harmsworth, G. (2015). Māori and collaborative freshwater planning: emerging insights. Nelson: Cawthorn Institute.

Sommarstrom, Sari, and Charles Huntington. (1999) An evaluation of selected watershed councils in the pacific northwest and northern California. Report prepared for Trout Unlimited and Pacific Rivers Council. Pacific Rivers Council, Oregon.

Sorensen, E. \& Torfing, J. (2005). The democratic anchorage of governance networks. Scandinavian Political Studies, 28(3), 195-218.

Sorensen, E. \& Torfing, J. (eds) (2007) Theories of democratic governance. Basingstoke: Palgrave Macmillan.

Special Districts Association of Oregon.(n.d.). Retrieved February 14, 2017 from https://www.sdao.com/

Starks, H., \& Trinidad, S. B. (2007.). Choose your method: a comparison of phenomenology, discourse analysis, and grounded theory. Retrieved March 16, 2017 from http://doi.org/10.1177/1049732307307031.

Statistics New Zealand. (2016, June 24). Statistics New Zealand. Retrieved March 13, 2017 from Census QuickStats about a place: Gisborne District: http://www.stats.govt.nz/Census/2013-census/profile-and-summaryreports/quickstats-about-a-place.aspx?request_value=13992 \& tabname=.

State of Oregon, Legislative Committee Services, State of Oregon, Water Resources Department, Patrino, B. \& Bateman, B. (contacts). (2012). Background Brief on Water Management. Retrieved February 20, 2017 from: 
https://www.oregonlegislature.gov/citizen_engagement/Reports/WaterManageme nt.pdf

State of Oregon, Water Resources Department. (n.d.). Klamath River Basin Adjudication. Retrieved February 20, 2017 from: https://www.oregon.gov/owrd/Pages/adj/index.aspx

State of Oregon, Water Resources Department. (2010). Oregon's Integrated Water Resources Strategy; Issue Papers (Draft). Retrieved February 22, 2017 from: https://www.oregon.gov/owrd/law/docs/iwrs/november_18_2010_issue_papers_v 2.pdf.

State of Oregon, Water Resources Department. (2017). Oregon's 2017 Integrated Water Resources Strategy; Public Review Draft. Retrieved May 4, 2017 from: https://www.oregon.gov/owrd/LAW/docs/IWRS/2017_04_19_2017_IWRS_Publi c_Review_Draft.pdf.

Story of the Treaty of Waitangi. (2016, May 12). Retrieved from Te Ara: The Encyclopedia of New Zealand. Retrieved March 7, 2017 from http://www.teara.govt.nz/en/treaty-of-waitangi.

Susskind, L., \& Cruikshank, J. L. (1987). Breaking the impasse: Consensual approaches to resolving public disputes. Chicago, IL: Basic Books.

United States Army Corps of Engineers. (2010, August). National report: responding to national water resources challenges.

United Sates Congress (1952) McCarran Amendment. Retrieved March 23, 2017 from https://en.wikipedia.org/wiki/McCarran_Amendment.

United States Department of Interior, Bureau of Indian Affairs. Retrieved March 23, 2017 from https://www.bia.gov/.

United States Environmental Protection Agency.Clean Water Act. Retrieved March 23, 2017 from http://www.dfw.state.or.us/OARs/400.pdf.

United States Environmental Protection Agency. (2017). Polluted Runoff: Nonpoint Source Pollution. Retrieved from https://www.epa.gov/nps/what-nonpoint-source

United Staes Library of Congress. Congressional Resource Center. Retrieved March 23, 2017 from https://fas.org/sgp/crs/.

United States Supreme Court(1905). United States vs. Winans. Retrieved March 23, 2017 from https://supreme.justia.com/cases/federal/us/198/371/case.html.

United States Supreme Court (1908). United States vs. Winters. Retrieved March 23, 2017 from https://supreme.justia.com/cases/federal/us/207/564/case.html.

United States Supreme Court (1942). Semonole Nation V. United States. Retrieved March 23, 2017 from https://supreme.justia.com/cases/federal/us/316/286/case.html.

United States Supreme Court (1983) Arizona v. San Carlos Apache Tribe. Retrieved March 23, 2017 from https://supreme.justia.com/cases/federal/us/463/545/.

United Nations Environment Program. (2009). Integrated Water Resources Management in Action. Centre for the Water and Environment.

Varis, O., Biswas, A. K., Tortajada, C., \& Lundqvist, J. (2006). Megacities and water management. Water Resources Development, 22(2), 377-394.

Walters, C. J., \& Hilborn, R. (1978). Ecological optimization and adaptive management. Annual Review of Ecology and Systematics, 9(1), 157-188. 
Warnock, C., \& Baker-Galloway, M. (2015). Focus on resource management law. Wellington: Lexis Nexis NZ Ltd.

Wiek, A., \& Larson, K. L. (2012). Water, people, and sustainability-a systems framework for analyzing and assessing water governance regimes. Water resources management, 26(11), 3153-3171.Retrieved February 5, 2017 from http://doi.org/10.1007/s11269-012-0065-6.

Wondolleck, J. M., \& Yaffee, S. L. (2000). Making collaboration work: Lessons from innovation in natural resource managment. Island Press: Washington D.C.www.parliament.nz. (2011, December).Retrieved March 14, 2017 from http://www.parliament.nz/en-nz/parl-support/researchpapers/00PlibCIP151/freshwater-use-in-new-zealand.

Yin, Robert K. (2003). Case study research: Design and methods. Newbury Park, CA: Sage Publications.

Yin, Robert K. (2009). Case study research: Design and methods $4^{\text {th }}$ Ed. Thousand Oaks, CA: Sage.

Young, O.R. (2011). Land use, environmental change, and sustainable development: the role of institutional diagnostics. International Journal of the Commons 5(1), 6685. 


\section{APPENDICES}

\section{Appendix A: New Zealand Protocol}

New Zealand Case Study

Collaborative Network Governance and Integrated Water Management

Interview Questions 2016

Hello, and thank you for agreeing to an interview. My name is Jackie Dingfelder and I am an Axford Fellow and doctorate student at Portland State University. As you may remember from my phone call/email, participation in this interview is voluntary. This means you may choose now not to participate, refuse to answer any question, or end the interview at any time. If you decide after the interview that you do not wish your interview to be included in the study, you can contact me and have your interview deleted. I will leave my contact information for you. Additionally, this interview will be recorded, per your approval. Recording the interview will help me ensure that I capture your answers more fully, but if you wish to not be recorded, that will in no way effect your participation in the interview process. Here is the consent form that goes into greater detail on the information that I have just provided to you. Please check the boxes accordingly and sign.

Thank you. Now I am going to ask a few questions that will help me better understand the integrated water governance work that is occurring in New Zealand. Please feel free to expand on any questions you find interesting. Any information you can provide is valuable to my research.

\section{INTERVIEW GUIDE}

\section{Part I: Introduction}

1. Please describe why are you interested in water governance? Help me understand why this is important to you?

2. Could you tell me about your background in water management and governance?

Part II: Integrated Water Resources Management

1. What is your involvement with the Land and Water Forum?

2. Could you describe how the LAWF process has worked? Why?

a. What has been your role, or your organization's role, in the LAWF process?

b. What values or interests do you or your organization represent?

3. In your view, what have been the successes and challenges with developing and implementing freshwater reforms through an integrated strategy? Why? 
4. What is your view on a locally-based collaborative approaches?

\section{Part III: Network and Collaborative Processes}

1. Can you share some lessons learned by participating in this collaborative process? What would you do differently?

2. What role do you see collaborative networks (involving public, private and NGOs) serving in implementation of integrated water management plans or programs?

3. How are decisions made in this process? By consensus?

4. What, if any, tangible outcomes have you observed with the LAWF collaborative approach? What do you attribute these outcomes to?

5. In your view, what are the institutional barriers to implementation?

\section{Part IV: Climate Change}

1. Do you think climate change has influenced approached to water management in New Zealand? Can you explain why you think that and provide some examples?

2. Please explain how these changes came about.

\section{Part V: Other Contacts}

1. Are there specific people I should talk to at the state and local level? If so, who are they?

This concludes the interview. Thank you again for your time and for participating in this research study. As stated in my introductory letter, if you would like to receive research and interview results, please email me at Jackie.dingfelder@mfe.govt.nz. Please notify me if you choose not to have your interview included in the final report. In addition, I may contact you in the next few weeks to clarify answers or confirm findings. If you do not wish to be contacted for follow up information, please let me know now or via email later.

Finally, are there other individuals with whom you think I should speak? If so, would you be willing to provide me with their contact information?

Thank you again for your time and interest, and here is my card. Please feel free to contact me with any questions, comments or feedback 


\section{Appendix B: Oregon Interview Protocol}

Oregon Case Study

Collaborative Network Governance and Integrated Water Management

Interview Questions 2016-2017

Jackie Dingfelder, Ph.D.Candidate, Portland State University

Hatfield School of Government

Thank you for agreeing to participate in my research study on integrated water resources management. My name is Jackie Dingfelder and I am a doctoral student at Portland State University at the Hatfield School of Government. As you may remember from my phone call/email, participation in this interview is voluntary. This means you may choose now not to participate, refuse to answer any question, or end the interview at any time. If you decide after the interview that you do not wish your interview to be included in the study, you can contact me and have your interview deleted. I will leave my contact information for you. Additionally, this interview will be recorded, per your approval. Recording the interview will help me ensure that I capture your answers more fully, but if you wish to not be recorded, that will in no way effect your participation in the interview process.

Thank you. Now I am going to ask a few questions that will help me better understand the integrated water governance work that is occurring in Oregon. Please feel free to expand on any questions you find interesting. Any information you can provide is valuable to my research.

\section{INTERVIEW GUIDE}

\section{Part I: Introduction}

3. Please describe why are you interested in water governance? Help me understand why this is important to you?

4. Could you tell me about your background in water management and governance?

Part II: Integrated Water Resources Management

5. What is your involvement with the Integrated Water Resources Strategy policy advisory committee at the state level?

a. Were you involved in the Policy Advisory Group that provided policy guidance and suggestions for Oregon's first Integrated Water Resources Strategy?

b. How long have you been following this process?

6. Could you describe how the IWRS process has worked? Why?

a. What has been your role, or your organization's role, in the IWRS process? 
b. What values or interests do you or your organization represent?

7. In your view, what have been the successes and challenges with developing and implementing an integrated water strategy? Why?

8. What is your view on a place-based approach as proposed in the Integrated Water Resources Strategy?

Part III: Network and Collaborative Processes

6. Can you share some lessons learned by participating in this collaborative process? What would you do differently?

7. What role do you see collaborative networks (involving public, private and NGOs) serving in implementation of an integrated water management or governance structure?

8. How are decisions made in this process? By consensus?

9. What, if any, tangible outcomes have you observed with the IWRS collaborative approach? What do you attribute these outcomes to?

10. In your view, what are the institutional barriers to implementing the IWRS?

\section{Part IV: Climate Change}

3. Do you think climate change has influenced approached to water management in Oregon? Can you explain why you think that and provide some examples?

4. Please explain how these changes came about.

\section{Part V: Other Contacts}

1. Are there specific people I should talk to at the state and local level? If so, who are they?

This concludes the interview. Thank you again for your time and for participating in this research study. As stated in my introductory letter, if you would like to receive research and interview results, please email me at jding2@pdx.edu. Please notify me if you choose not to have your interview included in the final report. In addition, I may contact you in the next few weeks to clarify answers or confirm findings. If you do not wish to be contacted for follow up information, please let me know now or via email later.

Thank you again for your time and interest. Please feel free to contact me with any questions, comments or feedback. 


\section{Appendix C: Dissertation Codebook}

$\underline{\text { Level } 1 \text { - Descriptors }}$

- Name: Interviewee

- Position: Interviewee role in network/collaborative

- Affiliation: Organization/interest interviewee represents

\section{Level 2 - Interview Questions}

- Q1-Intro: introduction questions

- Q2-IWRM: involvement with integrated strategy, LAWF or PAG, IWRS process description, successes and challenges

- Q3-Network and Collaborative Processes: lessons learned, role of collaborative processes, decision-making process, institutional barriers

- Q4-Climate Change: climate change influences

- Q5-Other Contacts: snowball interviews

\section{Level 3 - Themes (sub-bullets are Level 4)}

- Accountability: The obligation of an individual or organization to account for its activities, accept responsibility for them, and to disclose the results in a transparent manner.

○ Transparency: openness of the process; a prerequisite for ability to hold process accountable to the public

- Agreement: Refers to creating social acceptance to support certain policies or activities, and/or codifying that agreement in policy recommendations

- Capacity: Broad reference to existing resources (or lack thereof) to get work done. Could be internal (e.g., member investment, facilitator/coordinator, time) or external (e.g., funding, staffing, etc.)

- Climate Change: Specific references to climate change

- Collaboration: working cooperatively to solve problems

- Communication: act of conveying intended meaning

- External: How the collaborative communicates with the public, stakeholders, other collaborative groups, or other organizations (external communications).

- Internal: how the collaborative communicates internally; challenges in internal communication.

○ Inter-agency: communication between/among agencies

- Conflict: This could be internal conflict within the collaborative or conflict between the collaborative and external groups. 
- Coordination: refers to coordination among the different actors involved in water management

- Cultural: Refers to different cultural approaches to solving problems

- Decision-making: References to the decision-making process, consensus, agreements

- Environmental vs. Economic Considerations: refers to a balancing of environmental protection or sustainability vs. economic growth

- Equity: Refers to balancing in-stream with out-of-stream needs; balancing conservation with consumptive uses

- Formal Governance: Refers to structures, process elements, including meeting structure, meeting roles, rules of engagement, or meeting protocols.

- Committee: Roles or tasks taken on by committees and committee members. Includes leadership committees and small groups

- Facilitation: discussing roles, responsibilities, and other aspects of the facilitator, and/or chair

- Mission statement: Reading of or referencing mission statement.

- Goals/objectives: Reading of or referencing goals or objectives

o Procedures: Development or application of the group charter/by-laws, operating procedures, and/or ground rules

- Informal Governance: Elements that contribute to informal governance structures, such as trust and relationships.

○ Personality: the personality types or attributes that contribute to a good collaborator, or that's necessary in a collaborative.

- Relationship-building: Discussing relationships between members or members and the broader community, stakeholders, agencies, or others; how relationships are built, whether they exist prior to or outside of the collaborative group, etc.

- Representation: Discussing who is at the table; how balanced the group composition is

- Trust: Referencing the level of trust within the collaborative, trust between the collaborative and the local community, what trust looks like, how it's cultivated, or distrust (of any of the above)

- Fragmentation/silos: refers to actors/agencies/institutions/governments working in silos or isolated from each other; not part of a holistic, integrated system

- Funding: Any specific reference to how the network/collaborative is funded; challenges in obtaining funding or funding for implementation of plans/programs

- Institutional Barriers: barriers to process or implementation (i.e., policies, institutions, prior appropriation doctrine, laws, regulations) or lack thereof

- Information and data needs: need for additional information or data in order to make informed decisions

- Influence: refers to influence on the process or within the network

- Integration: integration of water quality and quantity; surface water and groundwater; water management with land use 
- Leadership: refers to leaders in the network or collaborative; or outside the process

- Learning and knowledge transfer: sharing and transfer of information between/among network actors

- Legitimacy: Reference to the validity and/or acceptance of the authority of an actor, institution, or decision

- "Low hanging fruit": refers to policies that are easy to reach agreement on

- Market-based approaches: water pricing or trading

- Policy: Refers to policies, regulations, laws

- Political acceptance: how supportive ministers/legislators, stakeholders, citizens are of recommendations/end product

- Prioritization: evaluating recommendations/tasks and ranking them in order of importance or urgency

- Resiliency: ability to adapt to change

- Science: Reflections on the interface with science, scientists, and research

- Social Capital: refers to "accumulated trust, reciprocity, and durability built up between two or more network actors that allow for the development of human knowledge and political capital (Putnam, 2000)

- Spatial Scale: Issues of water governance or management scale: regional or local

○ Place-based planning: Oregon: place-based planning refers to water strategies developed at the local level that roll up to the IWRS

○ In NZ, planning occurring at the regional scale

- Success: Discussing how successful the group has or has not been (challenges to success), what success looks like, and what might have been done differently

- Technical issues: related to specific technical issues around water management (i.e., water quality, TMDLs, allocation, groundwater, measurement, instream flows, stormwater, storage, non-point source)

○ Drought and water scarcity

- Ecological flows: water left instream for fish/ecological purposes

○ Groundwater management

○ Impaired Water Quality/TMDLs: Total Daily Maximum Loads

- Water Management Improvements: water measurement, conservation efficiency, storage, acquisition

- Water measurement

$\circ \quad$ Water storage

- Urban stormwater

- Top-down vs. bottom up: refers to hierarchical, vertical vs. bottom up (locally driven), horizontal scheme

- Urban vs. Rural divide: refers to differences in urban vs. rural viewpoints around water issues 


\section{Appendix D: New Zealand Land and Water Forum Membership}

Plenary Organizations

- Aqualinc Research Ltd

- Ballance Agri-Nutrients

- Beef + Lamb New Zealand

- Business NZ

- Contact Energy

- DairyNZ

- ECO

- Ecologic

- Environmental Defence Society

- Federated Farmers

- Federated Mountain Clubs of NZ

- FertResearch

- Fonterra

- Forest and Bird

- Foundation for Arable Research

- Genesis Energy

- Horticulture New Zealand

- Ihutai Trust

- Institute of Public Works Engineering Australasia

- Institution of Professional Engineers New Zealand

- Irrigation New Zealand

- King Country Energy

- Landcare Trust

- Lincoln University

- Massey University

- Meridian Energy

- Mighty River Power

- MWH

- National Institute of Water and Atmospheric Research

- Newmont Waihi Gold

- Ngati Kahungunu

- NZ Farm Forestry Association

- NZ Forest Owners Association

- NZ Institute of Forestry

- NZ Winegrowers

- Oji Fibre Solutions

- Opus International Consultants Ltd

- Pioneer Generation 
- Rural Women New Zealand

- Spiire

- Straterra Inc

- Sustainable Business Council Te Arawa Lakes Trust

- Te Runanga o Ngai Tahu

- Tourism Industry Association

- TrustPower

- Tuwharetoa Māori Trust Board

- Waikato River Authority

- Waikato-Tainui

- Water New Zealand

- Watercare Services Limited

- Whitewater New Zealand

- Wood Processors and Manufacturers Association of New Zealand

- Zespri

Small Group Organizations

- Beef + Lamb New Zealand

- Contact Energy

- DairyNZ

- Ecologic

- Environmental Defence Society

- Federated Farmers

- Fonterra

- Forest and Bird

- Horticulture New Zealand

- Irrigation New Zealand

- Meridian Energy

- National Institute of Water and Atmospheric Research

- Ngati Kahungunu

- NZ Forest Owners Association

- Te Arawa Lakes Trust

- Te Runanga o Ngai Tahu

- Tuwharetoa Māori Trust Board

- Waikato-Tainui

- Water New Zealand

- Whitewater New Zealand 
Central and Local Government Active Partners

- Auckland Council

- New Zealand Conservation Authority

- Department of Conservation

- Department of Internal Affairs

- Environment Canterbury

- Environment Southland

- Ministry for the Environment

- Ministry for Primary Industries

- Otago Regional Council

- Tasman District Council

- Treasury

- Waikato Regional Council

- Wellington City Council 


\section{Appendix E: Oregon Integrated Water Resources Strategy}

\section{Policy Advisory Group Members}

First Policy Advisory Group (convened from 2009-1013):

Glenn Barrett, Michael Campbell, Jay Chamberlin, John DeVoe, Dennis Doherty, Bill Gaffi, Patrick Griffiths, Todd Heidgerken, Tod Heisler, Teresa Huntsinger, Tracey Liskey, Peggy Lynch, Janet Neuman, Eric Quaempts, Mike Seppa, Lorna Stickel, Richard Wells, and Joe Whitworth

Second Policy Advisory Group (convened from 2016-2017):

Robert "Will” Collin, Suzanne DeLorenzo, Arlene Dietz, Allan Elliott, Ron Foggin, Rebecca Geisen, TJ Hansell, Valerie Kelley, Gayle Killam, Craig Lacy, Hiram Li, Tracey Liskey, Peggy Lynch, Curtis Martin, Craig Pope, Brent Stevenson, Stan van de Wetering, Mary Wahl 